University of Louisville

ThinkIR: The University of Louisville's Institutional Repository

Electronic Theses and Dissertations

$12-2011$

\title{
Gold catalysis and its applications in synthesis of fluorinated organic compounds.
}

Weibo Wang

University of Louisville

Follow this and additional works at: https://ir.library.louisville.edu/etd

\section{Recommended Citation}

Wang, Weibo, "Gold catalysis and its applications in synthesis of fluorinated organic compounds." (2011). Electronic Theses and Dissertations. Paper 1518.

https://doi.org/10.18297/etd/1518

This Doctoral Dissertation is brought to you for free and open access by ThinkIR: The University of Louisville's Institutional Repository. It has been accepted for inclusion in Electronic Theses and Dissertations by an authorized administrator of ThinkIR: The University of Louisville's Institutional Repository. This title appears here courtesy of the author, who has retained all other copyrights. For more information, please contact thinkir@louisville.edu. 


\title{
GOLD CATALYSIS AND ITS APPLICATIONS IN SYNTHESIS OF FLUORINATED ORGANIC COMPOUNDS
}

\author{
By \\ Weibo Wang

\begin{abstract}
A Dissertation
Submitted to the Faculty of the

College of Arts and Sciences of the University of Louisville

in Partial Fulfillment of the Requirements

for the Degree of

Doctor of Philosophy
\end{abstract} \\ Department of Chemistry \\ University of Louisville \\ Louisville, Kentucky
}

December, 2011 


\title{
GOLD CATALYSIS AND ITS APPLICATIONS IN SYNTHESIS OF FLUORINATED ORGANIC COMPOUNDS
}

\author{
By \\ Weibo Wang \\ A Dissertation Approved on \\ December. $7^{\text {th }}, 2011$ \\ by the following Dissertation Committee:

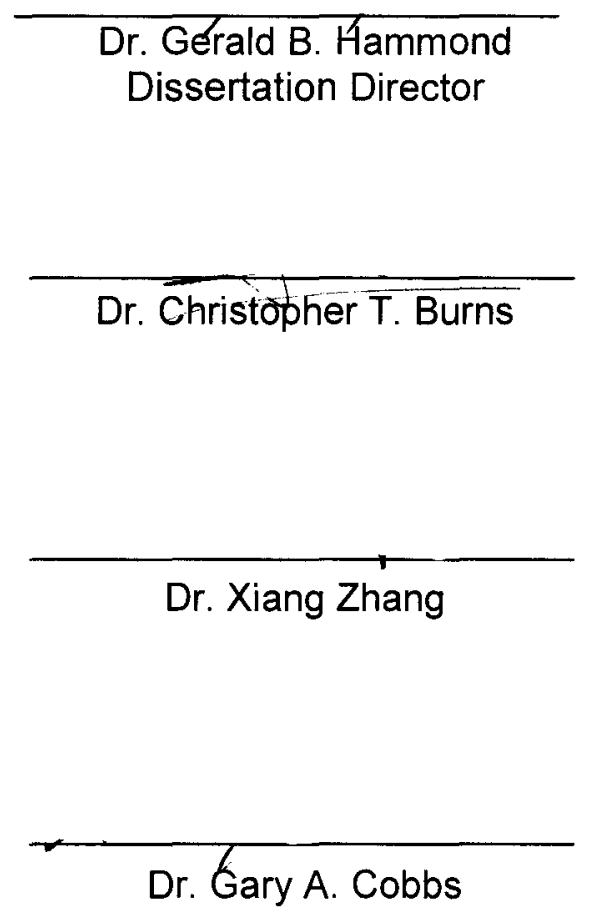




\section{ACKNOWLEDGEMENTS}

I will always be very grateful to Dr. G.B. Hammond for serving as my research advisor, as well as being an excellent teacher and friend during last 6 years. I am also indebted to $\mathrm{Dr}$. Bo $\mathrm{Xu}$, who has been my daily mentor during the course of my doctoral work, and who has taught me the skills of organic synthesis.

I would also like to thank the following faculty members for reading this thesis and sitting on my defense committee: Dr. Christopher T. Burns, Dr. Xiang Zhang, and Dr. Gary A. Cobbs. Also many thanks to Dr. Neal Stolowich who offered me numerous help on how to run NMR experiments.

Also I feel fortunate to have been a member of a terrific group of highly dedicated scientists. I am grateful to the past and present group members of the Hammond research group over the years: Dr. Bo Xu, Dr. Leping Liu, Zhuang Jin, Junbin Han, Deepika Malhotra, Manish Kumar, Rachel (present); Satoru Arimitsu, Jesse Jacobsen, Jose Aponte, Rebecca Bottom, Majeid Ali, Han Yang, Jiyoung A. Hong, Kevin Oliver, Alice Hong, Begoña Fernandez (former). People come and go, but their cooperation and friendship remain etched in my memory.

Last but not least, I have a deep appreciation to my parents, my caring husband, and my lovely son for their unconditional love and support. 


\title{
ABSTRACT
}

\section{GOLD CATALYSIS AND ITS APPLICATIONS IN SYNTHESIS OF FLUORINATED ORGANIC COMPOUNDS}

\author{
Weibo Wang
}

December, 2011

Our research activities are based on the catalytic systems that provide resourcesaving synthetic methodologies through gold-catalyzed reactions of alkynes and alkenes. We have worked on three applications: i) an effective and straightforward hydration of 3-alkynoates catalyzed by gold (III); this mild and atom-economical method can be used effectively with a wide range of substrates with high regioselectivity; ii) an efficient monofluorination of allyl silanes using Selectfluor has been achieved without gold catalysts; iii) a fluorine-enabled cationic metal species, generated by fluorination of a low valence gold $(I)$ complex, catalyzed the hydration of alkynes to give $\alpha$-substituted- $\alpha$-fluoroketones in one pot under mild conditions. The latter allowed a diverse range of fluorine building blocks or targets to be made available using tools that are amenable in combinatorial or parallel synthesis conditions in drug discovery laboratories or process chemistry. 


\section{TABLE OF CONTENTS}

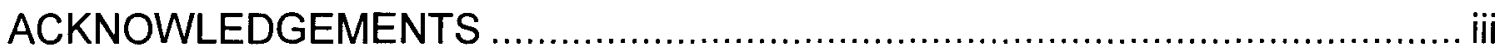

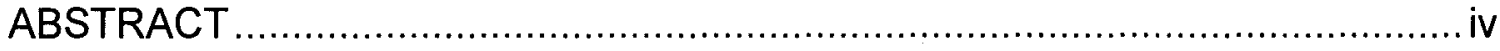

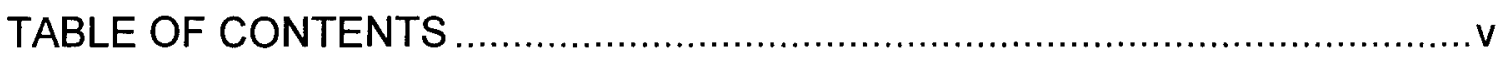

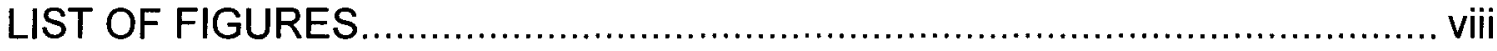

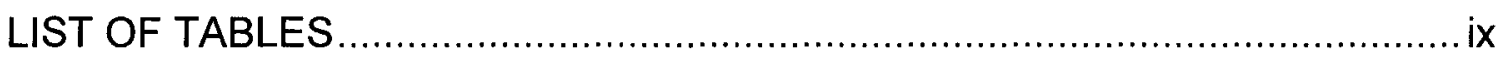

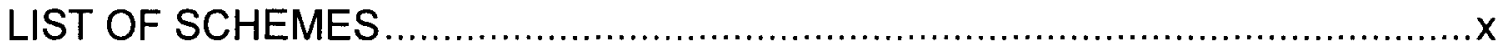

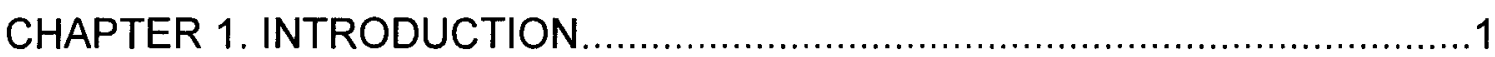

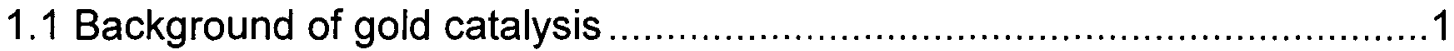

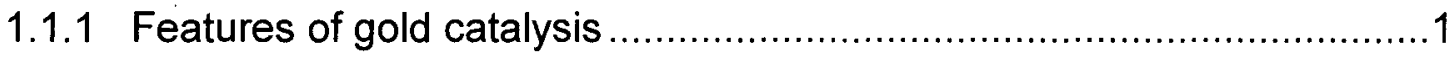

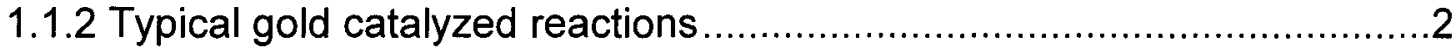

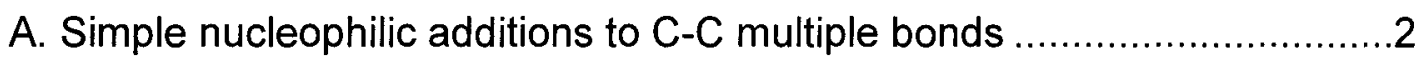

B. Intramolecular additions in conjugated $\pi$-systems and related reactions.. 4

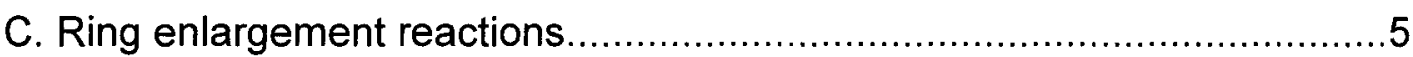

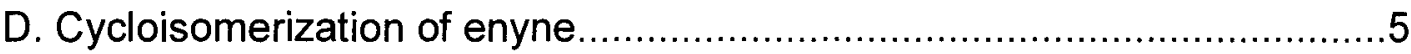

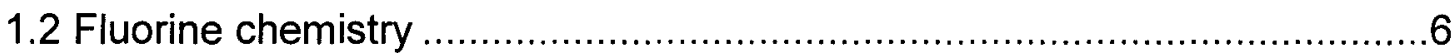

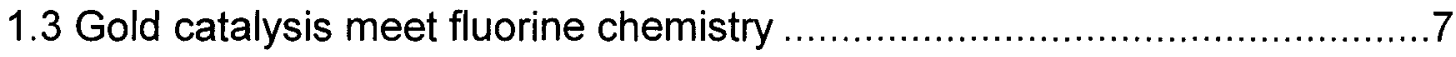

1.3.1 Library-friendly synthesis of aliphatic fluorinated compounds ..............7

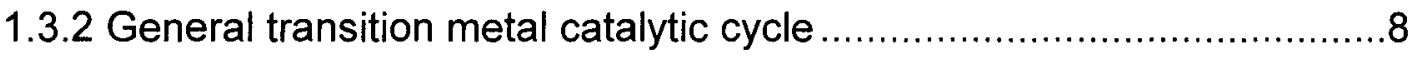

1.3.3 Fluorine-engendered cationic transition metal species. .....................

1.3.4 Literature reports involve Metal-F intermediate ...............................10

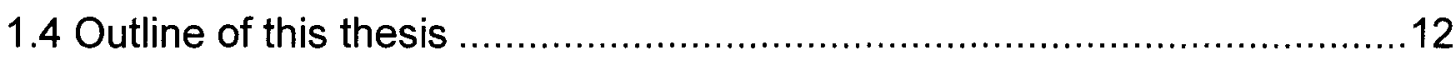

CHAPTER 2. GOLD CATALYZED HYDRATION OF ALKYNES ......................14

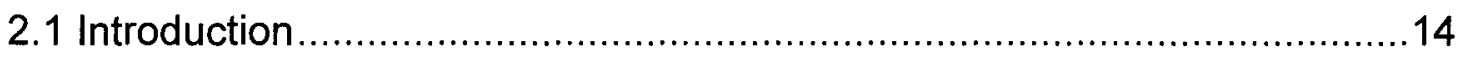


2.2 Directed gold-catalyzed hydration of alkynes through neighboring group assistance

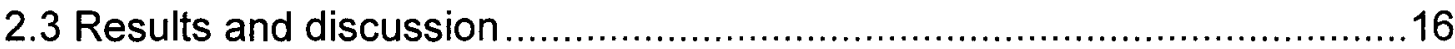

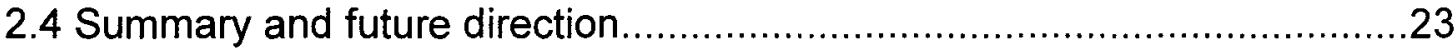

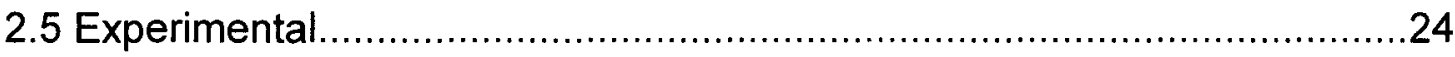

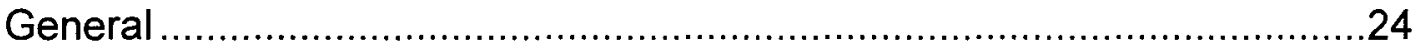

General procedure for preparation of 3-alkynoates $2-1^{93,94} \ldots \ldots \ldots \ldots \ldots \ldots \ldots . .25$

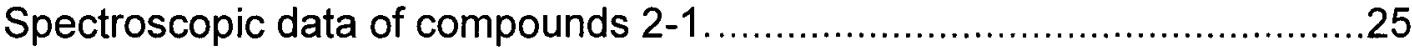

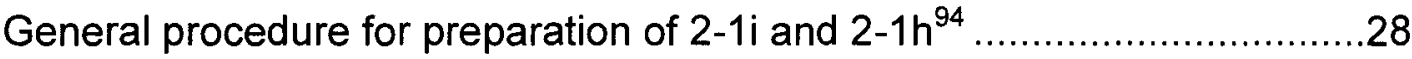

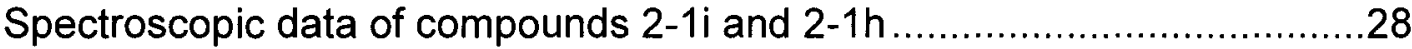

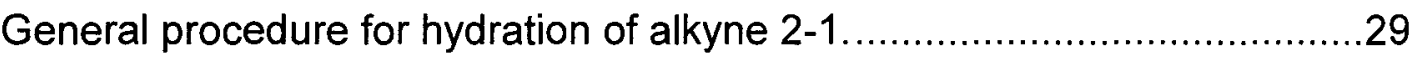

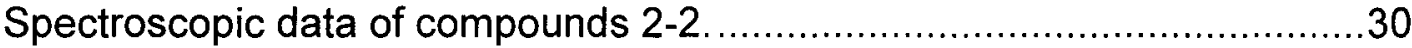

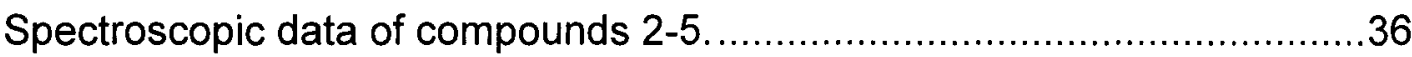

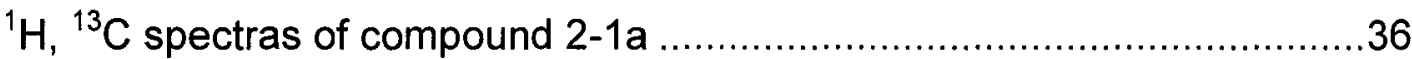

CHAPTER 3. GOLD CATALYZED FUNCTIONALIZED HYDRATION OF

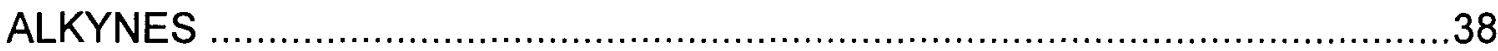

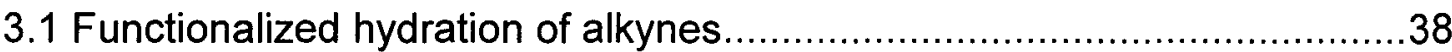

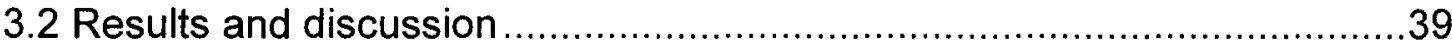

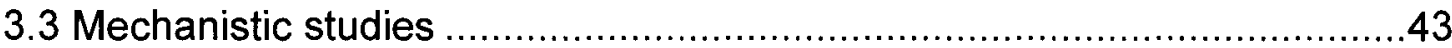

3.4 Mechanistic study of gold (III) species using X-ray photoelectron

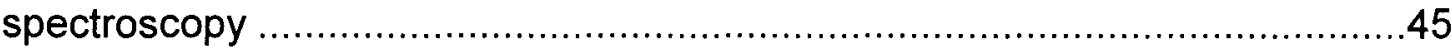

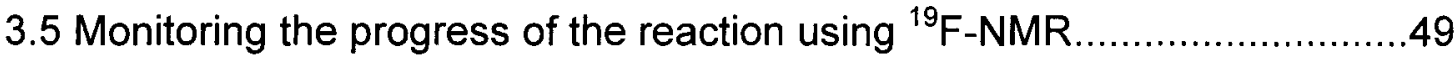

3.6 Electrospray ionization mass spectrometry (ESI-MS). Identification of

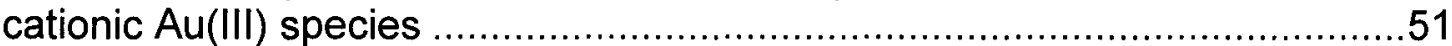

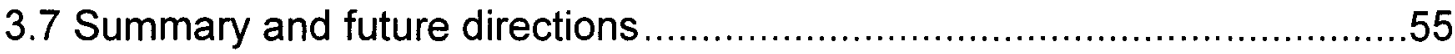

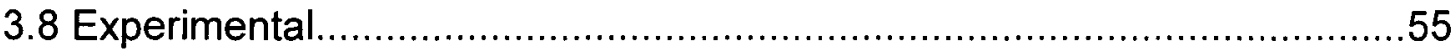

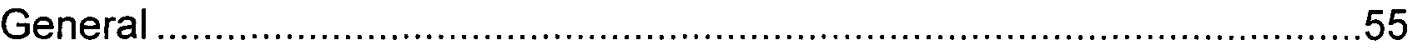

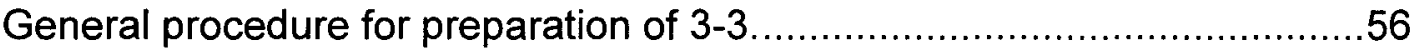

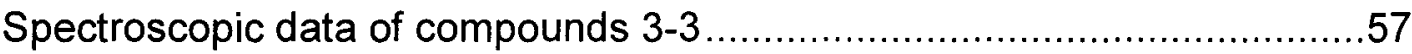

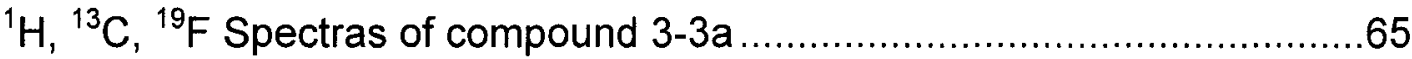

CHAPTER 4. SYNTHESIS OF FLUOROHYDRINS FROM ALLYL SILANES ....67 


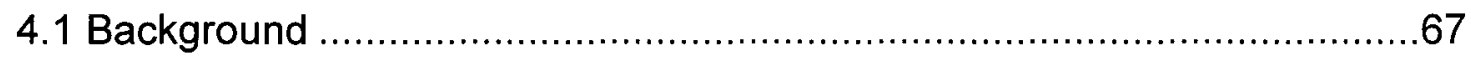

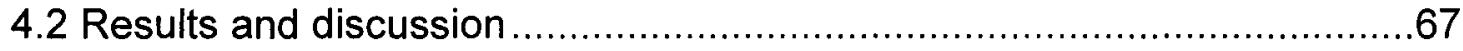

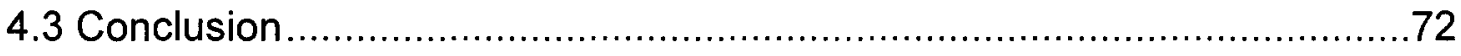

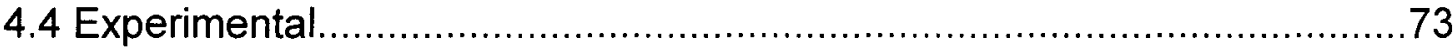

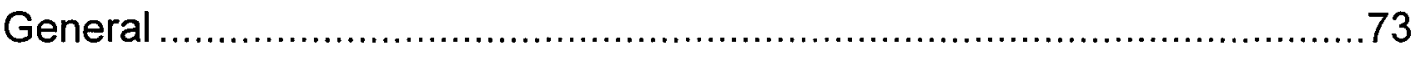

General procedure for synthesis of compound 4-2 ..............................74

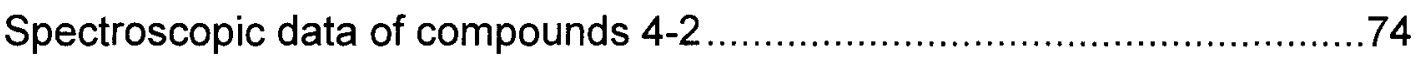

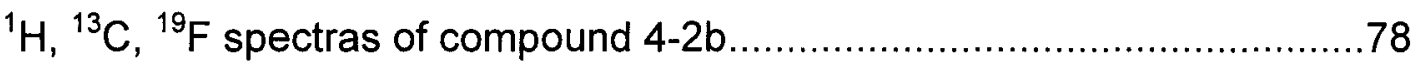

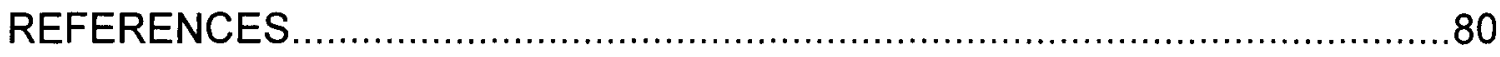

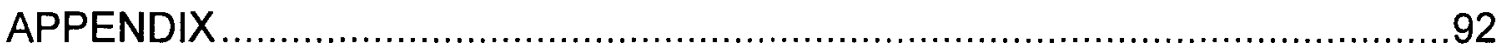

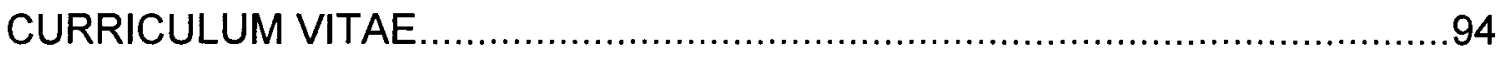




\section{LIST OF FIGURES}

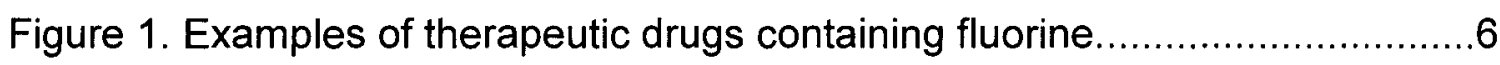

Figure 2. Library-friendly synthesis of aliphatic fluorinated compounds library. ....8

Figure 3. XPS curve fitting of the Au $4 \mathrm{f}$ photoelectron peaks..........................49

Figure 4. Monitoring the reaction of $\mathrm{AuCl}$ with Selectfluor using ${ }^{19} \mathrm{~F}-\mathrm{NMR}$ ( $\mathrm{Ln}=$

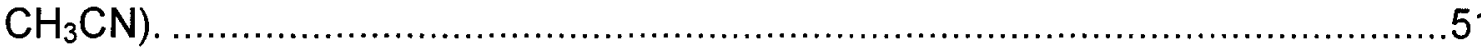

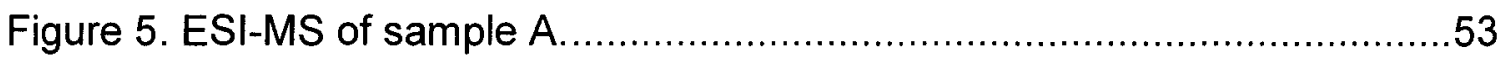

Figure 6. ESI-MS of sample $C$ (part 1, $\mathrm{m} / \mathrm{z}$ 360-460) ..................................53

Figure 7. ESI-MS of sample $C$ (part $2, \mathrm{~m} / \mathrm{z}$ from 50 to 360 )..........................54 


\section{LIST OF TABLES}

Table 1. Screening of metal catalysts for the hydration of $2-1 a \ldots \ldots \ldots \ldots \ldots \ldots \ldots \ldots . . . . .17$

Table 2. Screening of solvents and additives................................................19

Table 3. Au(III)-catalyzed hydration of internal 3-alkynoates. ...........................20

Table 4. Functionalized hydration: screening of conditions ..............................41

Table 5. Scope of the functionalized hydration. ..........................................42

Table 6. The literature reports of binding energy of $A u f_{7 / 2}$ electron...............46

Table 7. Screening conditions for the reaction of fluorohydroxylation of allyl

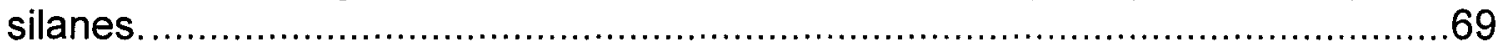

Table 8. Scope for the reaction of fluorohydroxylation of allyl silanes................71 


\section{LIST OF SCHEMES}

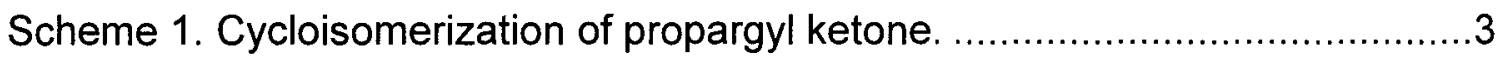

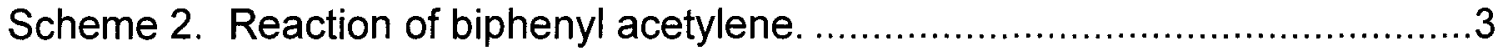

Scheme 3. Cyclization of N-propargyl carboxamides.....................................4

Scheme 4. Cyclization of allenyl thiocarbinols. ...............................................

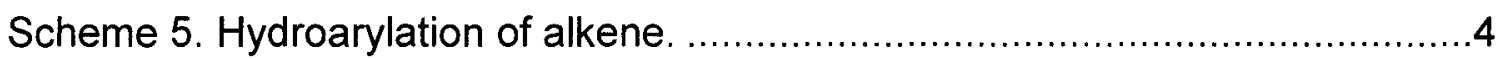

Scheme 6. Cycloisomerization of allenyl ketones. ........................................

Scheme 7. Ring expansion of ethynyl cyclopropanols...................................

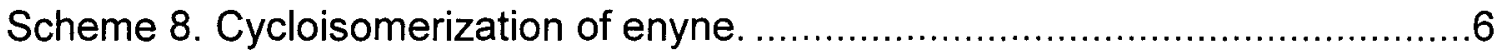

Scheme 9. Traditional methods for generation of $[\mathrm{LnAu}]^{+}$and its catalytic cycle. 9 Scheme 10. Fluorination-enabled cationic metal complex and its catalytic cycle.

Scheme 11. Selected examples of literature reports involving Metal-F intermediate.

Scheme 12. Synthesis of $\gamma$-keto esters through neighboring carbonyl groupassisted regioselective hydration of 3-alkynoates.

Scheme 13. Fluorine-enabled cationic gold catalysis: functionalized hydration of alkynes.

Scheme 14. Synthesis of fluorohydrins through electrophilic fluorination of allyl silanes.

Scheme 15. Directed gold-catalyzed hydration of alkynes through neighboring group assistance.

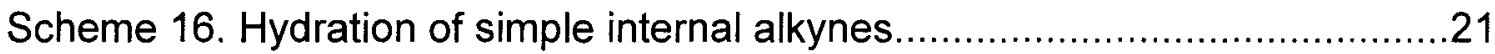

Scheme 17. Proposed mechanism for the hydration of 3-alkynoates. ...............23

Scheme 18. Concept of functionalized hydration. .............................................39

Scheme 19. Proposed mechanism for the functionalized hydration...................44

Scheme 20. Synthesis of fluoroketones and oxidative coupling of alkynes.........45 


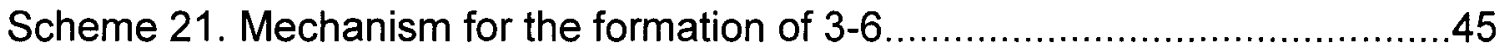

Scheme 22. Preparation of gold complex samples....................................46

Scheme 23. Conversion of cationic gold (III) intermediate to chloroaurate or

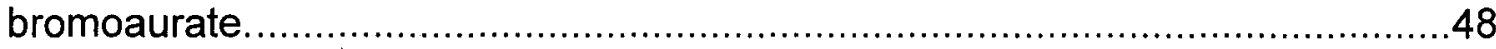

Scheme 24. Preparation of samples for ESI-MS study................................52

Scheme 25. Mechanism for the formation of gold(III) species in Figure 6..........55

Scheme 26. Proposed mechanism for formation of compound $4-2 \ldots \ldots \ldots \ldots \ldots \ldots . . .72$ 


\section{CHAPTER 1. INTRODUCTION}

\subsection{Background of gold catalysis}

The element of gold has been studied from the early days of human history, but it has found little use in chemical synthesis until recently. During the last 15 years or so, there has been an impressive focus on the utility of gold catalysis in

organic synthesis. ${ }^{1-8}$ Gold catalysis is considered as more environmentally benign and a resource-saving synthetic methodology for the synthesis of numerous target molecules. ${ }^{9}$ From a green chemistry standpoint, gold catalysts have clear advantages: reactions often proceed under room temperature within short time. ${ }^{10}$ Furthermore, gold catalysts can tolerate air and moisture environments. $^{3}$

\subsubsection{Features of gold catalysis}

Strong $\pi$-acidity: Cationic gold is a soft Lewis acid, with a large radius, low or partial $(\Delta+)$ positive charge. Electrons in its valence shell are easy to polarize. Because of the $\pi$-acidity, gold is considered an alkynophilic Lewis acid. A lower LUMO and the poor electron back donation of gold make it the most powerful catalyst for electrophilic activation of alkynes toward a variety of nucleophiles. 
Both $\mathrm{Au}^{\prime}$ and $\mathrm{Au}^{\prime \prime \prime}$ are active in catalysis: Of the different oxidation states of gold, gold(0), gold(I), and gold(III) are the main ones. In an aqueous solution without any ligand, gold(I) spontaneously disproportionates to gold(III) and gold(0). ${ }^{1}$ In contrast to tricoordinated and tetracoordinated $\mathrm{Cu}(\mathrm{I})$ and $\mathrm{Ag}(\mathrm{I})$ complexes, $\mathrm{Au}^{\prime}\left(\mathrm{d}^{10}\right)$ has a linear bicoordinate geometry, this fact makes it difficult to be used in asymmetric catalysis. Gold ${ }^{\prime \prime \prime}\left(d^{8}\right)$ complexes are four-coordinated (square planar) and diamagnetic. When the formal coordination number is less than 4 , ligands such as chlorine can make up for it by forming a bridging ligand. Cationic gold (III) complexes are generally considered stronger catalysts than gold (I).

No $\beta$-H elimination: In contrast to other transition metal complexes (e.g. Pd), organogold complexes have a low tendency to undergo $\beta-\mathrm{H}$ elimination; Au-H complexes are rare.

\subsubsection{Typical gold catalyzed reactions}

\section{A. Simple nucleophilic additions to $\mathrm{C}-\mathrm{C}$ multiple bonds}

This is by far the most common reaction pattern in gold catalyzed organic reactions. Gold activates the C-C bonds of alkynes, allene, or olefins toward attack by nucleophiles.

Alkynes as substrates: One typical example is shown in Scheme 1. Hashmi et al. ${ }^{11}$ initially found that gold (III) can complete the cycloisomerization of propargyl 
ketone 1-1 by nucleophlic attack of the carbonyl group, followed by aromatization of the intermediate arenium ion 1-2 to furan (Scheme 1).

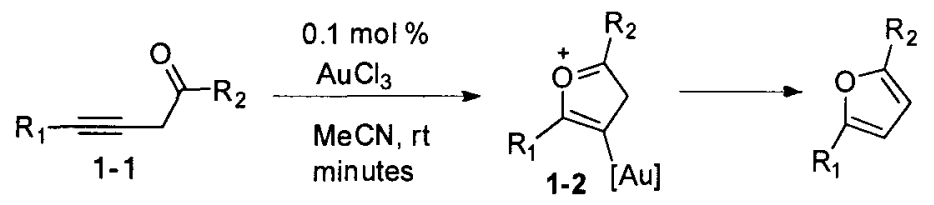

Scheme 1. Cycloisomerization of propargyl ketone.

In 1998, Teles et al. ${ }^{12}$ found very high activities, TON (turnover number) up to $10^{5}$, and TOF (turnover frequency) up to $5400 \mathrm{~h}^{-1}$ for cationic gold (I) phosphine complexes in the addition of alcohols to alkynes. This type of cationic complex is still the most homogeneous gold catalyst. Indeed, the $\mathrm{Ph}_{3} \mathrm{PAu}^{+} \mathrm{X}^{-}$system has been used by many of the authors cited in this chapter. The following example, shown in Scheme 2, depicts the reaction of biphenyl acetylene 1-3 by which methanol attacks the alkyne that has been activated by cationic gold $\mathrm{Ph}_{3} \mathrm{PAu}^{+}$ (generated in situ by reaction of $\mathrm{Ph}_{3} \mathrm{PAuMe}$ with the acidic promoters) to produce the (Z)-isomer 1-4.

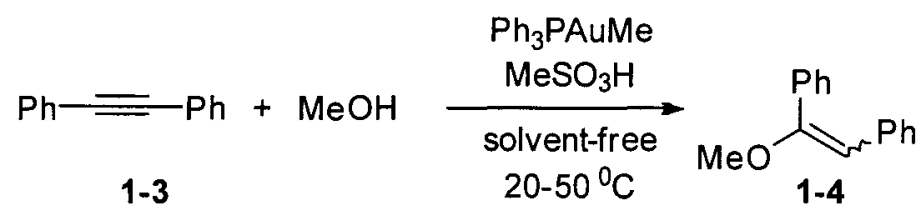

Scheme 2. Reaction of biphenyl acetylene.

In 2004, Hashmi ${ }^{13}$ reported the use of $\mathrm{N}$-propargyl carboxamides 1-5 having alkynyl groups (Scheme 3, R=H) for 5- exo-dig cyclizations, and in 2009 , they ${ }^{14}$ reported the 6-endo-dig cyclization of N-propargyl carboxamides 1-5 possessing an internal alkynyl group (Scheme $3, R \neq H$ ) . 


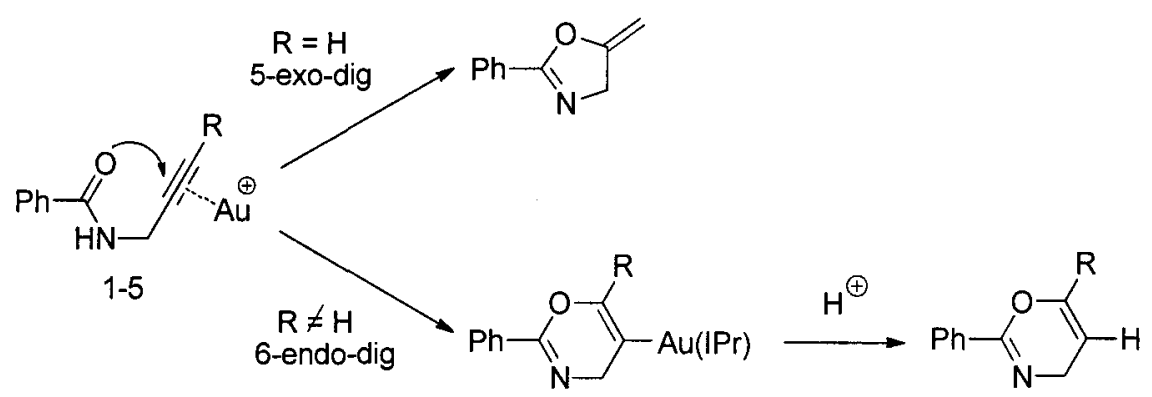

Scheme 3. Cyclization of N-propargyl carboxamides.

Allenes as Substrates : Krause et al. used allenyl thiocarbinols 1-6 as substrates ${ }^{15}$ in the cyclization to 2,5- dihydrothiophenes 1-7 (Scheme 4); the best results were obtained with $\mathrm{AuCl}$ in $\mathrm{CH}_{2} \mathrm{Cl}_{2}$.

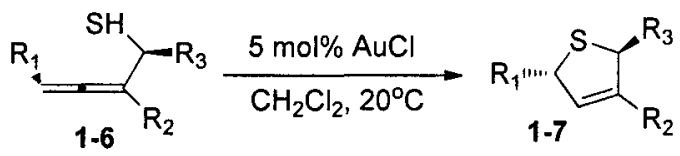

$$
\begin{aligned}
& \mathrm{R}_{1}=\text { alkyl } \\
& \mathrm{R}_{2}=\mathrm{H}, \mathrm{Me} \\
& \mathrm{R}_{3}=\mathrm{H}, \mathrm{CH}_{2} \mathrm{OAryl}
\end{aligned}
$$

Scheme 4. Cyclization of allenyl thiocarbinols.

Alkenes as Substrates: In 2000, Hashmi ${ }^{11}$ et al. reported the first goldcatalyzed intramolecular addition of a hydroxy group to an activated alkene 1-8 to form spirocycle 1-9 ( Scheme 5) .

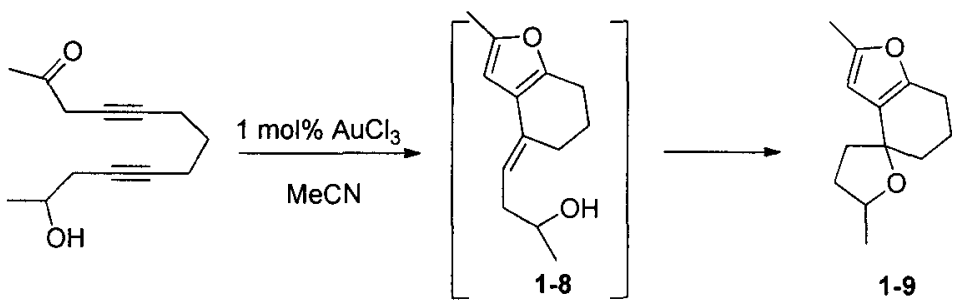

Scheme 5. Hydroarylation of alkene.

\section{B. Intramolecular additions in conjugated $\pi$-systems and related reactions}

In these intramolecular reactions, the nucleophilic group is in conjugation with the double bond, which is activated by the gold catalyst. In most cases, this 
ultimately leads to conjugated (aromatic) products. For example, the cycloisomerization of allenyl ketones 1-10 has been reported by Hashmi ${ }^{11}$ et al. The carbonyl oxygen atom serves as an intramolecular nucleophile, the Wheland-type intermediate 1-11 then delivers the product $1-12$ by aromatization to 1-11 via proton loss and subsequent protodeauration (Scheme 6).

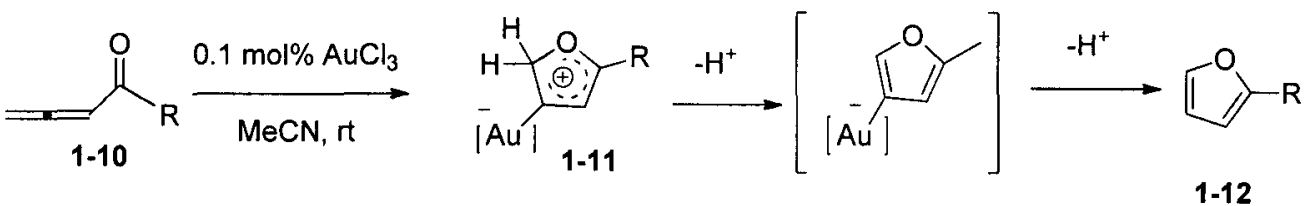

Scheme 6. Cycloisomerization of allenyl ketones.

\section{Ring enlargement reactions}

In 2005, Toste $^{16}$ et al. reported the ring expansion of ethynyl cyclopropanols 1-13 (Scheme 7). Here, the strained ring in 1-14 forms a bond with the proximal carbon of the alkyne and not with the distal one and the proton of the hydroxyl group is eliminated to give the ketone product 1-15.

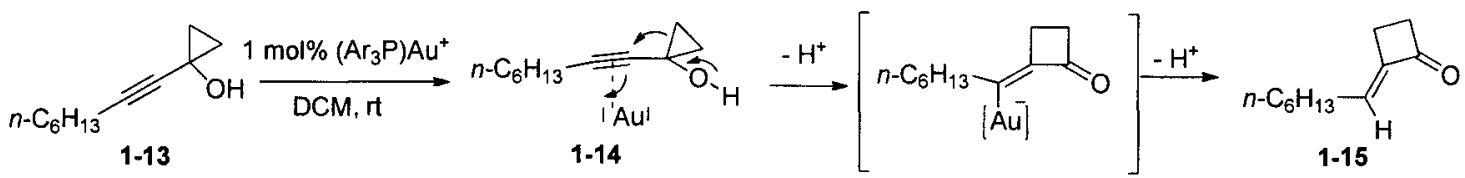

Scheme 7. Ring expansion of ethynyl cyclopropanols.

D. Cycloisomerization of enyne

Metal-catalyzed cyclizations of enyne 1-16 have been reported by Echavarren ${ }^{17}$ in 2006: the Au catalyst selectively activates the alkyne followed by an anti attack of the alkene (Scheme 8). 


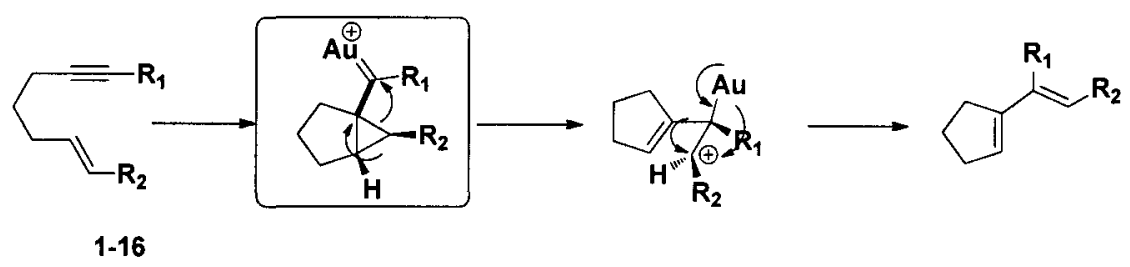

Scheme 8. Cycloisomerization of enyne.

\subsection{Fluorine chemistry}

Extensive research has established that the chemical reactivity of fluorinated organic compounds is distinctly different from other halide-containing analogues. ${ }^{18-24}$ The small size of fluorine, its high electro negativity, and its strong bond with carbon, contribute to the fact that, once fluorine is introduced into an organic compound-either in place of a hydrogen atom or another organic functionality-induces only minimal steric alterations but profound electronic changes in the resulting compound. Consequently, fluorine substitution can effectively modify the physical-chemical properties of the molecule. ${ }^{18-24}$ Until 1957, though, no F-containing drugs had been developed. These days, fluorinated drugs make up $20 \%$ of all pharmaceuticals sold worldwide, with even higher figures for agrochemicals (Figure 1).<smiles>O=C(Nc1c(Cl)cncc1Cl)c1ccc(OC(F)F)c(OCC2CC2)c1</smiles>

Roflumilast

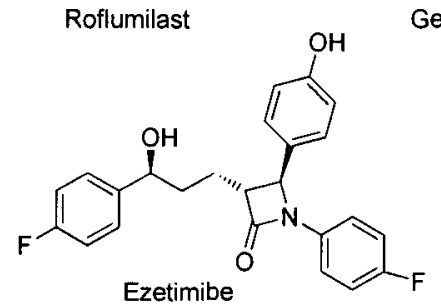<smiles>Nc1ccn(C2OC(CO)C(O)C2(F)F)c(=O)c1</smiles>

Gemcitabine

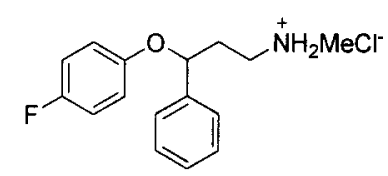

fluoxetine hydrochloride<smiles>O=C(O)c1cn(C2CC2)c2cc(N3CCNCC3)c(F)cc2c1=O</smiles>

Figure 1. Examples of therapeutic drugs containing fluorine. 
Compared with other heteroatom, It is not easy to introduce fluorine into an organic compound, especially in non-aromatic systems. Today, the synthesis of drugs and agrochemicals rely on commercially available stocks of fluorinated aromatic substrates (e.g. fluorine-substituted benzaldehydes). Fluoroaromatics can be made by traditional methods like conversion of aromatic amines via the aryldiazonium salt (Balz-Schiemann reaction) $)^{25}$ and the nucleophilic substitution of electron-poor bromo- or chloroarenes with KF (Halex reaction) ${ }^{26}$ as well as the more recent transition-metal promoted Ar-F bond formation with electrophilic " $\mathrm{F}^{+"}$ reagents such as Selectfluor or $\mathrm{N}$-fluoropyridinium salts. ${ }^{27-29}$ By far, the most common method that medicinal chemists use to make aliphatic fluorinated compounds is through the conversion of alcohol, carbonyl compounds or alkyl halides to fluorinated compounds by fluorination (e.g., DAST). ${ }^{20}$ But this protocol is not library-friendly, each fluorinated product need one specific starting material (Figure 2, left). Because of this, fluorine is not a user-friendly substituent to introduce, especially when it comes to generate synthetic libraries using combinatorial tools, so it comes as no surprise that the number of drug candidates possessing aliphatic or cyclic fluorine substituent is so dismally low.

\subsection{Gold catalysis meet fluorine chemistry}

\subsubsection{Library-friendly synthesis of aliphatic fluorinated compounds}

We propose here a more efficient strategy to access aliphatic fluorocompounds, using fluorine-generated cationic metal species to mediate a tandem nucleophilic addition /coupling/fluorinations reaction, starting from readily available alkynes. One advantage of alkynes is that they are ubiquitous in synthesis and many of 
them are commercially available. ${ }^{30,31}$ Their reaction with suitable coupling reagents (e.g. phenyl boronic acid) and suitable nucleophiles (e.g. water, amine, malonate) in the presence of fluorination reagents (e.g. Selectfluor) will generate a diversified library of aliphatic fluorinated compounds $\left(M^{*} N^{*} L\right.$ members, Figure 2 , right). An additional advantage is that alkynes are chemically inert to many reaction conditions (like acidic or basic conditions); which is especially important when using alkyne intermediates in late steps of target syntheses.

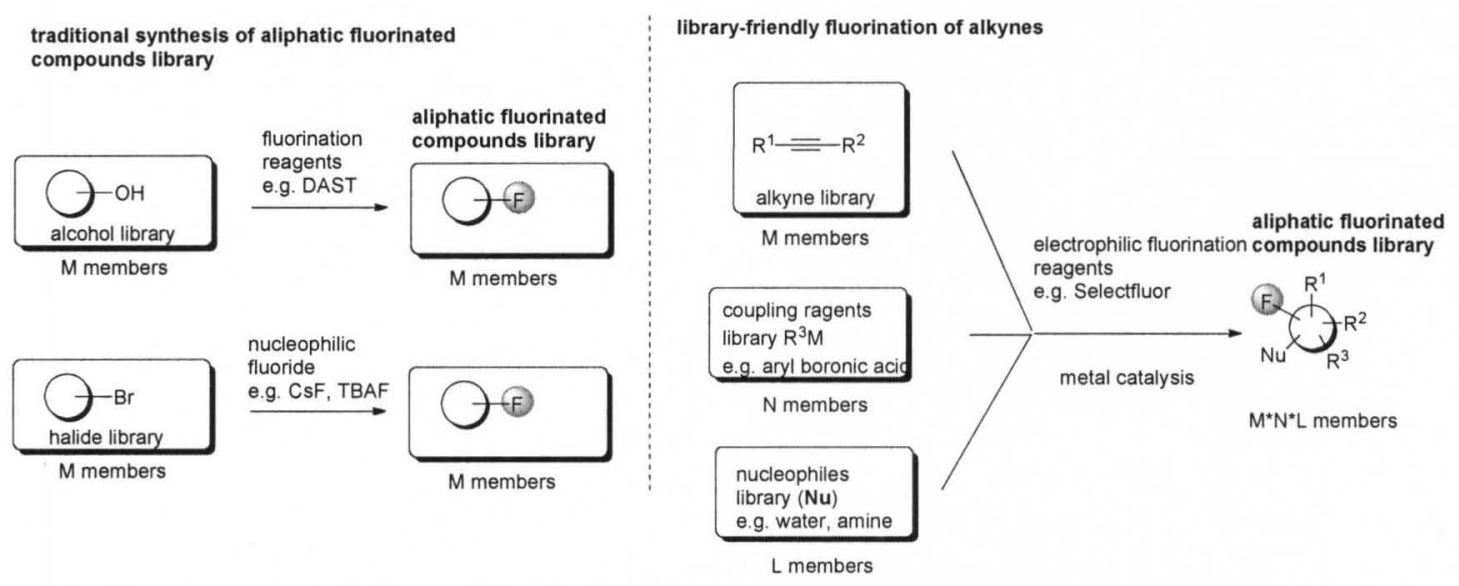

Figure 2. Library-friendly synthesis of aliphatic fluorinated compounds library.

\subsubsection{General transition metal catalytic cycle}

Transition metal catalysts play a major role in chemical synthesis. ${ }^{32}$ Many transition metals need to be cationic form to be catalytically active; a case in point is gold. ${ }^{1,3,4,6}$ Cationic gold salts have been regarded as the most powerful catalysts for electrophilic activation of alkynes toward a variety of nucleophiles. ${ }^{1,3-}$ ${ }^{8,33}$ Put simply, a nucleophilic attack on a $[\mathrm{AuL}]^{+}$-activated alkyne 1-17 proceeds via a $\pi$-complex to give a trans-alkenyl gold complex intermediate 1-18 capable of reacting with an electrophile $\left(\mathrm{E}^{+}\right)$--normally proton, to yield the final product 119 through protodeauration (Scheme 9). A common gold catalyst precursor, such 
as $\mathrm{Ph}_{3} \mathrm{PAuCl}$, is not catalytically active by itself. It is typically treated with a silver salt of a non-coordinating anion to generate the active cationic gold complex 1-20 (Scheme 9).

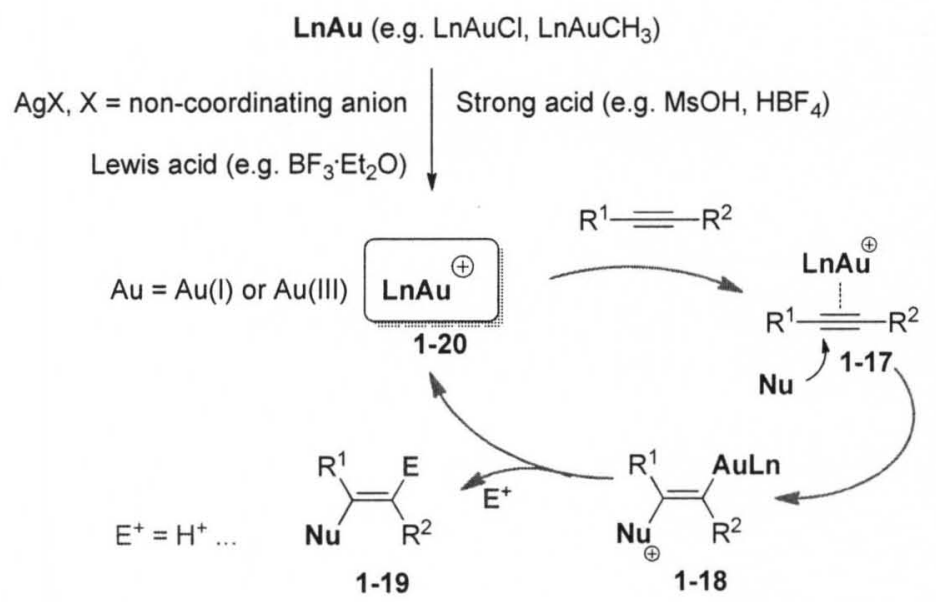

Scheme 9. Traditional methods for generation of [LnAu] ${ }^{+}$and its catalytic cycle.

\subsubsection{Fluorine-engendered cationic transition metal species.}

We envision a new mode of catalysis through a fluorine-enabled cationic metal species generated by fluorination of a low valence metal complex (e.g. $\mathrm{Au}(\mathrm{I}) \mathrm{Ln}$, $\operatorname{Pd}(0)$ ) with an ammonium $[\mathrm{N}-\mathrm{F}]^{+}$type fluorination reagent which has a noncoordinating counter ion (Scheme 10): Such species (intermediate 1-A in Scheme 10 ) is expected to be highly active, and its Lewis acidity is expected to be stronger than the corresponding metal prior to fluorination. This is due to the higher valence of the metal and the presence of a non-coordinating counter anion (e.g. $\mathrm{BF}_{4}^{-}$in case of Selectfluor). Our premise is that this cationic goldfluorine species would be able to catalyze not only the reactions that cationic metal normally catalyze (e.g. hydration or cyclization of alkynes), with similar or even higher efficiency, more importantly, it could mediate additional new transformations that regular cationic metal is less known for. This is illustrated in 
Scheme 10. For example, a fluoro-gold intermediate 1-C may undergo reductive elimination, fluorodemetalation or nucleophilic displacement to give a vinyl fluoride (right in Scheme 10); or transmetalation with an organometalic reagent $\mathrm{R}_{3} \mathrm{M}$ to give 1-D (e.g. $\mathrm{M}=\mathrm{B}, \mathrm{Si}, \mathrm{Sn}$, etc.). ${ }^{34}$ The weak $\mathrm{M}-\mathrm{F}$ bond ${ }^{35}$ and the strong B-F, Si-F and Sn-F bonds would drive the transmetalation. After reductive elimination, the low valence metal complex is re-fluorinated to resume its catalytic cycle. This strategy should deliver a diversity of fluorinated and nonfluorinated building blocks or targets.

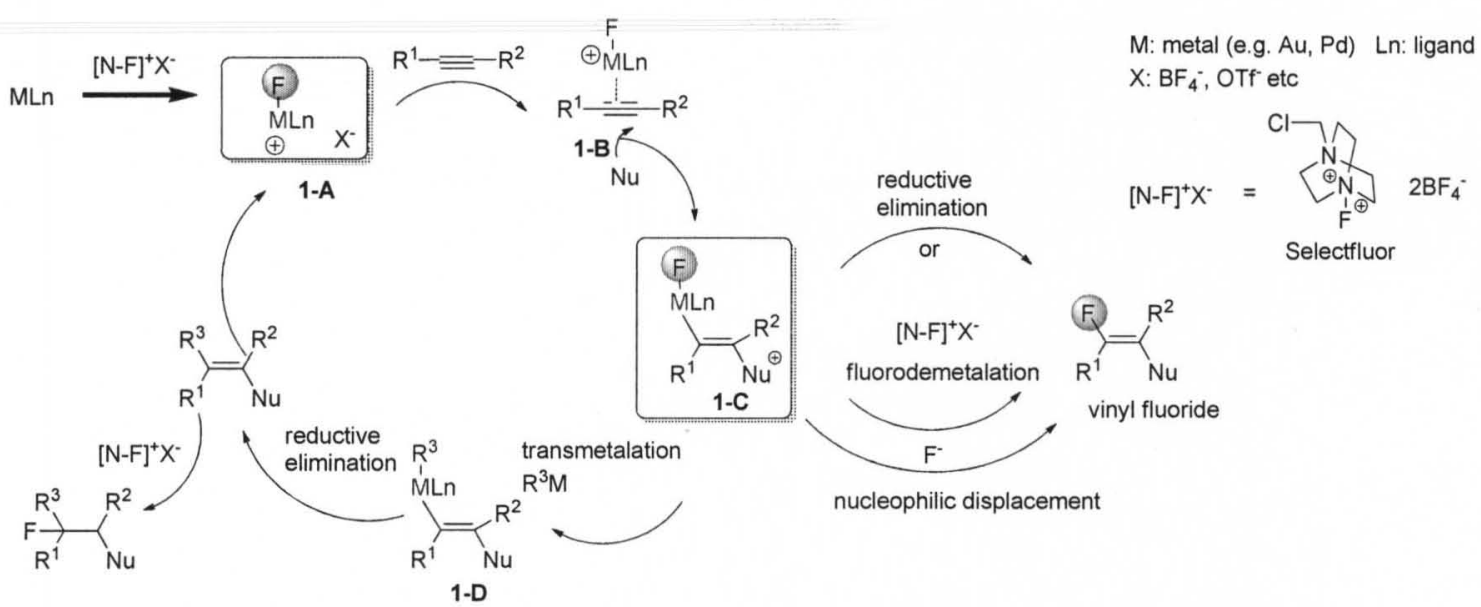

Scheme 10. Fluorination-enabled cationic metal complex and its catalytic cycle.

\subsubsection{Literature reports involve Metal-F intermediate}

Our proposed catalytic cycle has four key steps: 1) fluorination of low valence metal complex; 2) reductive elimination to give R-F compounds; 3) transmetalation of $\mathrm{M}-\mathrm{F}$ to $\mathrm{M}-\mathrm{R} ; 4)$ fluorodemetalation. Metal catalysis involving those steps has emerged in the recent literature. Fluorination reagents (e.g. Selectfluor ${ }^{36,37}$ ) have become lately the oxidant of choice in transition metalmediated $\mathrm{C}-\mathrm{H}$ activation, fluorination, oxidation and coupling reactions, as 
demonstrated by Ritter, ${ }^{38-40}$ Sanford, ${ }^{29,41}$ Gouverneur, ${ }^{42}$ Zhang, ${ }^{34,43}$ Michael, ${ }^{44}$ among others. For the reductive elimination of R-M-F, Buchwald ${ }^{45}$ (Scheme 11) and co-workers' recent breakthrough indicate that the correct choice of ligand is decisive for a successful outcome, allowing for the preparation of aryl fluoride from a stabilized 14-electron $\mathrm{Pd}(\mathrm{II})$ complex. The steric size of their ligand ( $t$ BuBrettPhos) may also compress the ArPdF angle, thereby forcing reductive elimination by bringing closer the aryl and fluorine substituents. For the fluorodemetalation process, Gouverneur and coworkers have proposed a mechanism for the gold-catalyzed cyclization of fluoro alkynyl ketone, ${ }^{42}$ although in very low yields (Scheme 11). In the case of nucleophilic displacement, Liu's method can be used in the synthesis of aliphatic system (Scheme 11), but still large excess of $\mathrm{AgF}$ (5 equiv) be used. Although promising, most of those studies are limited to aromatic systems and in many cases, a stoichiometric amount of the transition metal must be used. Compared to an aromatic system, transition metal catalysis in aliphatic systems may suffer from $\beta-\mathrm{H}$ elimination and some other side-reactions. But we believe it possible to overcome this problem with a systematic exploration of metal fluorine interaction. And our preliminary results show promising future. 
Buchwald's work

Ar-F reductive elimination form $\mathrm{Pd}(\mathrm{II})$ complex

$$
\begin{aligned}
& \text { ArOTf } \underset{\mathrm{CsF}}{\stackrel{\mathrm{Pd}}{\longrightarrow}} \mathrm{Ar}-\mathrm{F}
\end{aligned}
$$

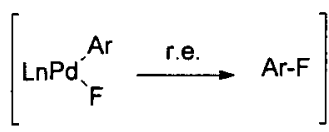

\section{Gouverneur's work}

may involve fluorodemetalation of gold complex

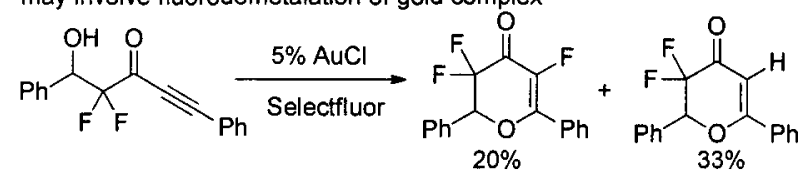

Liu's work

may involve reductive elimination of $\mathrm{RPd}(\mathrm{IV}) \mathrm{F}$

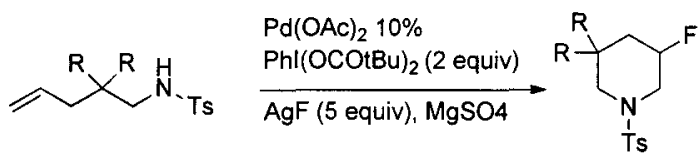

Scheme 11. Selected examples of literature reports involving Metal-F intermediate.

\subsection{Outline of this thesis}

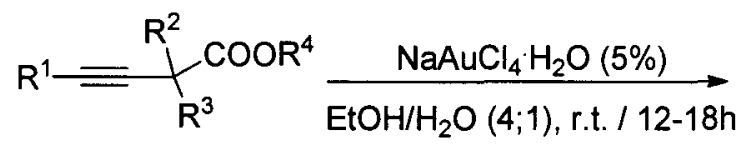<smiles>[R]OC(=O)C([R])([R])CC([R])=O</smiles>
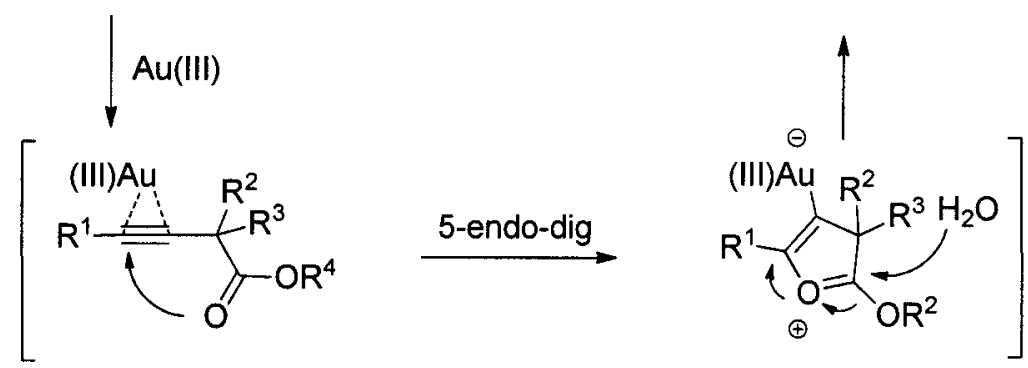

$\mathrm{R}^{1}$ : $\mathrm{Me}, n-\mathrm{C}_{6} \mathrm{H}_{13}, \mathrm{Ph} ; \mathrm{R}^{2}$ and $\mathrm{R}^{3}$ : alkenyl, alkyl, alkyl ether, alkyl ester; $\mathrm{R}^{4}$ : alkyl Chapter 2 (J.Org. Chem. 2009, 74, 1640)

Scheme 12. Synthesis of $\gamma$-keto esters through neighboring carbonyl group-assisted regioselective hydration of 3 -alkynoates. 


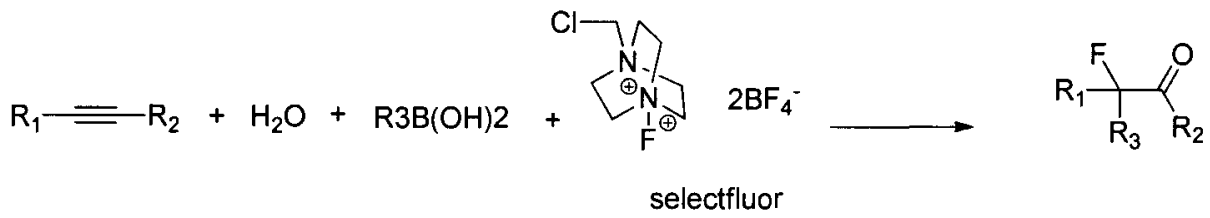

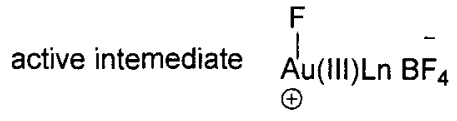

Chapter 3 (Angew. chem., Int. Ed. 2010, 49,7247)

Scheme 13. Fluorine-enabled cationic gold catalysis: functionalized hydration of alkynes.
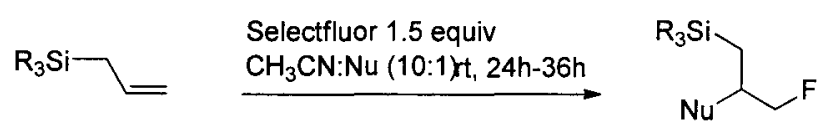

$R_{3}:$ TIPS<smiles>C=CC[SeH]c1ccccc1</smiles><smiles>C=CC[SnH2]CC=C</smiles><smiles>CC(=O)OC/C=C/C[In][In]</smiles>

Nu: $\quad \mathrm{H}_{2} \mathrm{O}$, alcohol

$$
\text { Chapter } 4 \text { ( Synthesis. 2011, 15, 2383) }
$$

Scheme 14. Synthesis of fluorohydrins through electrophilic fluorination of allyl silanes. 


\section{CHAPTER 2. GOLD CATALYZED HYDRATION OF ALKYNES}

\subsection{Introduction}

1,4-Dicarbonyl compounds are starting materials and intermediates in many important natural products and synthetic drug syntheses. ${ }^{46-48}$ Unlike their 1,3 or 1,5-counterparts, the disconnection of 1,4-dicarbonyl compounds, especially of highly substituted 1,4-dicarbonyl compounds like $\gamma$-keto- $\alpha, \alpha$-substituted esters, is not trivial. Radical or carbene ${ }^{49,50}$ methodologies, or some other relatively complex methods ${ }^{51-53}$ have to be used to synthesize them. A tactical approach that enables a one-step disconnection of highly substituted $\gamma$-keto esters could be the directed hydration of 3-alkynoates, provided this transformation can be carried out regioselectively, under mild conditions, and with good functional group tolerance. The attractiveness of this approach lies on the fact that the hydration of alkynes is one of the most straightforward methods to make carbonyl compounds. Unlike other syntheses of carbonyl compounds, the hydration of alkynes is an atom-economical addition of water without energy-intensive redox

chemistry. ${ }^{54}$ In addition, the alkyne functionality is chemically inert toward many reaction conditions, and so it can be considered as a masked ketone. 
The mercury (II)-catalyzed hydration of alkynes has been known for more than a century. To avoid the use of toxic mercury(II) salts, various catalysts such as Brønsted acids ${ }^{55-57}$ and metal catalysts, such as $\mathrm{Ru}(\mathrm{II})^{58-60}, \mathrm{Ru}(\mathrm{III})^{61}, \mathrm{Rh}(\mathrm{III}){ }^{62}$, Ir ${ }^{63}, \mathrm{Pt}(\mathrm{II}){ }^{64-67}, \mathrm{Au}^{68-71}$ as well as other systems ${ }^{72-78}$ have been examined. There are excellent catalysts for terminal alkynes but internal alkynes remain a challenge, in part because of regioselectivity issues. Gold catalysis is especially promising for the hydration of alkynes because of the higher affinity of gold towards alkynes compared to other common oxygen- or nitrogen-containing functional groups. In 1991, Fukuda and coworkers reported the use of an Au (III) salt in refluxing aqueous methanol for the hydration of terminal alkynes to methyl ketones (Markovnikov addition). But their hydration of internal alkynes was sluggish and non-regioselective. Many other gold catalysts have been also examined, but only terminal alkynes showed good regioselectivity (Markovnikov products), and most reactions needed elevated temperatures or strong acid cocatalysts. ${ }^{68-71} \mathrm{We}$ are pleased to report a neighboring carbonyl group-assisted hydration of internal alkynes in the presence of a gold (III) catalyst that yields a highly regioselective synthesis of $\gamma$-keto esters.

\subsection{Directed gold-catalyzed hydration of alkynes through neighboring group assistance}

In general, the regioselective hydration of internal alkynes may only proceed in the presence of a directing functionality (like heteroatoms, aromatic rings) nearby. ${ }^{79-85}$ We proposed that with internal alkynes possessing a nucleophilic site Nu nearby (Scheme 15), this nucleophile could attack a gold activated triple bond 
to form two regioisomeric cyclic intermediates. Although both carbons in the triple bond are prone to nucleophilic attack, one cyclic intermediate may be favored over the other according to Baldwin's rules. ${ }^{86}$ If $\mathrm{Nu}$ is a carboxylic ester, this neighboring group assistance may then lead to a highly regioselective synthesis of $\gamma$-keto esters through an alkyne hydration process.

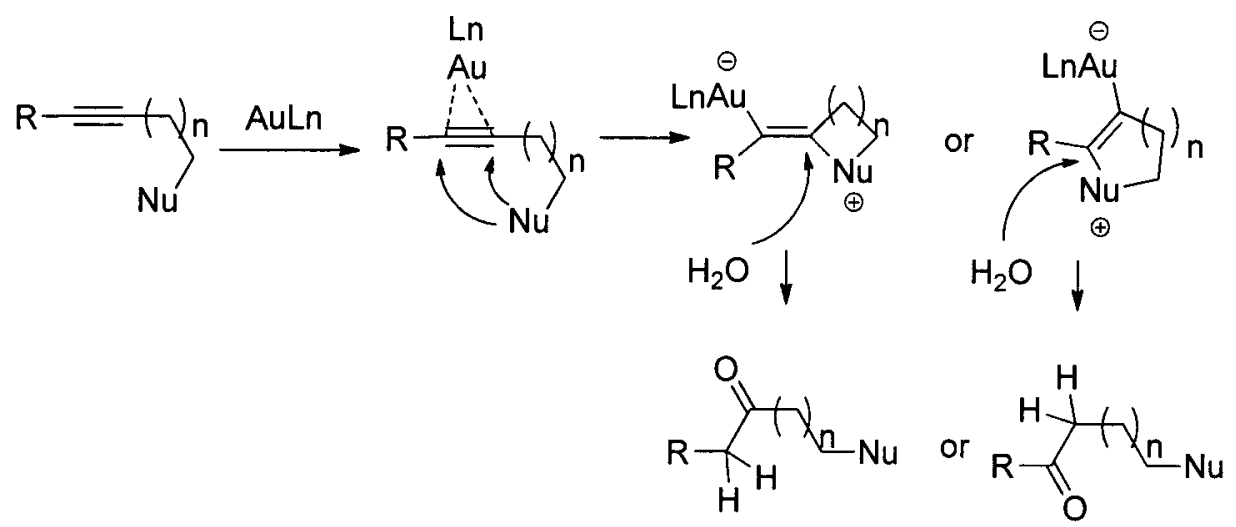

Scheme 15. Directed gold-catalyzed hydration of alkynes through neighboring group assistance.

\subsection{Results and discussion}

To test this hypothesis, we first examined the effect of transition metal catalysts on the hydration of 3-alkynoate 2-1a (Table 1). Our selection of metal catalysts was based on the known alkynophilicity of gold (I), gold (III), platinum (II), and silver (I) ${ }^{87}$ A strong acid alone ${ }^{55-57}$ had no effect on 2-1a (Table 1, entry 1 ).

Treatment of 2-1a with $\mathrm{Au}(\mathrm{I})$ or $\mathrm{PtCl}_{2}$ catalysts gave traces of hydration product 2-2a at room temperature (Table 1, entries $2-5$ ). Conversely, the addition of a strong acid to $\mathrm{AuCl}$, or $\mathrm{Au}\left(\mathrm{PPh}_{3}\right) \mathrm{Cl}$ produced the desired ketone but in less than desirable yields, due to side-reactions induced by the prevailing acidic conditions (Table 1, entries 6 and 7). On the other hand, the use of $A u(I I I)$ catalysts such as 
$\mathrm{AuBr}_{3}, \mathrm{AuCl}_{3}$ or $\mathrm{NaAuCl}_{4} \cdot 2 \mathrm{H}_{2} \mathrm{O}$ offered hope (Table 1, entries 8 - 10). After these results, we decided to investigate the effects of solvents and additives/ligands on the hydration of 2-1a employing $\mathrm{Au}(\mathrm{III})$ catalysts. Using $\mathrm{AuBr}_{3}$ in various solvent combinations did not improve the yield of 2-2a significantly (Table 2, entries 1-5). We then tested a combination of $\mathrm{AuBr}_{3}$ with various additives or ligands, such as $n \mathrm{Bu}_{4} \mathrm{NBr}, \mathrm{P}(\mathrm{OEt})_{3}$ or pyridine, with disappointing results (Table 2, entries 6-9). A complex mixture was observed when a combination of $\mathrm{AuCl}_{3}$ and $\mathrm{AgOTf}$ in $\mathrm{MeOH} / \mathrm{H}_{2} \mathrm{O}$ was used, whereas $\mathrm{AuCl}_{3}$ alone produced $2-2 \mathrm{a}$ in only $33 \%$ yield (Table 2, entries 10 and 11).

Table 1. Screening of metal catalysts for the hydration of 2-1a.

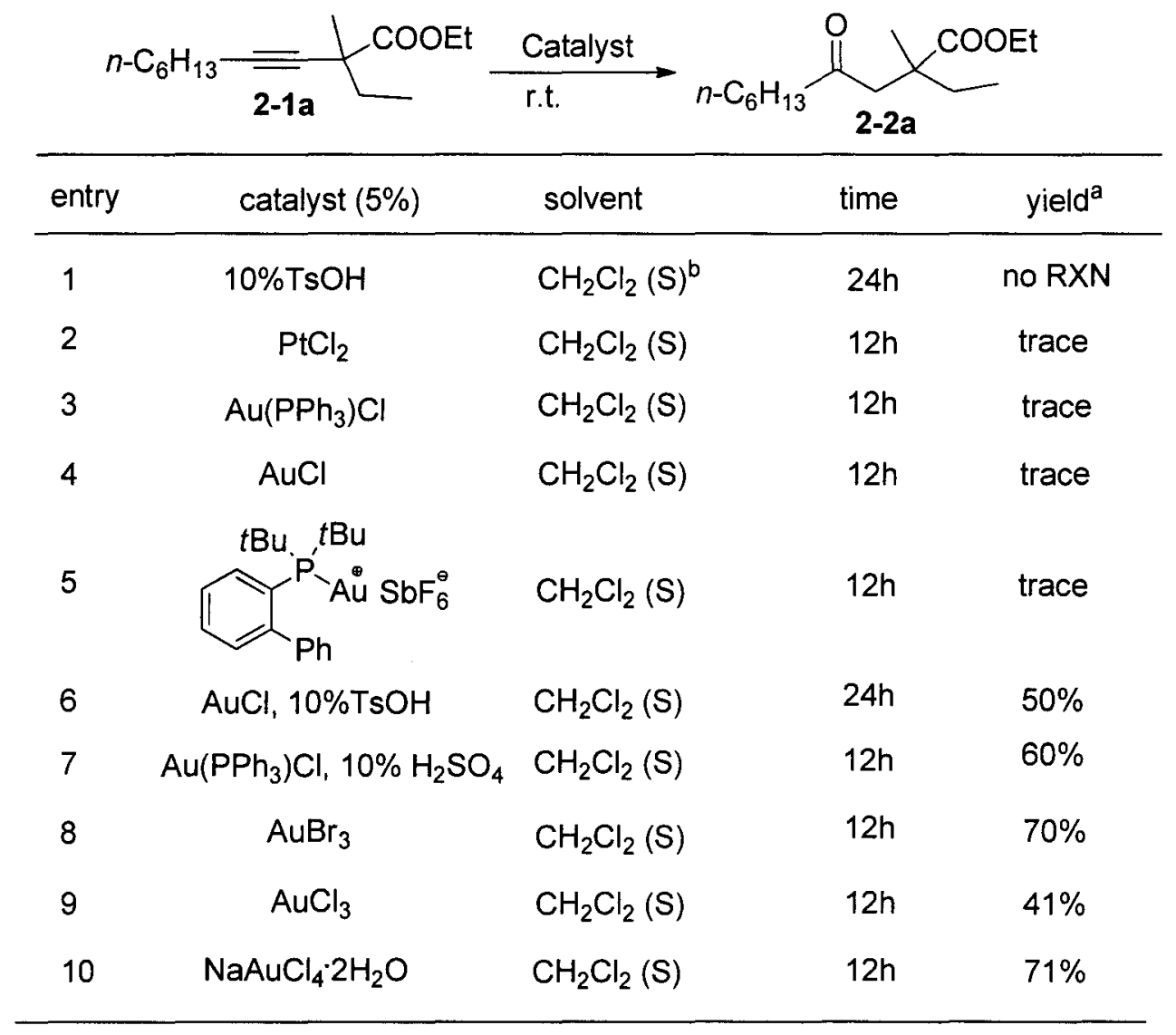

a Yields are based on ${ }^{1} \mathrm{H} N M R .{ }^{b} \mathrm{CH}_{2} \mathrm{Cl}_{2}$ saturated with water. 
After screening $\mathrm{NaAuCl}_{4} \cdot 2 \mathrm{H}_{2} \mathrm{O}$ using different solvent combinations (Table 2, entries 12-17), we concluded that $\mathrm{NaAuCl}_{4} \cdot 2 \mathrm{H}_{2} \mathrm{O}$ in $\mathrm{EtOH} / \mathrm{H}_{2} \mathrm{O}(4: 1)$ offered the best conditions for the hydration of alkyne 2-1a. When methanol was used as solvent, the reaction gave a mixture of $\mathbf{2 - 2 a}$ and the corresponding methyl ester due to transesterification (Table 2 , entry 17 ). When a smaller catalyst loading $\left(\mathrm{NaAuCl}_{4} \cdot 2 \mathrm{H}_{2} \mathrm{O}, 2 \%\right)$ was used, the reaction was slower, but hydration of compound 2-2a still could be completed in $24 \mathrm{~h}$. Using these optimal conditions in hand, we explored the scope of this reaction (Table 3). The hydration proceeded smoothly in high yields with regioselectivity, and was tolerant of an ether, double bond, or other ester functionalities (Table 3 , entries 4,5 , and 8 , respectively). Indeed, only one regioisomer was detected among all the crude products examined. The steric hindrance of the quaternary $\alpha$-carbon could be ruled out as the reason for the high selectivity of the hydration because a 3-alkynoate possessing no substituents in its $\alpha$-carbon also showed excellent regioselectivity after hydration (Table 3, entry 10). The stereoelectronic effects of a phenyl group could account for the lower yield observed in (Table 3, entry 7). The hydration of 2-fluoro-3-alkynoate 2-1k gives $\alpha, \beta$-unsaturated ester $\mathbf{2 - 2 k}$ (Table 3 entry 11) through concomitant elimination of HF during the hydration process. 
Table 2. Screening of solvents and additives.

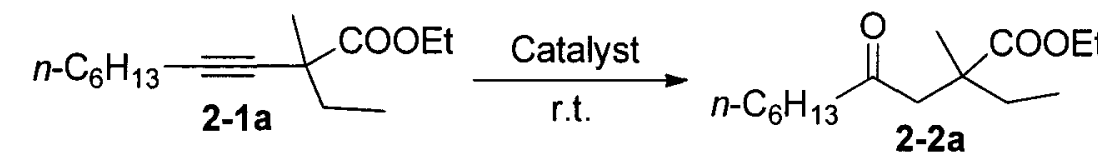

\begin{tabular}{|c|c|c|c|c|}
\hline entry & catalyst $(5 \%)$ /additves & solvent & time & yield $^{a}$ \\
\hline 1 & $\mathrm{AuBr}_{3}$ & $\mathrm{CH}_{2} \mathrm{Cl}_{2}(\mathrm{~S})^{\mathrm{b}}$ & $12 \mathrm{~h}$ & $70 \%$ \\
\hline 2 & $\mathrm{AuBr}_{3}$ & $\mathrm{MeOH} / \mathrm{H}_{2} \mathrm{O}(10: 1)$ & $12 \mathrm{~h}$ & $17 \%$ \\
\hline 3 & $\mathrm{AuBr}_{3}$ & $\mathrm{CH}_{2} \mathrm{Cl}_{2} / \mathrm{H}_{2} \mathrm{O}(100: 1)$ & $72 h$ & trace \\
\hline 4 & AuBr3 & $t-\mathrm{BuOH} / \mathrm{H}_{2} \mathrm{O}(10: 1)$ & $12 \mathrm{~h}$ & $25 \%$ \\
\hline 5 & $\mathrm{AuBr}_{3}$ & $\mathrm{CH}_{3} \mathrm{CN} / \mathrm{H}_{2} \mathrm{O}(10: 1)$ & $12 \mathrm{~h}$ & $35 \%$ \\
\hline 6 & $\mathrm{AuBr}_{3} / \mathrm{Bu}_{4} \mathrm{NBr}(5 \%)$ & $\mathrm{CH}_{2} \mathrm{Cl}_{2}(\mathrm{~S})$ & $12 \mathrm{~h}$ & $6 \%$ \\
\hline 7 & $\mathrm{AuBr}_{3} / \mathrm{Bu}_{4} \mathrm{NBr}(5 \%)$ & $\mathrm{MeOH} / \mathrm{H}_{2} \mathrm{O}(10: 1)$ & $12 \mathrm{~h}$ & trace \\
\hline 8 & $\mathrm{AuBr}_{3} /$ pyridine $(5 \%)$ & $\mathrm{MeOH} / \mathrm{H}_{2} \mathrm{O}(10: 1)$ & $12 \mathrm{~h}$ & No RXN \\
\hline 9 & $\mathrm{AuBr}_{3} / \mathrm{P}(\mathrm{OEt})_{3}(5 \%)$ & $\mathrm{MeOH} / \mathrm{H}_{2} \mathrm{O}(10: 1)$ & $12 \mathrm{~h}$ & No RXN \\
\hline 10 & $\mathrm{AuCl}_{3}$ & $\mathrm{MeOH} / \mathrm{H}_{2} \mathrm{O}(10: 1)$ & $24 h$ & $33 \%$ \\
\hline 11 & $\mathrm{AuCl}_{3} / \mathrm{AgOTf}(15 \%)$ & $\mathrm{MeOH} / \mathrm{H}_{2} \mathrm{O}(10: 1)$ & $24 h$ & complex \\
\hline 12 & $\mathrm{NaAuCl}_{4} \cdot 2 \mathrm{H}_{2} \mathrm{O}$ & $\mathrm{CH}_{2} \mathrm{Cl}_{2}(\mathrm{~S})$ & $12 \mathrm{~h}$ & $71 \%$ \\
\hline 13 & $\mathrm{NaAuCl}_{4} \cdot 2 \mathrm{H}_{2} \mathrm{O}$ & $t-\mathrm{BuOH} / \mathrm{H}_{2} \mathrm{O}$ & $12 \mathrm{~h}$ & $56 \%$ \\
\hline 14 & $\mathrm{NaAuCl}_{4} \cdot 2 \mathrm{H}_{2} \mathrm{O}$ & $\mathrm{EtOH} / \mathrm{H}_{2} \mathrm{O}(50: 1)$ & $12 \mathrm{~h}$ & $33 \%$ \\
\hline 15 & $\mathrm{NaAuCl}_{4} \cdot 2 \mathrm{H}_{2} \mathrm{O}$ & $\mathrm{EtOH} / \mathrm{H}_{2} \mathrm{O}(4: 1)$ & $12 \mathrm{~h}$ & $78 \%$ \\
\hline 16 & $\mathrm{NaAuCl}_{4} \cdot 2 \mathrm{H}_{2} \mathrm{O}$ & $\mathrm{EtOH} / \mathrm{H}_{2} \mathrm{O}(1: 1)$ & $12 \mathrm{~h}$ & $33 \%$ \\
\hline 17 & $\mathrm{NaAuCl}_{4} \cdot 2 \mathrm{H}_{2} \mathrm{O}$ & $\mathrm{MeOH} / \mathrm{H}_{2} \mathrm{O}(10: 1)$ & $12 \mathrm{~h}$ & mixture ${ }^{c}$ \\
\hline
\end{tabular}

${ }^{a}$ Yields are based on ${ }^{1} \mathrm{H}$ NMR. ${ }^{b} \mathrm{CH}_{2} \mathrm{Cl}_{2}$ saturated by water. ${ }^{\mathrm{c}}$ Mixture of 2-2a and corresponding methyl ester. 
Table 3. Au(III)-catalyzed hydration of internal 3-alkynoates.

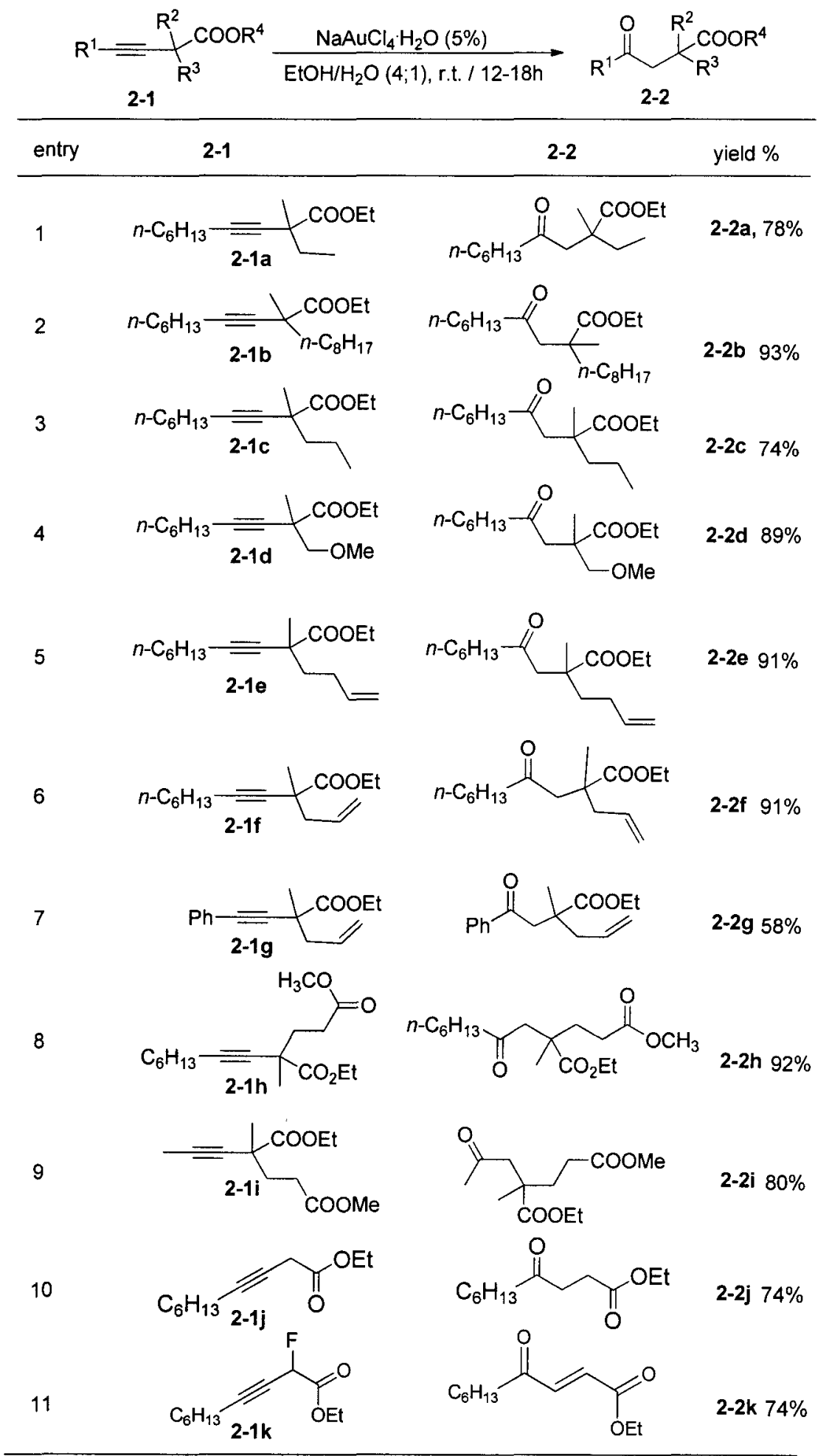

Reactions were performed using $5 \mathrm{~mol} \% \mathrm{NaAuCl}_{4} \cdot 2 \mathrm{H}_{2} \mathrm{O}$, alkyne $2-1(0.5 \mathrm{mmol}), \mathrm{EtOH} / \mathrm{H}_{2} \mathrm{O}(4: 1,1.0 \mathrm{~mL})$. 
The adjacent carbonyl group in alkyne 2-1 plays an important role in both, reaction rate and regioselectivity. For example, the hydration of dec-2-yne 2-11 under similar conditions was much slower (Scheme 16, top), and although the chemical yield was high, the regioselectivity was poor. The hydration of the sterically demanding 4,4-dimethylpent-2-yne 2-1m was even slower; indeed, after $72 \mathrm{~h}$, almost no reaction had taken place (Scheme 16, bottom). These results were in sharp contrast with the hydration of $\beta$-alkynyl esters. Even the hydration of sterically encumbered $\beta$-alkynyl esters $2-1$ h proceeded smoothly at room temperature (Table 3, entries 8 ).

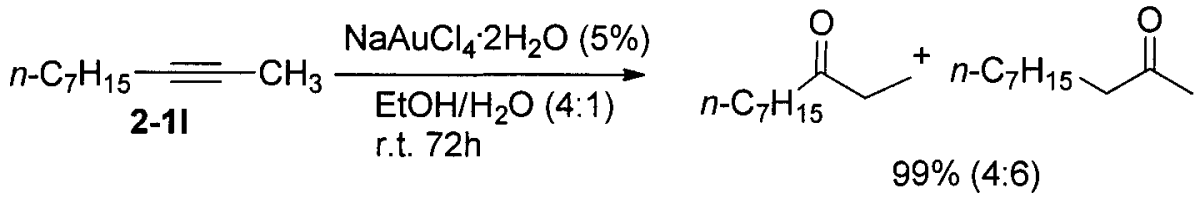

$$
\begin{aligned}
& \underset{\text { 2-1m }}{\overline{\bar{m}}}\left\langle\frac{\mathrm{NaAuCl}_{4} \cdot 2 \mathrm{H}_{2} \mathrm{O}(5 \%)}{\begin{array}{l}
\mathrm{EtOH} / \mathrm{H}_{2} \mathrm{O}(4: 1) \\
\text { r.t. } 72 \mathrm{~h}
\end{array}}\right. \text { almost no reaction }
\end{aligned}
$$

Scheme 16. Hydration of simple internal alkynes.

It is noteworthy that in some cases we obtained small or trace amounts of a cyclic by-product (e.g., 2-3c in eq 1 ).

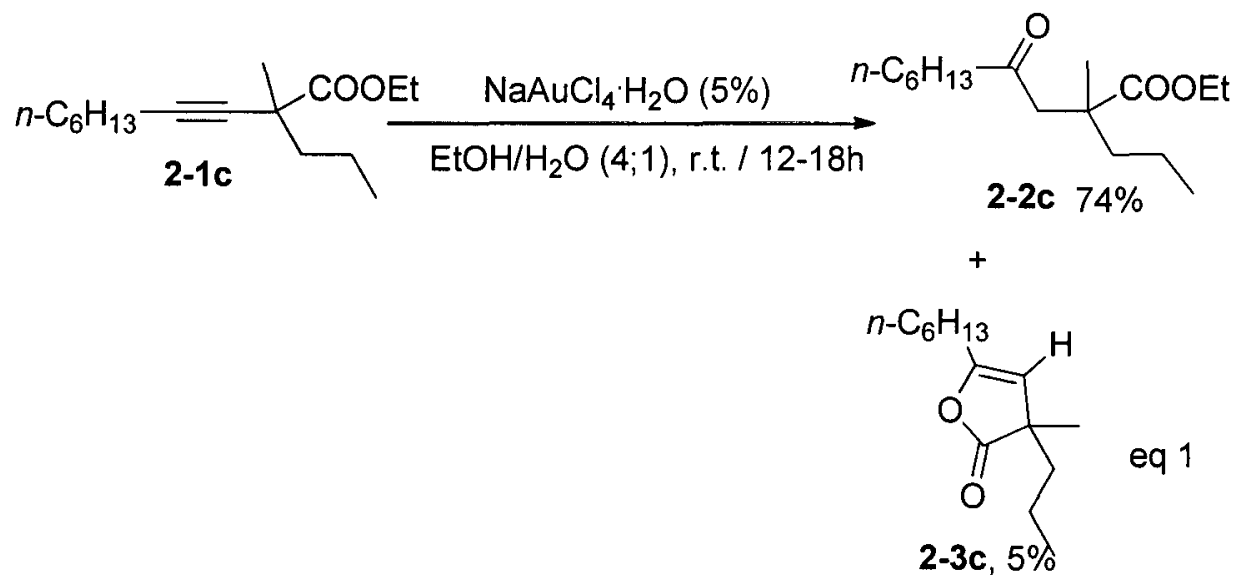


The proposed mechanism for the reaction, based on similar reaction systems, ${ }^{88}$ is shown in Scheme 17. First, the gold (III) catalyst coordinates with alkyne 2-1, activating the triple bond, and triggering the carbonyl group nearby which acts as a nucleophile to attack the triple bond to form a cyclized vinyl gold intermediate of type 2-A or 2-B. ${ }^{89,90}$ According to Baldwin's rules ${ }^{86}$, if the carbonyl oxygen attacks the $\beta$-carbon, it is considered a 4-exo-dig process, which is disfavored. But if the carbonyl oxygen attacks the $\gamma$-carbon, it would then be a 5-endo-dig attack, which is regarded as favored. ${ }^{91,92}$ For example; Hashmi and co-workers have reported the cyclization of an ethynylketone to a furan through 5-endo-dig process. ${ }^{61}$ Thus, 2-B should be the predominating intermediate. Then, upon water attack to 2-B, this forms the ring-opened product 2-C, which in turn would form intermediate 2-D by proto-deauration. Finally, isomerization of 2-D produced $\gamma$-keto ester 2-2. A competing side reaction, namely the elimination of $\mathrm{R}^{2} \mathrm{OH}$ from 2-B, is also possible. This would account for the trace amounts of cyclic byproduct obtained in some cases (eq. 1).

Hydration of 2-alkynoate 2-4a under similar condition gave the $\beta$-keto ester $\mathbf{2 - 5 a}$ in high yield (eq 2); this reaction is also highly regioselective. Its selectivity may arise through the electronic effect of the ester group. Due to the strong electron withdrawing effect of the conjugated ester, the $\beta$-carbon of $\mathbf{2 - 4 a}$ is more electronically deficient, promoting an attack by water to this position to give $\mathbf{2 - 5 a}$. 


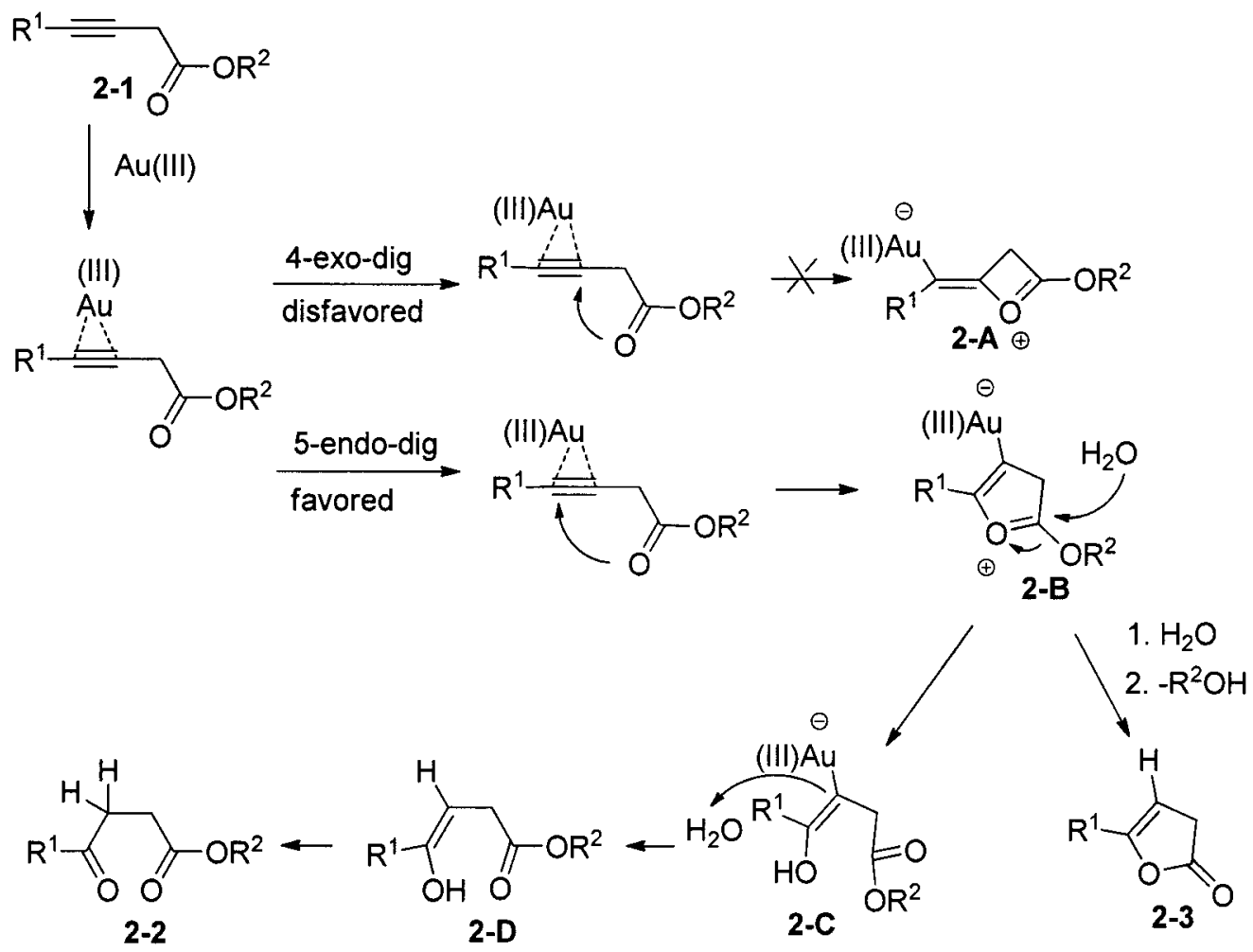

Scheme 17. Proposed mechanism for the hydration of 3-alkynoates.

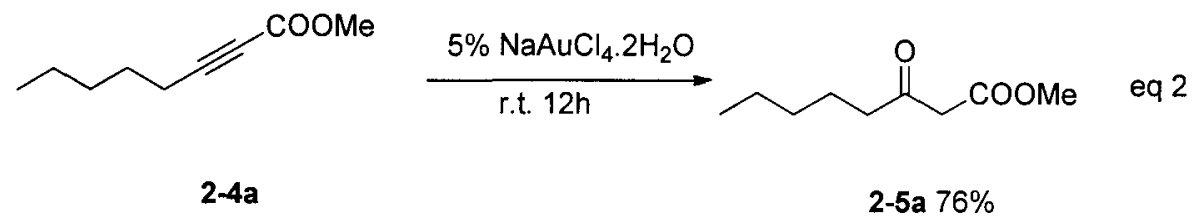

\subsection{Summary and future direction}

In summary, we have developed an effective and straightforward hydration of 3alkynoates in the presence of catalytic amounts of Au (III) salt in aqueous ethanol at room temperature to give $\gamma$-keto esters regioselectively and in high yields. This mild and atom-economical method can be used effectively with a wide range of substrates, yielding densely functionalized products. With a propargyl ester this 
reaction yields $\beta$-keto esters in high yield. The broader applications of this reaction in organic synthesis are currently under investigation.

\subsection{Experimental}

\section{General}

${ }^{1} \mathrm{H},{ }^{13} \mathrm{C}$ NMR spectra were recorded at $500,126 \mathrm{MHz}$ respectively, using $\mathrm{CDCl}_{3}$ as a solvent. The chemical shifts are reported in $\delta(\mathrm{ppm})$ values relative to $\mathrm{CHCl}_{3}$ ( $\delta 7.26 \mathrm{ppm}$ for ${ }^{1} \mathrm{H}$ NMR and $\delta 77.0 \mathrm{ppm}$ for $\left.{ }^{13} \mathrm{C} \mathrm{NMR}\right)$, multiplicities are indicated by $s$ (singlet), $d$ (doublet), $t$ (triplet), $q$ (quartet), $p$ (pentet), $h$ (hextet), $m$ (multiplet) and br (broad). Coupling constants, $J$, are reported in Hertz. Coupling constants are reported in hertz $(\mathrm{Hz})$. All air and/or moisture sensitive reactions were carried out under argon atmosphere. Solvents (tetrahydrofuran, ether, dichloromethane and DMF) were chemically dried using a commercial solvent purification system. All other reagents and solvents were employed without further purification. The products were purified using a Biotage flash+ system or Chromatotron apparatus or a regular glass column. TLC was developed on Merck silica gel 60 F254 aluminum sheets. Elemental analysis was performed at Atlantic Microlabs Inc., Norcross, Georgia 30091. Accurate mass determinations were performed at the Nebraska Center for Mass Spectrometry, University of Nebraska-Lincoln, Nebraska 68588. 
General procedure for preparation of 3-alkynoates $2-1^{93,94}$

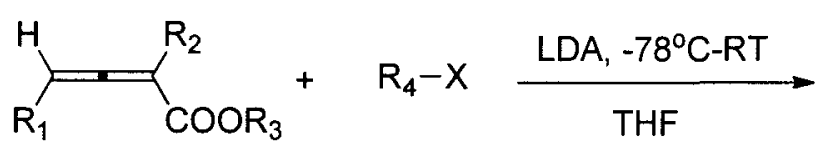<smiles>[R]C#CC([R])([R])C(=O)OCC</smiles>

To an oven-dried, air-free $10 \mathrm{~mL}$ flask of an allenoate $(0.5 \mathrm{mmol})$ was added dry THF $(2 \mathrm{~mL})$ and the reaction mixture was cooled down to $-78^{\circ} \mathrm{C}$; LDA (2M in THF, $0.375 \mathrm{~mL}, 0.75 \mathrm{mmol}$ ) was then added slowly over $5 \mathrm{~min}$. The reaction mixture was stirred at $-78^{\circ} \mathrm{C}$ for $5 \mathrm{~min}$, and then alkyl bromide $(0.75 \mathrm{mmol})$ was injected dropwise slowly. The resulting solution was stirred for $10 \mathrm{~min}$, then warmed up to room temperature, and stirred overnight at room temperature. The reaction mixture was then quenched with saturated $\mathrm{NH}_{4} \mathrm{Cl}$ solution $(2-3 \mathrm{~mL})$. After stirring for 5 mins at the room temperature, the resulting aqueous mixture was extracted with ether (three times) and the combined organic layers were dried over anhydrous $\mathrm{Na}_{2} \mathrm{SO}_{4}$, filtered, and evaporated under reduced pressure. The crude product was purified by flash silica gel chromatography $\left(25 \% \mathrm{CH}_{2} \mathrm{Cl}_{2}\right.$ in hexane $-50 \% \mathrm{CH}_{2} \mathrm{Cl}_{2}$ in hexane) to give the product $\alpha, \alpha$-disubstituted $\beta$ alkynyl esters.

\section{Spectroscopic data of compounds 2-1.}

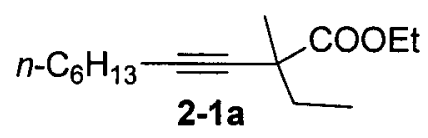

Compound 2-1a: ethyl 2-ethyl-2-methyldec-3-ynoate

Colorless oil, 74\%: ${ }^{1} \mathrm{H}$ NMR $\left(500 \mathrm{MHz}, \mathrm{CDCl}_{3}\right) \delta 0.88(\mathrm{t}, J=6.5 \mathrm{~Hz}, 3 \mathrm{H}), 0.95(\mathrm{t}$, $J=7 \mathrm{~Hz}, 3 \mathrm{H}), 1.25-1.32(\mathrm{~m}, 3 \mathrm{H}), 1.35-1.41(\mathrm{~m}, 2 \mathrm{H}), 1.39(\mathrm{~s}, 2 \mathrm{H}), 1.46-1.51(\mathrm{~m}$, 
2H), 1.61-1.66 (m, 2H), 1.79-1.84 (m, H), $2.18(\mathrm{t}, J=7 \mathrm{~Hz}, 2 \mathrm{H}), 4.16(\mathrm{q}, J=7 \mathrm{~Hz}$, $2 \mathrm{H})$.

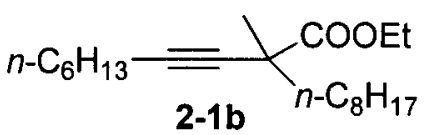

Compound 2-1b: ethyl 2-methyl-2-octyldec-3-ynoate

Colorless oil, 67\%: ${ }^{1} \mathrm{H}$ NMR $\left(500 \mathrm{MHz}, \mathrm{CDCl}_{3}\right) \delta$ 0.85-0.89 (m, 6H) 1.24-1.33 (m, $17 \mathrm{H}), 1.39(\mathrm{~s}, 3 \mathrm{H}), 1.35-1.45(\mathrm{~m}, 2 \mathrm{H}), 1.45-1.51(\mathrm{~m}, 2 \mathrm{H}), 1.55-1.61(\mathrm{~m}, 2 \mathrm{H}), 1.73-$ $1.77(\mathrm{~m}, 2 \mathrm{H}), 2.18(\mathrm{t}, J=7 \mathrm{~Hz}, 2 \mathrm{H}), 4.16(q, J=7 \mathrm{~Hz}, 2 \mathrm{H})$.

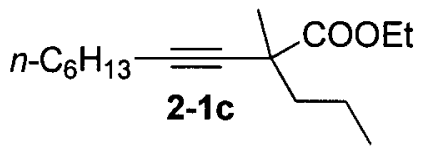

Compound 2-1c: ethyl 2-methyl-2-propyldec-3-ynoate

Colorless oil, 54\%: ${ }^{1} \mathrm{H}$ NMR $\left(500 \mathrm{MHz}, \mathrm{CDCl}_{3}\right) \delta$ 0.87-0.92 (m, 6H), 1.25-1.31 (m, 7H), 1.31-1.38 (m, 4H), $1.40(\mathrm{~s}, 3 \mathrm{H}), 1.44-1.50(\mathrm{~m}, 2 \mathrm{H}), 1.54-1.60(\mathrm{~m}, 1 \mathrm{H}), 1.73-$ $1.79(\mathrm{~m}, 1 \mathrm{H}), 2.18(\mathrm{t}, J=6.5 \mathrm{~Hz}, 2 \mathrm{H}), 4.16(\mathrm{q}, J=7.0 \mathrm{~Hz}, 2 \mathrm{H})$.

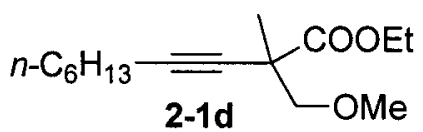

Compound 2-1d: ethyl 2-(methoxymethyl)-2-methyldec-3-ynoate

Colorless oil , 90\%: ${ }^{1} \mathrm{H}$ NMR $\left(500 \mathrm{MHz}, \mathrm{CDCl}_{3}\right) \delta 0.85(\mathrm{t}, J=7.0 \mathrm{~Hz}, 3 \mathrm{H}), 1.23-$ $1.29(\mathrm{~m}, 7 \mathrm{H}), 1.31-1.36(\mathrm{~m}, 2 \mathrm{H}), 1.39(\mathrm{~s}, 3 \mathrm{H}), 1.42-1.46(\mathrm{~m}, 2 \mathrm{H}), 2.14(\mathrm{t}, J=7.0$ 
$\mathrm{Hz}, 2 \mathrm{H}), 3.33(\mathrm{~s}, 3 \mathrm{H}), 3.45(\mathrm{~d}, J=8.5 \mathrm{~Hz}, 1 \mathrm{H}), 3.59(\mathrm{~d}, J=9.0 \mathrm{~Hz}, 1 \mathrm{H}), 4.16(\mathrm{q}, J$ $=7.0 \mathrm{~Hz}, 2 \mathrm{H})$.

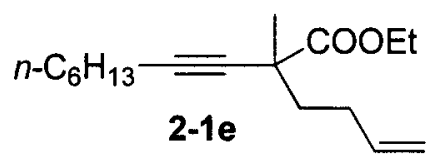

Compound 2-1e: ethyl 2-(but-3-en-1-yl)-2-methyldec-3-ynoate

Colorless oil, $81 \%:{ }^{1} \mathrm{H}$ NMR $\left(500 \mathrm{MHz}, \mathrm{CDCl}_{3}\right) \delta 0.88(\mathrm{t}, J=6.5 \mathrm{~Hz}, 3 \mathrm{H}), 1.25$ $1.32(\mathrm{~m}, 7 \mathrm{H}), 1.36-1.40(\mathrm{~m}, 2 \mathrm{H}), 1.42(\mathrm{~s}, 3 \mathrm{H}), 1.46-1.50(\mathrm{~m}, 2 \mathrm{H}), 1.65-1.70(\mathrm{~m}$, $1 \mathrm{H}), 1.86-1.92(\mathrm{~m}, 1 \mathrm{H}), 2.11-2.14(\mathrm{~m}, 2 \mathrm{H}), 2.18(\mathrm{~d}, J=6.5 \mathrm{~Hz}, 2 \mathrm{H}), 4.16(\mathrm{q}, J=$ $6.5 \mathrm{~Hz}, 2 \mathrm{H}), 4.93-5.03(\mathrm{~m}, 2 \mathrm{H}), 5.77-5.83(\mathrm{~m}, 1 \mathrm{H})$.

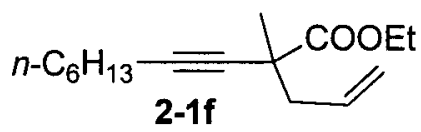

Compound 2-1f: ethyl 2-allyl-2-methyldec-3-ynoate

Colorless oil, $88 \%:{ }^{1} \mathrm{H}$ NMR $\left(500 \mathrm{MHz}, \mathrm{CDCl}_{3}\right) \delta 0.89(\mathrm{t}, J=7.0 \mathrm{~Hz}, 3 \mathrm{H}), 1.26-$ $1.31(\mathrm{~m}, 7 \mathrm{H}), 1.4(\mathrm{~s}, 3 \mathrm{H}), 1.38-1.52(\mathrm{~m}, 4 \mathrm{H}), 2.19(\mathrm{t}, J=6.5 \mathrm{~Hz}, 2 \mathrm{H}), 2.38-2.42$ $(m, 1 \mathrm{H}), 2.52-2.56(\mathrm{~m}, 1 \mathrm{H}), 4.17(\mathrm{q}, J=7 \mathrm{~Hz}, 2 \mathrm{H}), 5.08-5.11(\mathrm{~m}, 2 \mathrm{H}), 5.82-5.88(\mathrm{~m}$, 1H). 


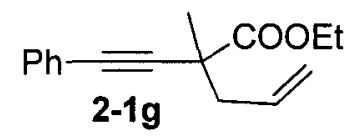

Compound 2-1g: ethyl 2-methyl-2-(phenylethynyl)pent-4-enoate

Colorless oil, 79\%: ${ }^{1} \mathrm{H}$ NMR $\left(500 \mathrm{MHz}, \mathrm{CDCl}_{3}\right) \delta 1.32(\mathrm{t}, J=7.0 \mathrm{~Hz}, 3 \mathrm{H}), 1.55(\mathrm{~s}$, $3 \mathrm{H}), 2.53-2.57(\mathrm{~m}, \mathrm{H}), 2.67-2.71(\mathrm{~m}, \mathrm{H}), 4.24(\mathrm{q}, J=7.0 \mathrm{~Hz}, 2 \mathrm{H}), 5.16-5.20(\mathrm{~m}$, $2 \mathrm{H}), 5.92-5.98(\mathrm{~m}, 1 \mathrm{H}), 7.20-7.30(\mathrm{~m}, 3 \mathrm{H}), 7.44-7.45(\mathrm{~m}, 2 \mathrm{H})$.

General procedure for preparation of $2-1 i$ and $2-1 h^{94}$

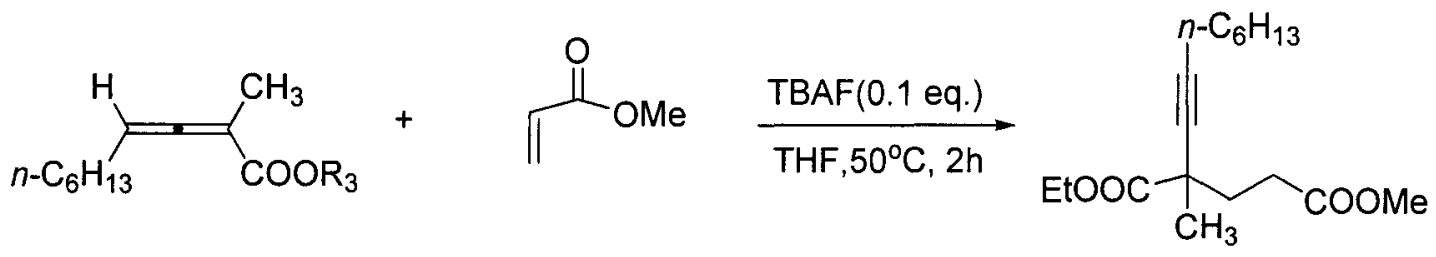

To a solution of ethyl $\alpha$-methyl- $-(n$-hexyl)-allenoate $(63 \mathrm{mg}, 0.3 \mathrm{mmol})$ and methyl acrylate $(31 \mathrm{mg}, 0.36 \mathrm{mmol})$ in THF $(2.0 \mathrm{~mL})$ was add a solution of TBAF in THF (1.0 M solution in THF, $0.03 \mathrm{~mL})$. The mixture was stirred for $2 \mathrm{hr}$ at 50 ${ }^{\circ} \mathrm{C}$; afterwards the solvent was removed under reduced pressure and the residue was subjected to flash column chromatography (eluent: ethyl acetate/petroleum ether, $1: 20)$ to give product $1 \mathrm{~h}(71 \mathrm{mg}, 80 \%)$ as a colorless oil.

\section{Spectroscopic data of compounds 2-1i and 2-1h}

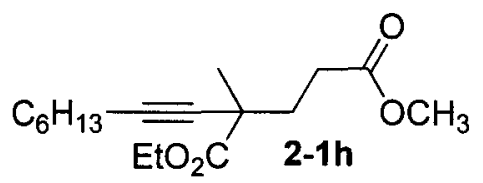

Compound 2-1h: 1-ethyl 5-methyl 2-methyl-2-(oct-1-yn-1-yl)pentanedioate 
a colorless oil; IR (neat): v 2933, 2859, 1739, 1437, 1238, $1024 \mathrm{~cm}^{-1} ;{ }^{1} \mathrm{H}$ NMR $\left(\mathrm{CDCl}_{3}, 500 \mathrm{MHz}\right) \delta 0.87(3 \mathrm{H}, \mathrm{t}, J=7.0 \mathrm{~Hz}), 1.26-1.50(14 \mathrm{H}, \mathrm{m}), 1.87-1.92(1 \mathrm{H}$, m), 1.93-2.18 (m, 3H), 2.39-2.45 (m, 1H), 2.49-2.55 (m, 1H), $3.66(\mathrm{~s}, 3 \mathrm{H}), 4.16$ $(q, J=7.0 \mathrm{~Hz}, 2 \mathrm{H}) ;{ }^{13} \mathrm{C} \mathrm{NMR}\left(\mathrm{CDCl}_{3}, 126 \mathrm{MHz}\right) \delta 14.0,14.1,18.7,22.5,26.0$, $28.4,28.7,30.5,31.3,34.8,42.2,51.6,61.4,80.0,84.1,173.4,173.6$; MS (EI) $\mathrm{m} / \mathrm{z} 286\left(\mathrm{M}^{+}, 100\right), 252,214 ;$ Anal. Calcd. for $\mathrm{C}_{17} \mathrm{H}_{28} \mathrm{O}_{4}: \mathrm{C}, 68.89 ; \mathrm{H}, 9.52$. Found: C, $68.94 ; H, 9.61$.

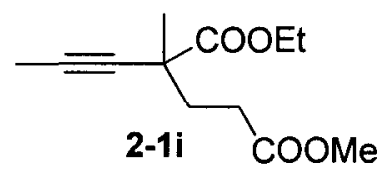

Compound 2-1i: 1-ethyl 5-methyl 2-methyl-2-(prop-1-yn-1-yl)pentanedioate a colorless oil; IR (neat): $\cup 2983,1738,1443,1241,1115,1022,1126 \mathrm{~cm}^{-1} ;{ }^{1} \mathrm{H}$ NMR $\left(\mathrm{CDCl}_{3}, 500 \mathrm{MHz}\right) \delta 1.24(\mathrm{t}, J=7.0 \mathrm{~Hz}, 3 \mathrm{H}), 1.39(\mathrm{~s}, 3 \mathrm{H}), 1.78(\mathrm{~s}, 3 \mathrm{H})$, 1.85-1.91 (m, 1H), 2.09-2.15 (m, 1H), 2.35-2.42 (m, 1H), 2.45-2.52 (m, 1H), 3.63 $(\mathrm{s}, 3 \mathrm{H}), 4.14(\mathrm{q}, J=7.0 \mathrm{~Hz}, 2 \mathrm{H}) ;{ }^{13} \mathrm{C} \mathrm{NMR}\left(\mathrm{CDCl}_{3}, 126 \mathrm{MHz}\right) \delta 3.5,14.0,25.9$, $30.4,34.8,42.2,51.5,61.4,79.0,79.4,173.2,173.5 ; \mathrm{MS}(\mathrm{EI}) \mathrm{m} / \mathrm{z} 226\left(\mathrm{M}^{+}, 100\right)$, 178, 151; Anal. Calcd. for $\mathrm{C}_{12} \mathrm{H}_{18} \mathrm{O}_{4}: \mathrm{C}, 63.70 ; \mathrm{H}, 8.02$. Found: $\mathrm{C}, 63.90 ; \mathrm{H}, 8.13$.

\section{General procedure for hydration of alkyne 2-1.}

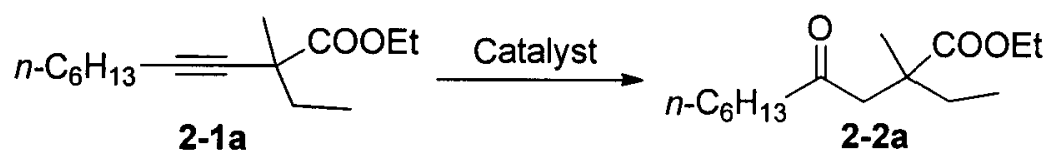

$\mathrm{NaAuCl}_{4} \cdot 2 \mathrm{H}_{2} \mathrm{O}(3 \mathrm{mg}, 5 \%)$ was added to a stirred solution of alkyne 2-1a (71.4 $\mathrm{mg}, 0.3 \mathrm{mmol})$ in $\mathrm{EtOH} / \mathrm{H}_{2} \mathrm{O}(4: 1,1 \mathrm{~mL})$. After stirring for $12-18 \mathrm{~h}$ at r.t., the 
reaction mixture was concentrated under reduced pressure and the crude product was purified by flash silica gel chromatography (EtOAc/hexane 1: 20 $1: 4)$ to give the final product $2-2 \mathrm{a}$ as a colorless oil $(60 \mathrm{mg}, 78 \%)$.

\section{Spectroscopic data of compounds 2-2.}<smiles>CCCCCC(=O)CC(C)(CC)OCC</smiles>

Compound 2-2a: ethyl 2-ethyl-2-methyl-4-oxodecanoate

Colorless oil, $78 \%$ : IR (neat): v 2957, 2930, 2859, 1734, 1457, 1177, $1134 \mathrm{~cm}^{-1}$;

${ }^{1} \mathrm{H}$ NMR $\left(500 \mathrm{MHz}, \mathrm{CDCl}_{3}\right) \delta$ 0.83-0.89 (m, 6H), $1.20(\mathrm{~s}, 3 \mathrm{H}), 1.22-1.32(\mathrm{~m}, 9 \mathrm{H})$, 1.52-1.67 (m, 4H), 2.34-2.38 (m, 2H), $2.49(\mathrm{~d}, J=17.5 \mathrm{~Hz}, 1 \mathrm{H}), 2.89(\mathrm{~d}, J=17.5$ $\left.\mathrm{Hz}, 1 \mathrm{H}), 4.13(\mathrm{q}, J=7.0 \mathrm{~Hz}, 2 \mathrm{H}) ;{ }^{13} \mathrm{C}-\mathrm{NMR}\left(125 \mathrm{MHz}^{\mathrm{CDCl}}\right)_{3}\right): \delta 8.7,14.2,14.4$, $21.3,22.7,24.0,29.1,31.8,32.7,43.6,44.0,50.8,60.6,176.8,209.1 ;$ GC/MS (EI) $m / z: 257,211,171,143,113,85,69,42$; HRMS (ESI) calcd. for $\left(\mathrm{C}_{15} \mathrm{H}_{28} \mathrm{O}_{3}+\right.$ $\mathrm{Na})^{+} 279.1936$, found 279.1930 .

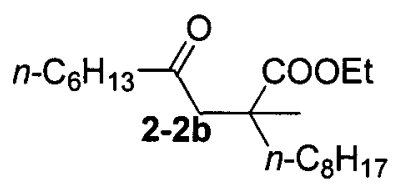

Compound 2-2b: ethyl 2-methyl-2-octyl-4-oxodecanoate

Colorless oil, 93\%: IR (neat): v 2927, 2855, 2359, 1717, 1457, $1176 \mathrm{~cm}^{-1} ;{ }^{1} \mathrm{H}$ NMR $\left(500 \mathrm{MHz}, \mathrm{CDCl}_{3}\right) \delta 0.87(\mathrm{t}, J=7.0 \mathrm{~Hz}, 6 \mathrm{H}), 1.20-1.29(\mathrm{~m}, 24 \mathrm{H}), 1.52-1.55$ (m, 4H), 2.29-2.36 (m, 2H), $2.49(\mathrm{~d}, J=17.5 \mathrm{~Hz}, 1 \mathrm{H}), 2.88(\mathrm{~d}, J=17.5 \mathrm{~Hz}, 1 \mathrm{H})$, 
$4.12(q, J=7.0 \mathrm{~Hz}, 2 \mathrm{H}) ;{ }^{13} \mathrm{C}-\mathrm{NMR}\left(125 \mathrm{MHz}, \mathrm{CDCl}_{3}\right): \delta 14.2,14.3,14.4,21.8$, $22.7,22.9,24.0,24.3,29.1,29.4,29.6,30.2,31.8,32.1,40.1,43.6,43.7,51.1$, 60.6, 176.9, 209.1; GC/MS (EI) m/z: 341, 295, 270, 227, 181, 163, 135, 112. HRMS (ESI) calcd. for $\left(\mathrm{C}_{21} \mathrm{H}_{40} \mathrm{O}_{3}+\mathrm{Na}\right)^{+} 363.2875$, found 363.2872 .

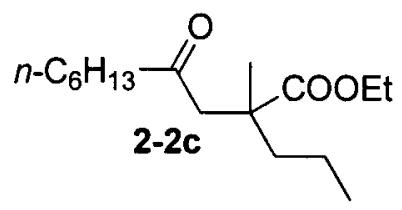

Compound 2-2c: ethyl 2-methyl-4-oxo-2-propyldecanoate

Colorless oil, 74\%: IR (neat): v 2931, 2873, 1717, 1457, $1176 \mathrm{~cm}^{-1} ;{ }^{1} \mathrm{H}$ NMR (500 $\left.\mathrm{MHz}, \mathrm{CDCl}_{3}\right) \delta$ 0.86-0.90 (m, 6H), 1.19-1.31 (m, 14H), 1.46-1.55 (m, 4H), 2.32$2.36(\mathrm{~m}, 2 \mathrm{H}), 2.50(\mathrm{~d}, J=17.5 \mathrm{~Hz}, 1 \mathrm{H}), 2.89(\mathrm{~d}, J=17.5 \mathrm{~Hz}, 1 \mathrm{H}), 4.12(\mathrm{q}, J=7.5$ $\mathrm{Hz}, 2 \mathrm{H}) ;{ }^{13} \mathrm{C}-\mathrm{NMR}\left(125 \mathrm{MHz}, \mathrm{CDCl}_{3}\right): \delta 14.2,14.4,14.7,17.6,21.8,22.7,24.0$, $29.1,31.8,42.4,43.6,43.8,51.1,60.6,176.9,209.1$; GC/MS (EI) $m / z: 271,225$, $197,157,112,85,42$.

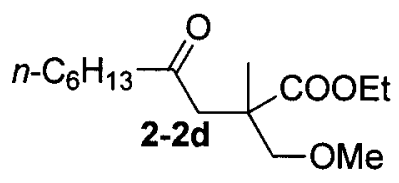

Compound 2-2d: ethyl 2-(methoxymethyl)-2-methyl-4-oxodecanoate

Colorless oil, 89\%: IR (neat): v 2927, 2857, 2359, 1733, 1457, $1110 \mathrm{~cm}^{-1} ;{ }^{1} \mathrm{H}$ NMR $\left(500 \mathrm{MHz}, \mathrm{CDCl}_{3}\right) \delta$ 0.85-0.88 (m, 3H), 1.21-1.29 (m, 12H), 1.52-1.55 (m, 2H), $2.36(\mathrm{t}, J=6.5 \mathrm{~Hz}, 2 \mathrm{H}), 2.63(\mathrm{~d}, J=17.5 \mathrm{~Hz}, 1 \mathrm{H}), 2.90(\mathrm{~d}, J=17.5 \mathrm{~Hz}, 1 \mathrm{H})$, 
$3.30(\mathrm{~s}, 3 \mathrm{H}), 3.39(\mathrm{~d}, J=9.0 \mathrm{~Hz}, 1 \mathrm{H}), 3.53(\mathrm{~d}, J=9.0 \mathrm{~Hz}, 1 \mathrm{H}), 4.13(\mathrm{q}, J=7.5 \mathrm{~Hz}$, $2 \mathrm{H}) ;{ }^{13} \mathrm{C}-\mathrm{NMR}\left(125 \mathrm{MHz}, \mathrm{CDCl}_{3}\right): \delta 14.2,14.3,21.3,22.7,24.0,29.1,29.9,31.8$, $43.5,45.1,47.0,59.4,60.8,175.5,209.3$; GC/MS (EI) $m / z: 273,227,187,145$, $99,42$.

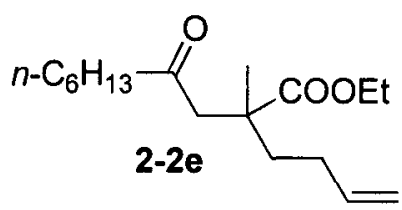

Compound 2-2e: ethyl 2-(but-3-en-1-yl)-2-methyl-4-oxodecanoate

Colorless oil, $91 \%$ : IR (neat): v 2929, 2857, 1717, 1457, 1176, $910 \mathrm{~cm}^{-1} ;{ }^{1} \mathrm{H}$ NMR $\left(500 \mathrm{MHz}, \mathrm{CDCl}_{3}\right) \delta 0.86(\mathrm{t}, J=7.0 \mathrm{~Hz}, 3 \mathrm{H}), 1.21-1.30(\mathrm{~m}, 12 \mathrm{H}), 1.52-1.66(\mathrm{~m}$, $4 \mathrm{H}), 1.94-2.00(\mathrm{~m}, 2 \mathrm{H}), 2.32-2.36(\mathrm{~m}, 2 \mathrm{H}), 2.52(\mathrm{~d}, J=17.5 \mathrm{~Hz}, 1 \mathrm{H}), 2.89(\mathrm{~d}, J=$ $17.5 \mathrm{~Hz}, 1 \mathrm{H}), 4.11(\mathrm{q}, J=7.5 \mathrm{~Hz}, 2 \mathrm{H}), 5.72-5.77(\mathrm{~m}, 1 \mathrm{H}), 4.93(\mathrm{~d}, J=10.0 \mathrm{~Hz}$, 1H), $4.99(\mathrm{~d}, J=10.0 \mathrm{~Hz}, 1 \mathrm{H}) ;{ }^{13} \mathrm{C}-\mathrm{NMR}\left(125 \mathrm{MHz}, \mathrm{CDCl}_{3}\right): \delta 14.2,14.3,21.8$, $22.7,24.0,28.7,29.1,31.8,39.1,43.5,51.0,60.7,114.9,138.3,176.6,208.9$; GC/MS (EI) m/z: 283, 237, 209, 182, 151, 95, 42. HRMS (ESI) calcd. for $\left(\mathrm{C}_{17} \mathrm{H}_{30} \mathrm{O}_{3}+\mathrm{Na}\right)^{+}$305.2093, found 305.2084 .

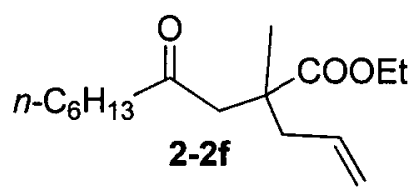

Compound 2-2f: ethyl 2-allyl-2-methyl-4-oxodecanoate 
Colorless oil, 91\%: IR (neat): v 2929, 2857, 2359, 1717, 1457, 1175, $917 \mathrm{~cm}^{-1}$;

${ }^{1} \mathrm{H}$ NMR $\left(500 \mathrm{MHz}, \mathrm{CDCl}_{3}\right) \delta 0.86(\mathrm{t}, J=7.0 \mathrm{~Hz}, 3 \mathrm{H}), 1.20-1.29(\mathrm{~m}, 12 \mathrm{H}), 1.50-$ $1.53(\mathrm{~m}, 2 \mathrm{H}), 2.31-2.34(\mathrm{~m}, 4 \mathrm{H}), 2.53(\mathrm{~d}, J=17.5 \mathrm{~Hz}, 1 \mathrm{H}), 2.81(\mathrm{~d}, J=17.5 \mathrm{~Hz}$, $1 \mathrm{H}), \quad$ 4.09-4.13 $(\mathrm{m}, 2 \mathrm{H}), \quad 5.00-5.06(\mathrm{~m}, 2 \mathrm{H}), \quad 5.66-5.71(\mathrm{~m}, 1 \mathrm{H}) ;{ }^{13} \mathrm{C}-\mathrm{NMR}$ $\left(125 \mathrm{MHz}, \mathrm{CDCl}_{3}\right): \delta 14.2,14.3,22.3,22.7,23.9,29.0,31.8,43.3,43.5,43.6$, 50.1, 60.7, 118.7, 133.6, 176.5, 208.9; GC/MS (EI) m/z: 269, 223, 195, 141, 113, 42. HRMS (ESI) calcd. for $\left(\mathrm{C}_{16} \mathrm{H}_{28} \mathrm{O}_{3}+\mathrm{Na}\right)^{+} 292.1936$, found 292.1934 .<smiles>C=CCC(C)(C)C(=O)OCC</smiles>

Compound 2-2g: ethyl 2-methyl-2-(2-oxo-2-phenylethyl)pent-4-enoate Colorless oil, $58 \%$ : IR (neat): $\cup$ 2926, $1733,1685,1456,1224,753 \mathrm{~cm}^{-1} ;{ }^{1} \mathrm{H}$ NMR $\left(500 \mathrm{MHz}, \mathrm{CDCl}_{3}\right) \delta 1.20-1.26(\mathrm{~m}, 3 \mathrm{H}), 1.32(\mathrm{~s}, 3 \mathrm{H}), 2.45-2.47(\mathrm{~m}, 2 \mathrm{H}), 3.16(\mathrm{~d}, J$ $=17.5 \mathrm{~Hz}, 1 \mathrm{H}), 3.41(\mathrm{~d}, J=17.5 \mathrm{~Hz}, 1 \mathrm{H}), 4.15(\mathrm{q}, J=7.5 \mathrm{~Hz}, 2 \mathrm{H}), 5.06-5.10(\mathrm{~m}$, 2H), 5.75-5.81 (m, H), $7.45(\mathrm{t}, J=7.5 \mathrm{~Hz}, 2 \mathrm{H}), 7.56(\mathrm{t}, J=7.0 \mathrm{~Hz}, 1 \mathrm{H}), 7.93(\mathrm{~d}, J$ $=8.0 \mathrm{~Hz}, 2 \mathrm{H}) ;{ }^{13} \mathrm{C}-\mathrm{NMR}\left(125 \mathrm{MHz}, \mathrm{CDCl}_{3}\right): \delta 14.4,22.4,43.4,43.7,46.4,60.7$, 118.9, 128.1, 128.8, 133.3, 133.6, 137.4, 176.6, 197.8; GC/MS (EI) m/z: 261, $215,187,170,141,105,77$; Anal. Calcd. for $\mathrm{C}_{16} \mathrm{H}_{20} \mathrm{O}_{3}: \mathrm{C}, 73.82 ; \mathrm{H}, 7.74$. Found: C, $73.97 ; \mathrm{H}, 8.00$. 
<smiles>[Z20]OC(C)(CCC(=O)OC)CC(=O)OCC</smiles>

Compound 2-2h: 1-ethyl 5-methyl 2-methyl-2-(2-oxooctyl)pentanedioate

Colorless oil, $92 \%$ : IR (neat): v 2928, 2856, 1734, 1457, 1175 $\mathrm{cm}^{-1} ;{ }^{1} \mathrm{H}$ NMR (500 $\left.\mathrm{MHz}, \mathrm{CDCl}_{3}\right) \delta 0.88(\mathrm{t}, J=7.0 \mathrm{~Hz}, 3 \mathrm{H}), 1.22-1.31(\mathrm{~m}, 12 \mathrm{H}), 1.53-1.56(\mathrm{~m}, 2 \mathrm{H})$, 1.82-1.87 (m, 1H), 1.92-1.98 (m, 1H), 2.27-2.37 (m, 4H), $2.55(\mathrm{~d}, J=17.5 \mathrm{~Hz}$, $1 \mathrm{H}), 2.88(\mathrm{~d}, J=17.5 \mathrm{~Hz}, \mathrm{H}), 3.67(\mathrm{~s}, 3 \mathrm{H}), 4.13(\mathrm{q}, J=7.0 \mathrm{~Hz}, 2 \mathrm{H}) ;{ }^{13} \mathrm{C}-\mathrm{NMR}(125$ $\left.\mathrm{MHz}, \mathrm{CDCl}_{3}\right): \delta 14.2,14.3,21.7,22.7,24.0,29.0,29.5,31.8,34.4,43.0,43.5$, $51.0,51.9,60.9,173.9,176.0,208.6$; GC/MS (EI) $m / z: 315,269,229,201,155$, 85

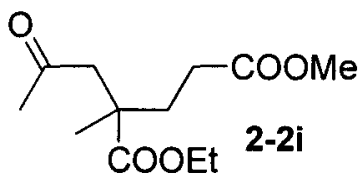

Compound 2-2i: 1-ethyl 5-methyl 2-methyl-2-(2-oxopropyl)pentanedioate

Colorless oil, $80 \%$ : IR (neat): v 2981, 2361, 1734, 1363, 1176, 1117, $1026 \mathrm{~cm}^{-1}$; ${ }^{1} \mathrm{H}$ NMR $\left(500 \mathrm{MHz} \mathrm{CDCl}_{3}\right) \delta 1.23-1.25(\mathrm{~m}, 6 \mathrm{H}), 1.82-1.88(\mathrm{~m}, 1 \mathrm{H}), 1.92-1.98(\mathrm{~m}$, 1H), $2.12(\mathrm{~s}, 3 \mathrm{H}), 2.25-2.33(\mathrm{~m}, 2 \mathrm{H}), 2.57(\mathrm{~d}, J=17.5 \mathrm{~Hz}, 1 \mathrm{H}), 2.92(\mathrm{~d}, J=17.5$ $\mathrm{Hz}, 1 \mathrm{H}), 3.67(\mathrm{~s}, 3 \mathrm{H}), 4.13(\mathrm{q}, J=7.5 \mathrm{~Hz}, 2 \mathrm{H}) ;{ }^{13} \mathrm{C}-\mathrm{NMR}\left(125 \mathrm{MHz}^{\mathrm{C}} \mathrm{CDCl}_{3}\right): \delta$ $14.3,21.7,29.5,30.7,34.3,43.1,51.8,51.9,61.0,173.8,176.0,206.1 ;$ GC/MS (El) $m / z: 245,200,141,113,85$; Anal. Calcd. for $\mathrm{C}_{12} \mathrm{H}_{20} \mathrm{O}_{5}: \mathrm{C}, 59.00 ; \mathrm{H}, 8.25$. Found: $\mathrm{C}, 59.41 ; \mathrm{H}, 8.41$. 
<smiles>CCOC(=O)CCC(=O)c1ccccc1</smiles>

Compound 2-2j: ethyl 4-oxodecanoate

Colorless oil, 74\%: IR (neat): v 2929, 2858, 1735, 1373, 1187, $1033 \mathrm{~cm}^{-1} ;{ }^{1} \mathrm{H}$ NMR $\left(500 \mathrm{MHz} \mathrm{CDCl}_{3}\right) \delta 0.88(\mathrm{t}, J=6.5 \mathrm{~Hz}, 3 \mathrm{H}), 1.24-1.30(\mathrm{~m}, 9 \mathrm{H}), 1.57-1.60$ $(\mathrm{m}, 2 \mathrm{H}), 2.44(\mathrm{t}, J=7.5 \mathrm{~Hz}, 2 \mathrm{H}), 2.57(\mathrm{t}, J=6.5 \mathrm{~Hz}, 2 \mathrm{H}), 2.71(\mathrm{t}, J=6.0 \mathrm{~Hz}, 2 \mathrm{H})$, $4.12(q, J=7.0 \mathrm{~Hz}, 2 \mathrm{H}) ;{ }^{13} \mathrm{C}-\mathrm{NMR}\left(125 \mathrm{MHz}, \mathrm{CDCl}_{3}\right): \delta 14.2,14.4,22.7,24.0$, 28.2, 29.1, 31.8, 37.2, 43.1, 60.8, 173.1, 209.5; GC/MS (EI) m/z: 215, 169, 144, $127,113,98,85,69$.<smiles>CCOC(=O)/C=C/C(=O)c1ccccc1</smiles>

Compound 2-2k: (E)-ethyl 4-oxodec-2-enoate

Colorless oil, 74\%: IR (neat): v 2930, 2858, 1727, 1466, 1302, 1182, $1033 \mathrm{~cm}^{-1}$; ${ }^{1} \mathrm{H}$ NMR $\left(500 \mathrm{MHz}, \mathrm{CDCl}_{3}\right) \delta 0.87(\mathrm{t}, J=7.0 \mathrm{~Hz}, 3 \mathrm{H}), 1.25-1.33(\mathrm{~m}, 9 \mathrm{H}), 1.61-$ $1.64(\mathrm{~m}, 2 \mathrm{H}), 2.62(\mathrm{t}, J=7.0 \mathrm{~Hz}, 2 \mathrm{H}), 4.26(q, J=7.0 \mathrm{~Hz}, 2 \mathrm{H}), 6.66(\mathrm{~d}, J=16.5$ $\mathrm{Hz}, 1 \mathrm{H}), 7.05$ (d, $J=16.5 \mathrm{~Hz}, 1 \mathrm{H}) ;{ }^{13} \mathrm{C}-\mathrm{NMR}\left(125 \mathrm{MHz}, \mathrm{CDCl}_{3}\right): \delta$ 14.2, 14.3, $22.7,23.9,29.0,31.8,41.8,61.6,130.9,140.0,165.8,200.2 ;$ GC/MS (EI) m/z: $213,169,139,127,114,97,85,69,56$; Anal. Calcd. for $\mathrm{C}_{12} \mathrm{H}_{20} \mathrm{O}_{3}: \mathrm{C}, 67.89 ; \mathrm{H}$, 9.50. Found: C, $68.38 ; \mathrm{H}, 9.79$. 
Spectroscopic data of compounds 2-5.

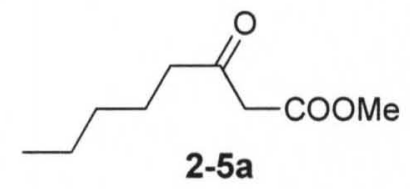

Compound 2-5a: methyl 3-oxooctanoate

Colorless oil, 76\%: IR (neat): v 2955, 2860, 2359, 1749, 1716, 1320, 1241, 1154, $1014 \mathrm{~cm}^{-1} ;{ }^{1} \mathrm{H}$ NMR $\left(500 \mathrm{MHz}, \mathrm{CDCl}_{3}\right) \delta 0.86(\mathrm{t}, J=7.0 \mathrm{~Hz}, 3 \mathrm{H}), 1.23-1.30(\mathrm{~m}$, $4 \mathrm{H}), 1.56-1.59(\mathrm{~m}, 2 \mathrm{H}), 2.50(\mathrm{t}, J=7.5 \mathrm{~Hz}, 2 \mathrm{H}), 3.42(\mathrm{~s}, 2 \mathrm{H}), 3.71(\mathrm{~s}, 3 \mathrm{H}) ;{ }^{13} \mathrm{C}-$ NMR $\left(125 \mathrm{MHz}, \mathrm{CDCl}_{3}\right): \delta 14.1,22.6,23.3,31.3,43.2,49.2,52.5,167.9,203.1$; GC/MS (EI) m/z: 173, 130, 100, 40. GC/MS (EI) m/z: 269, 223, 195, 141, 113, 42. HRMS (ESI) calcd. for $\left(\mathrm{C}_{9} \mathrm{H}_{16} \mathrm{O}_{3}+\mathrm{Na}\right)^{+} 195.0997$, found 195.0998 .

${ }^{1} \mathrm{H},{ }^{13} \mathrm{C}$ spectras of compound $2-1 \mathrm{a}$
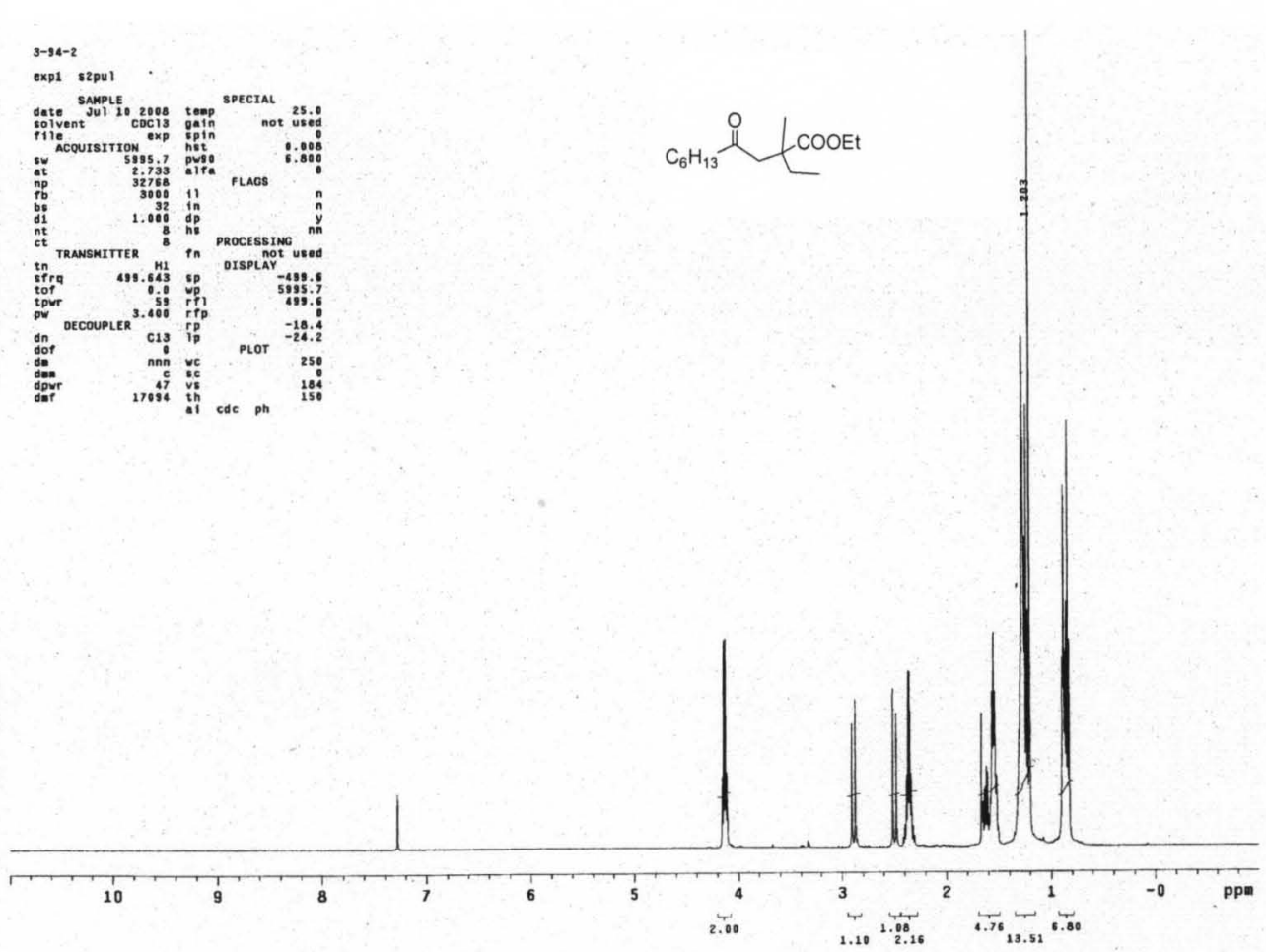
3-94-2

exp1 s2pul

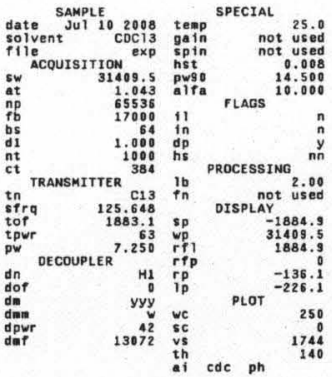

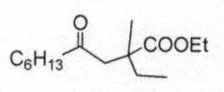

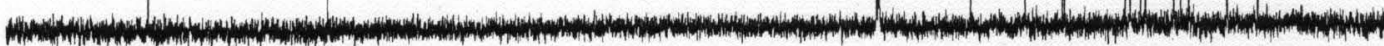

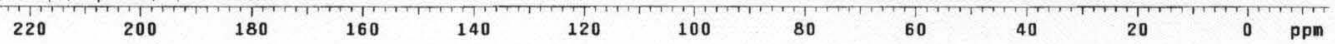




\section{CHAPTER 3. GOLD CATALYZED FUNCTIONALIZED HYDRATION OF ALKYNES}

\subsection{Functionalized hydration of alkynes}

The hydration of alkynes is a straightforward and green method for preparing

carbonyl compounds. ${ }^{54,95}$ We used a gold-catalyzed synthesis of $\gamma$-keto esters through regioselective hydration of 3 -alkynoate (see Chapter 2 ) ${ }^{96} \mathrm{~A}$ major shortcoming of a transition metal catalyzed hydration is that it only adds the elements of $\mathrm{H}_{2} \mathrm{O}$ to an alkyne (Scheme $18-\mathrm{a}$ ) ${ }^{97-100}$ We believed that the fluorineenabled cationic gold catalyst could do more than simple hydration. We proposed that the vinyl metal complex hydration intermediate can react further with organoboronic acid (reagent $\mathrm{X}$ ) and an electrophilic fluorine source such as Selectfluor (reagent $Y$ ) to give an $\alpha, \alpha$-disubstituted ketone (Scheme 18-b) in a one-pot reaction. We coined this process 'functionalized hydration'. A proof of principle is the synthesis of functionalized $\alpha$-fluoroketones-well-known targets and important synthetic intermediates. ${ }^{101-112}$ Tertiary $\alpha$-fluorinated ketones have received much attention recently because compounds having an $\alpha$ fluorocarbonyl moiety are biologically active, they are effective mimics of $\alpha$ hydroxy ketones, useful probes in various biological processes, and enzyme inhibitors. ${ }^{101,103}$ They also provide configurationally stable substituents for 
molecules containing a tertiary chiral carbon atom next to a carbonyl group, an important structural motif in medicinal chemistry. ${ }^{103}$ This one-pot tandem addition/oxidative coupling/fluorination sequence-using readily available starting materials (alkyne, water, organoboronic acid and Selectfluor)—would have clear advantages over literature methods, all of which require multiple synthetic steps. ${ }^{97-100}$

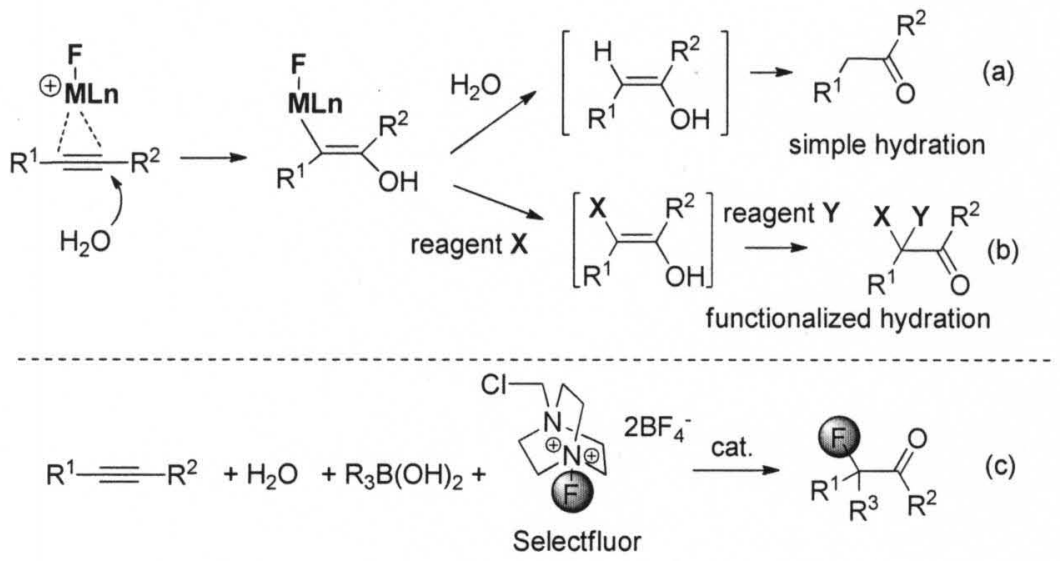

Scheme 18. Concept of functionalized hydration.

\subsection{Results and discussion}

We examined the reaction of 3-1a with phenyl boronic acid (Table 4). Various metal catalysts were screened. Without additives, $\mathrm{AuCl}$ or $\mathrm{Ph}_{3} \mathrm{PAuCl}$ could not catalyze the reaction of 3-1 with phenyl boronic acid (Table 4, entries 1-2), but in combination with Selectfluor (1.5 equiv), we obtained $50 \%$ yield of 3-3 (Table 4, entry 4). Increasing the amount of Selectfluor further increases the yield (Table 4, entry 5,6$)$. Reducing the loading of $\mathrm{Ph}_{3} \mathrm{PAuCl}$ from $5 \%$ to $2 \%$ had no deleterious effect (Table 4, entry 7). Replacing Selectfluor with NFSi was not effective (Table 4, entry 8 ). We tested other gold(I) catalysts, but they were less 
effective (Table 4, entries 9-11). We also tested gold(III) catalysts $\left(\mathrm{AuCl}_{3}\right.$ and $\mathrm{AuCl}_{3} / \mathrm{AgOTf}$, Table 4, entries 12-13), but they gave much lower yields. Other transition metals like copper, silver or palladium could not catalyze this transformation under similar conditions (Table 4, entries 14-16). On exploring the scope of this novel functionalized hydration, we found that functionalized and unfunctionalized internal alkynes reacted with aryl boronic acid, giving very good yields of $\alpha$-substituted ketones, with moderate regioselectivity (Table 5, entries 1 12). Steric and electronic effects determined the regioselectivity. ${ }^{54,95}$ For internal alkynes possessing a nucleophilic site nearby (e.g. the ester group in 3-1a), this site may influence the regioselectivity through neighboring group participation. ${ }^{54,95,96}$ 
Table 4. Functionalized hydration: screening of conditions

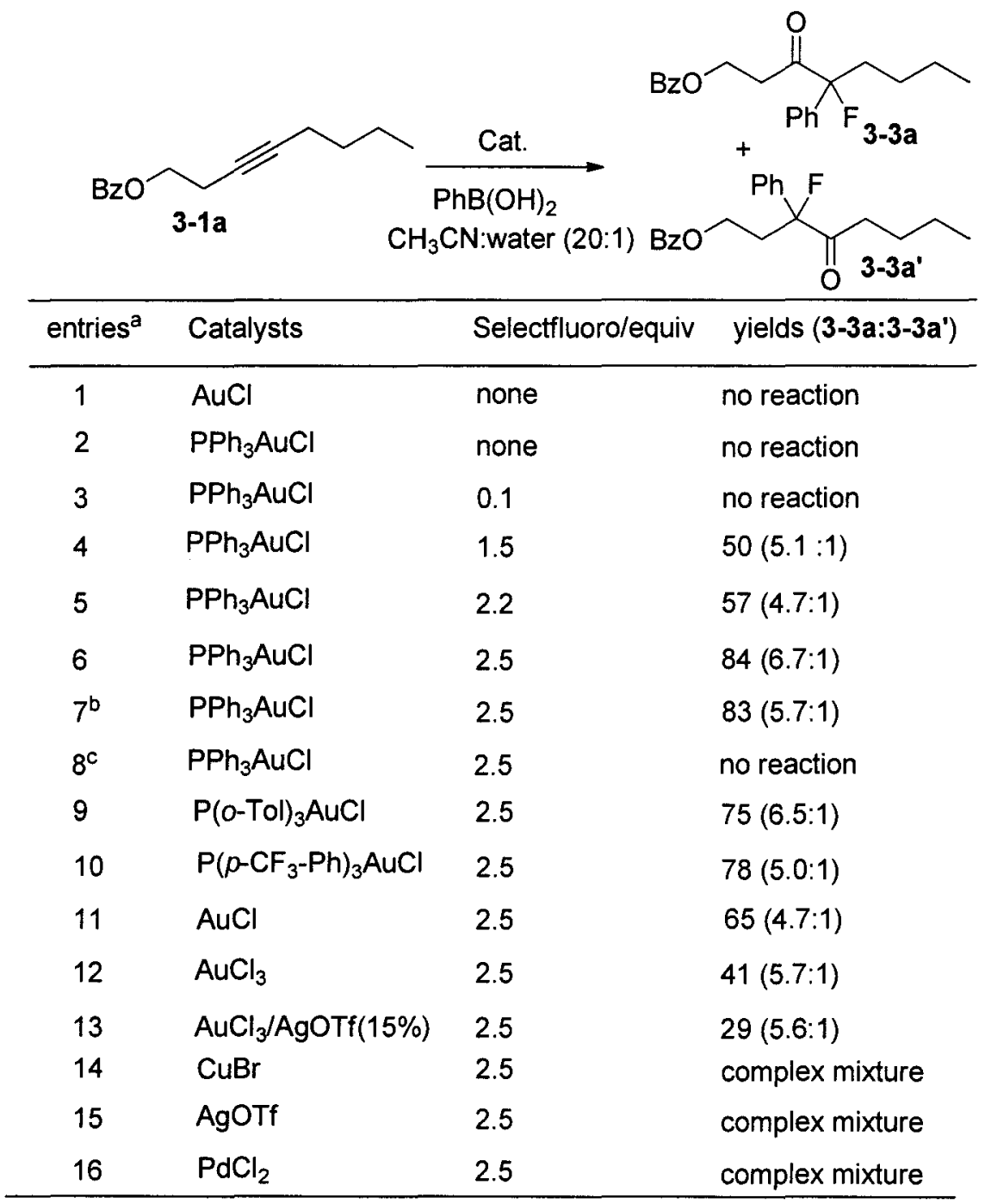

${ }^{a_{5}} \%$ catalyst, it for $18 \mathrm{~h} ;{ }^{b}{ }_{2} \%$ catalyst, it for $24 \mathrm{~h} ;{ }^{c}$ use NFSI in stead of selectfluoro. Selectfluoro: 1-Chloromethyl-4-fluoro-1,4-diazoniabicyclo[2.2.2]octane bis(tetrafluoroborate). NFSi: N-Fluorobenzenesulfonimide. 
Table 5. Scope of the functionalized hydration.

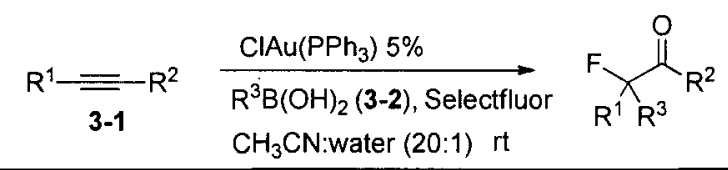

\begin{tabular}{llll}
\hline entries & $3-1$ & $3-2\left(\mathrm{R}^{3} \mathrm{~B}(\mathrm{OH})_{2}\right)$ & products \\
\hline
\end{tabular}

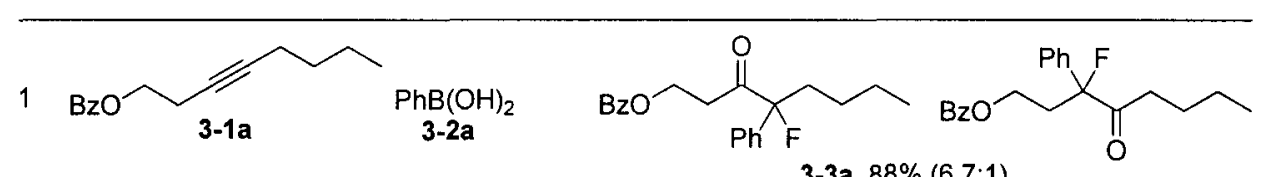<smiles>CCCCC#CCCOC(C)=O</smiles>

3<smiles>CCCCC#CCCCC</smiles>

4<smiles>CCC#CCCC</smiles>

5<smiles>CC#CCCCCCCC</smiles>

3-1e

6<smiles>CC#CCCC</smiles>

3-1f

3-2a

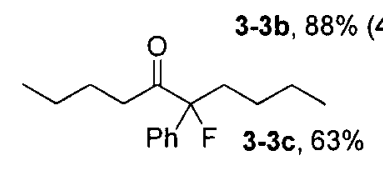

$3-2 a$<smiles>CCCC(=O)C(F)(CCC)C(=O)CCC</smiles>

3-2a

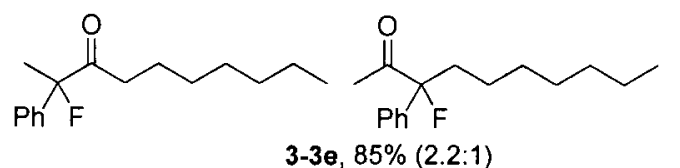

$3-2 a$<smiles>CCCCC#CCCCCOC(=O)OCCCCC(=O)C(F)(CCCC)c1ccccc1</smiles>
3-3f, $47 \%(2.1: 1)$<smiles>CCCC(F)(C(C)=O)c1ccccc1</smiles><smiles>[TeH2][TeH2]</smiles><smiles>CCCCC(=O)C(F)(CCCCOC(=O)OCc1ccccc1)c1ccccc1</smiles>

$3-3 g, 83 \%(5: 1)$

$8 \mathrm{PhCH}_{2} \mathrm{COO} \overbrace{3-1 \mathrm{~h}}$<smiles>CC#CCCCCCCCCCCCCCCC</smiles>

9

3-1a $\quad p-\mathrm{F}-\mathrm{C}_{6} \mathrm{H}_{4}-\mathrm{B}(\mathrm{OH})_{2}$ 3-2b

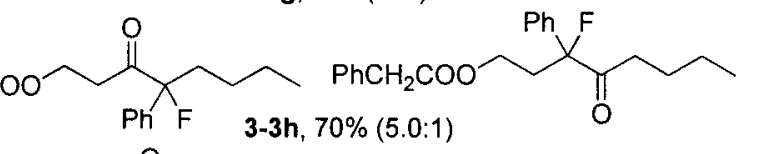

$10 \quad 3-1 \mathrm{a} \quad m-\mathrm{Cl}_{-} \mathrm{C}_{6} \mathrm{H}_{4}-\mathrm{B}(\mathrm{OH})_{2}$

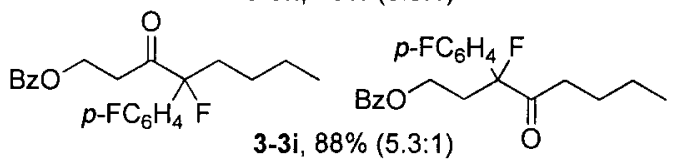
$3-3 \mathbf{i}, 88 \%(5.3: 1)$

11

3-1a $\quad p-\mathrm{Me}^{-} \mathrm{C}_{6} \mathrm{H}_{4}-\mathrm{B}(\mathrm{OH})_{2}$ 3-2d

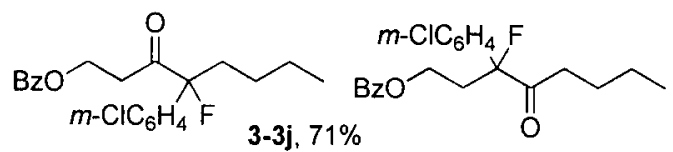
(3.4:1)

12

3-1a $\quad p-P h-\mathrm{C}_{6} \mathrm{H}_{4}-\mathrm{B}(\mathrm{OH})_{2}$
$3-2 \mathrm{e}$

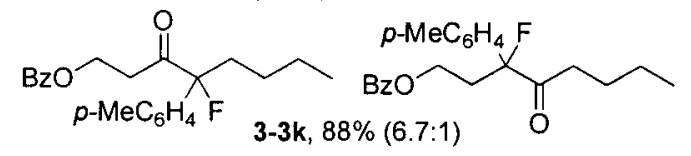

2<smiles>CCCCC(F)(CCCO)C(=O)CCC(=O)O</smiles>

3-31, $90 \%(5.3: 1)$ 


\subsection{Mechanistic studies}

Our proposed mechanism, (shown in Scheme 19), takes its cue from the reaction of boronic acid with alkynes. ${ }^{113-128}$ Initially, water attacks the gold-activated alkyne 3-B to form a vinyl gold complex 3-C, ${ }^{129}$ which then reacts with a metal reagent $\mathrm{RM}$ (e.g., $\mathrm{PhB}(\mathrm{OH})_{2}$ ) through a transmetalation process, to give intermediate 3-D. We believe that the strong B-F bond and the weak Au-F bond are the driving forces behind this transmetalation. Reductive elimination of 3-D gives 3-E. The reaction doesn't stop at this stage; instead 3-E can be fluorinated by Selectfluor to give the functionalized ketone $3-3 .{ }^{130}$ Because we never isolated 3-5 in any cases, it is possible that intermediate 3-D reacts with Selectfluor first to give 3-F, Following reductive elimination gives the final product $3-3$. The transmetalation of $\mathrm{Au}^{\prime}-\mathrm{Cl}$ complex with boronic acid has been demonstrated by Hashmi and coworkers in a recent paper. ${ }^{131}$ The transmetalation of Au-F with boronic acid has also been proposed by Zhang and co-workers in their gold catalyzed cross-coupling reaction of propargylic acetate. ${ }^{34}$ To probe the proposed mechanism in Scheme 19. We conducted two control experiments (Scheme 20). According to Scheme 19, fluoroketones 3-4 could be formed in the absence of a coupling partner $R_{3} M$, in which case, the vinyl metal complex 3-C undergoes reductive elimination or fluorodemetalation ${ }^{15}$ to give fluoroketone 3-4. This was found experimentally, although only moderate yields have been obtained (Scheme 20-a). The reaction of terminal alkyne 3-1i gives the oxidative coupling product 3-6. ${ }^{132}$ The formation of 3-6 hints towards a tandem mechanism 
that may involve the following steps: fluorination of the gold complex, transmetalation with boronic acid, and reductive elimination, as shown in (Scheme 21). It may be possible that a base-promoted deprotonation of a terminal alkyne, whose acidity has increased due to gold complexation, could account for the formation of alkynyl gold intermediate 3-G. The formation alkynyl gold complex through desilylation has been reported by Russell and co-workers recently. ${ }^{133}$ It is interesting to note that gold catalysts undergo transmetalation and reductive elimination readily, although they are not able to undergo oxidative addition-as $\mathrm{Pd}$ does in coupling reactions.

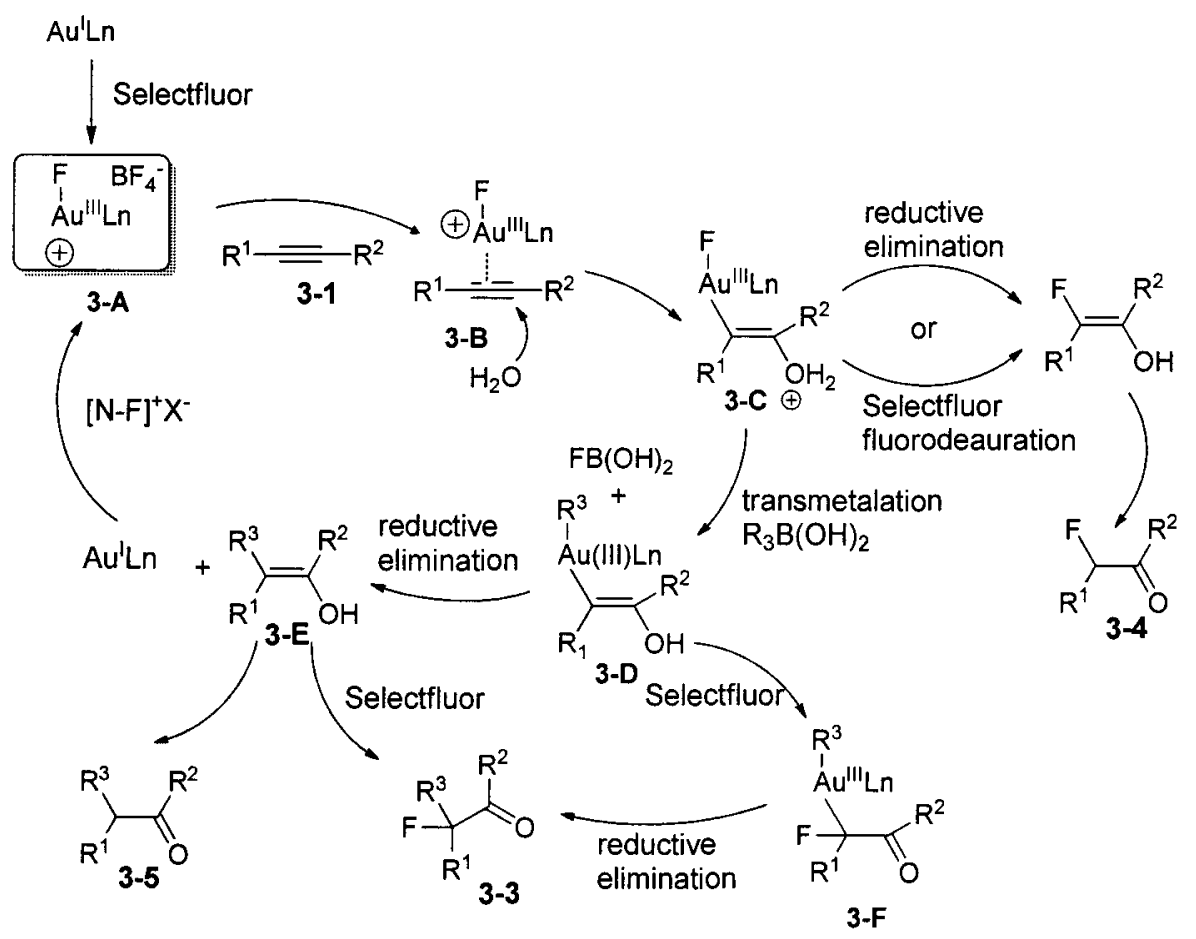

Scheme 19. Proposed mechanism for the functionalized hydration. 


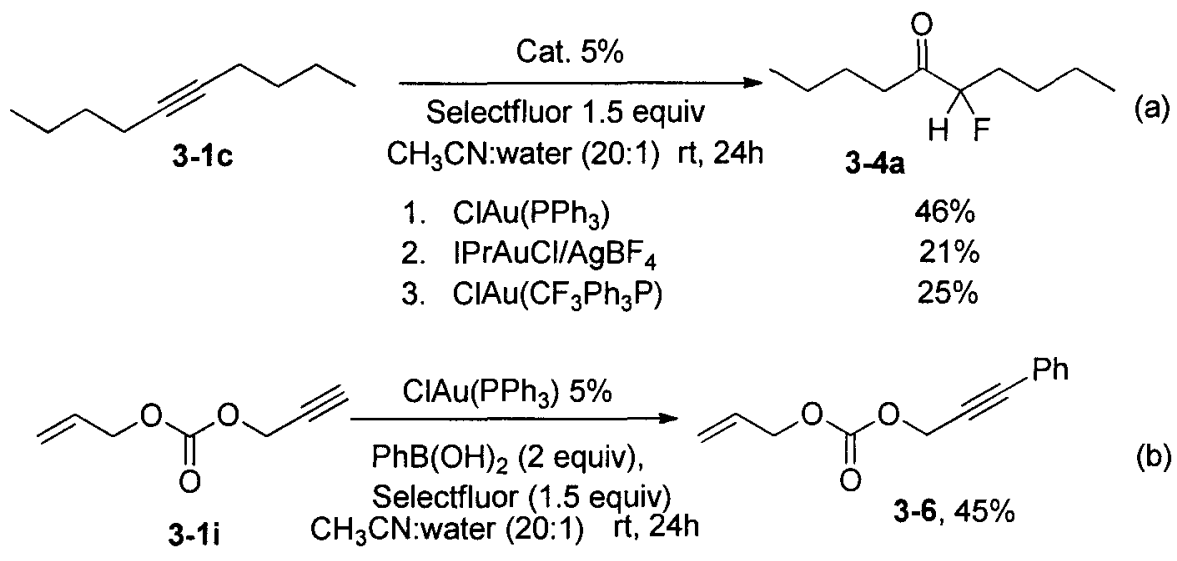

Scheme 20. Synthesis of fluoroketones and oxidative coupling of alkynes.

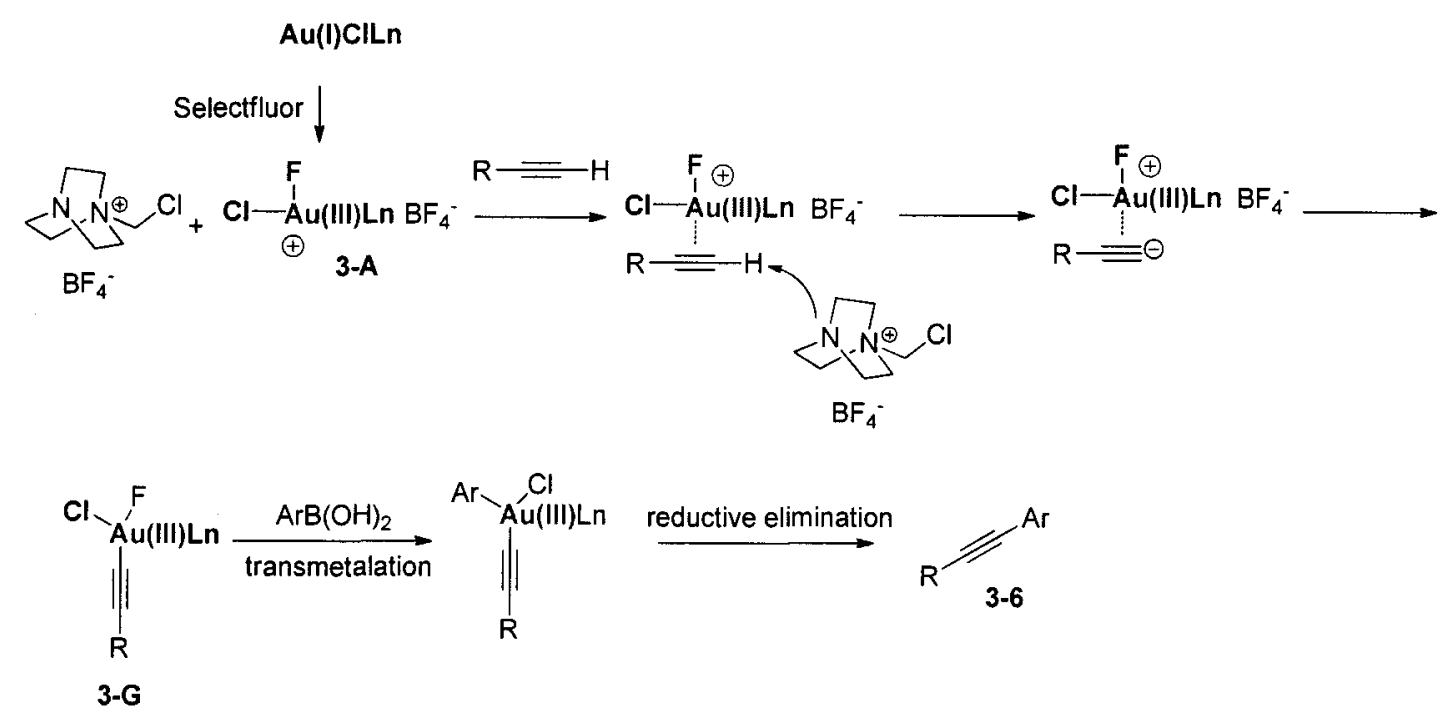

Scheme 21. Mechanism for the formation of 3-6.

\subsection{Mechanistic study of gold (III) species using X-ray photoelectron spectroscopy}

X-ray photoelectron spectroscopy (XPS) is a quantitative spectroscopic technique that can be used to measure the chemical or electronic state of an element from $\mathrm{Li}$ to $\mathrm{U}$, empirical formula of pure materials, uniformity of elemental composition. ${ }^{134}$ XPS spectra are obtained by irradiating a material with a beam of X-rays while simultaneously measuring the kinetic energy and number of electrons that escape from the top 1 to $10 \mathrm{~nm}$ of the material being analyzed. 
That collection of spectra yielded peaks with binding energies (reported as BEs) that are characteristic for each specific element. Tables of binding energies (BEs) that identify the shell and spin-orbit of each peak produced by a given element are included with modern XPS instruments, and can be found in various handbooks. Because these experimentally determined BEs are characteristic of specific elements, they can be directly used to identify experimentally measured peaks of a material with unknown elemental composition. For the same element, different chemical states have the different BEs, For example, it has been used in the determination of the chemical states of supported gold catalysts. ${ }^{135}$ The binding energy $(\mathrm{BE})$ of $\mathrm{Au} 4 \mathrm{f}_{7 / 2}$ electron of each gold oxidation states are usually different enough to allow differentiation. ${ }^{134}$

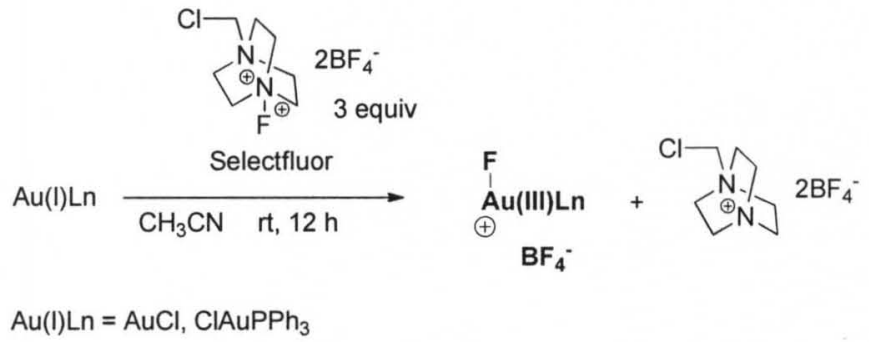

Scheme 22. Preparation of gold complex samples.

Table 6. The literature reports of binding energy of $A u \mathbf{4 f}_{7 / 2}$ electron.

\begin{tabular}{|c|c|c|c|c|}
\hline Sample & $\mathrm{Au}(0)$ & $\mathrm{ClAu}(\mathrm{I}) \mathrm{PPh}_{3}$ & $\mathrm{ClAu}(\mathrm{I})\left(\mathrm{PPh}_{3}\right)_{2}$ & $\mathrm{Cl}_{3} \mathrm{Au}(\mathrm{III}) \mathrm{PPh}_{3}$ \\
\hline $\begin{array}{l}\mathrm{Au} 4 \mathrm{f}_{7 / 2} \mathrm{BE} \\
(\mathrm{eV})\end{array}$ & $84.0 \pm 0.1$ & 85.4 & 85.4 & 87.3 \\
\hline
\end{tabular}

We collect the X-ray photoelectron spectroscopy spectra by a XPS spectrometer from Thermo Fisher Scientific, equipped with a standard Al $\mathrm{K}_{\alpha}$ excitation source (1486.6 eV). Gold complex standards $\left(\mathrm{ClAuPPh}_{3}\right.$ and $\left.\mathrm{NaAuCl}_{4}\right)$ were sampled as powders and pressed on a double-sided adhesive carbon tape. Gold catalysts 
samples were sampled as solution and dried in normal atmosphere on a doublesided adhesive carbon tape. The binding energy (BE) scale was calibrated by measuring $C$ 1s peak (BE D $284.6 \mathrm{eV}$ ). A non-linear least-square peak fitting routine was used for the analysis of XPS spectra, separating elemental species in different oxidation states. The curve fitting of the Au $4 f$ core-level spectrum is performed by using two spin-orbit split $A u 4 f_{7 / 2}$ and $A u 4 f_{5 / 2}$ components, separated by $3.67 \mathrm{eV}$, in a fixed intensity ratio.

In our proposed mechanism, the low valence gold $(I)$ complex first reacts with Selectfluor to generate a high valence gold(III) complex, which activates the alkyne towards nucleophilic attack (Scheme 22). In order to test this mechanism, first we tested our gold standard samples $\left(\mathrm{ClAu}^{\prime} \mathrm{PPh}_{3}\right.$ and $\mathrm{NaAu}^{\prime \prime \prime} \mathrm{Cl}_{4}$,), the $\mathrm{Au}$ $4 \mathrm{f}_{7 / 2}$ photoelectron peak is located at a $\mathrm{BE}$ values of 85.7 and $87.6 \mathrm{eV}$ respectively (Figure 3), which is quite consistent with the literature (Table 6). ${ }^{134}$ Our preliminary XPS study show that gold complexes like $\mathrm{AuCl}$ and $\mathrm{AuCl}_{3}$ without suitable ligands are not stable under the conditions used in XPS measurements (e.g. high vacuum). Here we used the halides to react with gold (III) to give the more stable chloroaurate or bromoaurate (Scheme 23). We prepared our samples A-C using the same conditions as the standards (Figure 3). Sample A appeared as a mixture of two gold oxidation states ( $B E$ of $A u 4 f_{7 / 2}=84.4,87.5$ $\mathrm{eV}$ ). We then tested the chloride stabilized sample $B\left(B E\right.$ of $A u 4 f_{7 / 2}=84.2,87.6$ e), sample $C$ (BE of $A u 4 f_{7 / 2}=84.4,87.1 \mathrm{eV}$ ); they gave similar patterns but with higher percentage of gold(III) species. Because the gap between Au4f peak of two gold states is large (ca $3.0 \mathrm{eV}$ ), we assigned them as $\mathrm{Au}^{0}$ and $\mathrm{Au}^{\mathrm{III}}$ species, 
respectively. The chloride stabilized samples B and C show a very similar pattern, but with higher percentage of gold(III) species. Our XPS measurements confirm the existence of gold(III) $\left(B E\right.$ of $\left.A u 4 f_{7 / 2}=87.6 \mathrm{eV}\right)$ in the reaction mixture of gold $(I)$ catalyst and Selectfluor (Figure 3 ). The existence of gold( 0 ) can be explained by disproportionation of unreacted $\mathrm{Au}^{\prime}$ complex or decomposition/reduction of $\mathrm{Au}^{\text {III }}$ species in high vacuum during XPS measurements. Because $\mathrm{Au}$ III species are the major components in all tests, the existence of $A u^{\prime \prime \prime}$ species can't attributed to disproportionation of unreacted $\mathrm{Au}^{\prime}$ complexes alone. Because the bonding energy of gold $(0)$ and gold $(I)$ are close (the difference is ca. $1 \mathrm{eV}$ ), and mean measurement error of XPS is around 0.5 $\mathrm{eV}$. It is very possible than all the sample contains certain amount of unreacted gold(I) species, especially in sample B.

$$
\begin{aligned}
& \mathrm{ClAuPhPh}_{3}+\text { Selectfluor ( } 3 \text { equiv) } \frac{\mathrm{rt}, 12 \mathrm{~h}}{\mathrm{CH}_{3} \mathrm{CN}} \text { sample A } \\
& \mathrm{ClAuPPh}_{3}+\text { Selectfluor (3 equiv) } \underset{\mathrm{CH}_{3} \mathrm{CN}}{\stackrel{1) \mathrm{rt}, 12 \mathrm{~h}}{\mathrm{C}}} \frac{\text { 2) } 20 \text { equiv } \mathrm{NaCl}}{1 \mathrm{~h}} \text { sample B } \\
& \mathrm{AuCl}+\text { Selectfluor (3 equiv) } \underset{\mathrm{CH}_{3} \mathrm{CN}}{\stackrel{1) \mathrm{rt}, 12 \mathrm{~h}}{\longrightarrow}} \frac{\text { 2) } 20 \text { equiv } \mathrm{NaCl}}{1 \mathrm{~h}} \text { sample } \mathrm{C}
\end{aligned}
$$

Scheme 23. Conversion of cationic gold (III) intermediate to chloroaurate or bromoaurate. 


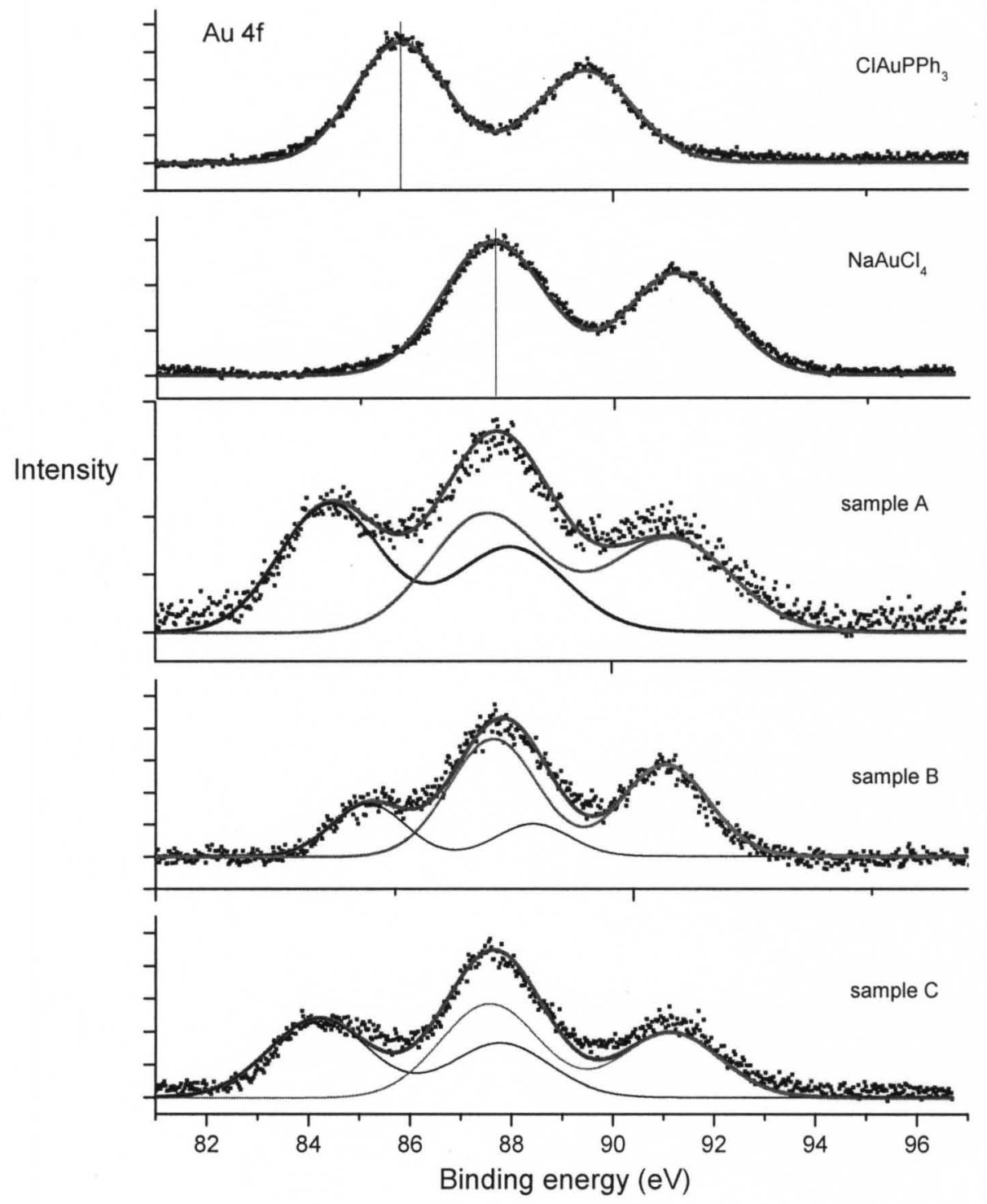

Figure 3. XPS curve fitting of the Au $4 f$ photoelectron peaks.

\subsection{Monitoring the progress of the reaction using ${ }^{19} \mathrm{~F}$ - NMR}

Our XPS measurements indicate the existence of gold (III) species, but XPS experiments can only be conducted in vacuum in the solid state. In order to investigate the reaction in solution phase, we monitored the progress of the reaction using ${ }^{19}$ F-NMR (Figure 4). Our preliminary experiments showed that 
Selectfluor did react with gold $(I)$ complex at room temperature. For example, after addition of Selectfluor to $\mathrm{AuCl}$ in $\mathrm{CD}_{3} \mathrm{CN}$, a new peak (bs, $-184 \mathrm{ppm}$ ) appeared and its intensity increased with time (Figure 4-1, 4-2). When we added $\mathrm{PhB}(\mathrm{OH})_{2}$ to the system, this peak disappeared immediately and biphenyl was detected by TLC 10 min after $\mathrm{PhB}(\mathrm{OH})_{2}$ was added (Figure 4-3). And chromatographic separation and comparison of NMR with authentic sample indicate biphenyl is indeed generated in these transformations. This suggests that the new peak represents a reactive metal fluoride species, which we tentatively assigned as $\left[\mathrm{Au}^{\mathrm{III}} \mathrm{CIFLn}\right]^{+}\left(\mathrm{Ln}=\mathrm{CH}_{3} \mathrm{CN}\right)$. The formation of $\mathrm{FB}(\mathrm{OH})_{2}$ has been proposed by Toste and co-workers in transmetalation of gold intermediate, ${ }^{136}$ but we don't have the authentic sample to compare the NMR, so we tentatively assign the peak at $-149 \mathrm{ppm}$ as $\mathrm{FB}(\mathrm{OH})_{2}$. The formation of biphenyl could be rationalized by transmetalation with phenylboronic acid in a first stage, the second equivalent of phenyl boronic acid could replace the $\mathrm{BF}_{4}{ }^{-}$or the chloride in a manner that is still the subject of discussion, and this would be followed by reductive elimination to give biphenyl (Figure 4 top). This high reactivity rules out the possibility that it is a simple fluoride anion. $\mathrm{Ph}_{3} \mathrm{PAuCl}$ can also be oxidized under the same conditions but at a slower rate; however, in this case the phosphine ligand $\mathrm{Ph}_{3} \mathrm{P}$ was also oxidized (by the high valence gold or Selectfluor), after prolonged times. $\mathrm{Ph}_{3} \mathrm{P}=\mathrm{O}$ was detected in the reaction mixture (confirmed by ${ }^{31} \mathrm{P}-\mathrm{NMR}$ and ESI-MS). ${ }^{34,43}$ 
At this time, for formation of biphenyl, we could not rule out the possibility of other mechanism like radical mechanism, which is also a common process for organoboronic acids.
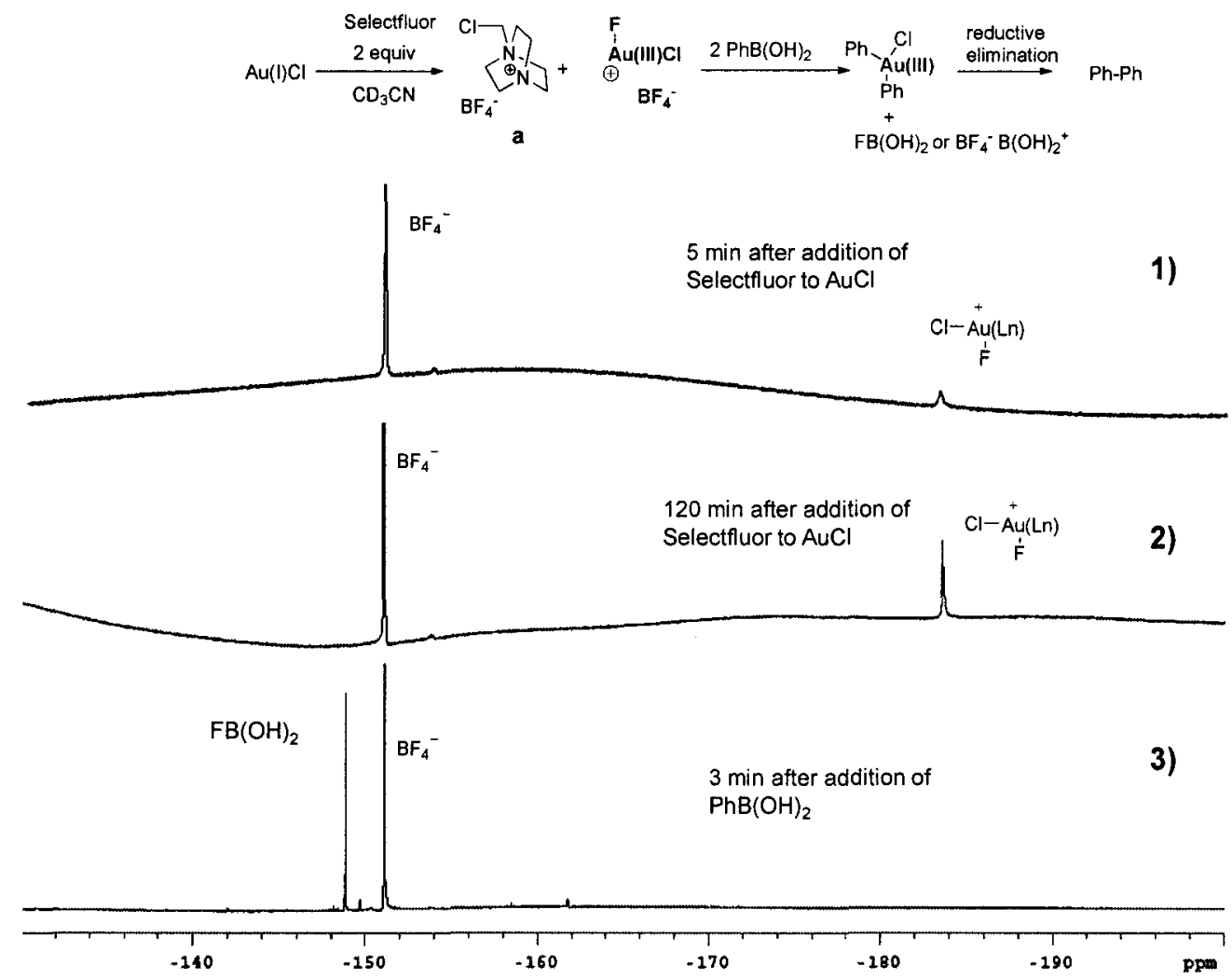

Figure 4. Monitoring the reaction of $\mathrm{AuCl}$ with Selectfluor using ${ }^{19} \mathrm{~F}-\mathrm{NMR}\left(\mathrm{Ln}=\mathrm{CH}_{3} \mathrm{CN}\right)$.

\subsection{Electrospray ionization mass spectrometry (ESI-MS). Identification of cationic Au(III) species}

Electrospray ionization mass spectrometry (ESI-MS) has become an important tool in the identification of labile reaction intermediates. An advantage of ESI-MS is that it allows direct sampling from the reaction mixture, and because many of our gold intermediates are charged species, ESI-MS could help us to detect charged species. We conducted a high-resolution ESI-MS investigation of the 
cationic or anionic species in the catalytic system. First, we checked the highresolution ESI-MS spectra of samples A and B (Scheme 24, Sample A, B) but only $A u(I)$ species (peaks $\mathbf{c}, \mathbf{d}, \mathbf{f}$ ) and reduced Selectfluor (peak b) were detected (Figure 5) and we could not detect a Au(III) species. Because a Au(III) complex has a square-planar geometry, a bidentate ligand should greatly stabilize this Au(III) complex, which in turn, could be easier to detect by ESI-MS spectrometry. Hence, we added excess amounts of bipyridine to the reaction mixture (Scheme 24, sample C). The high-resolution ESI-MS spectrum is shown in Figure 6 and Figure 7.

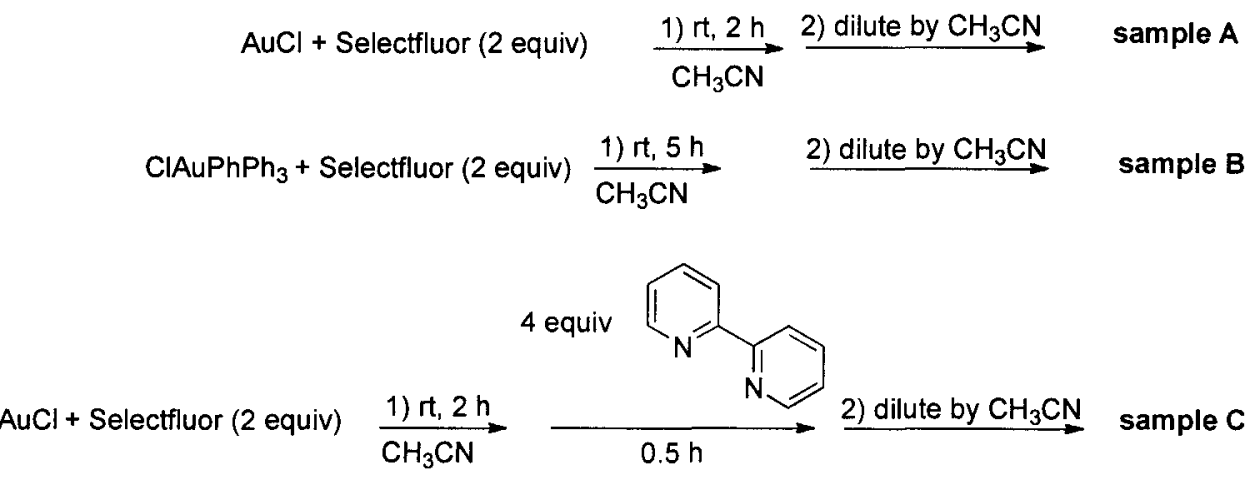

Scheme 24. Preparation of samples for ESI-MS study. 


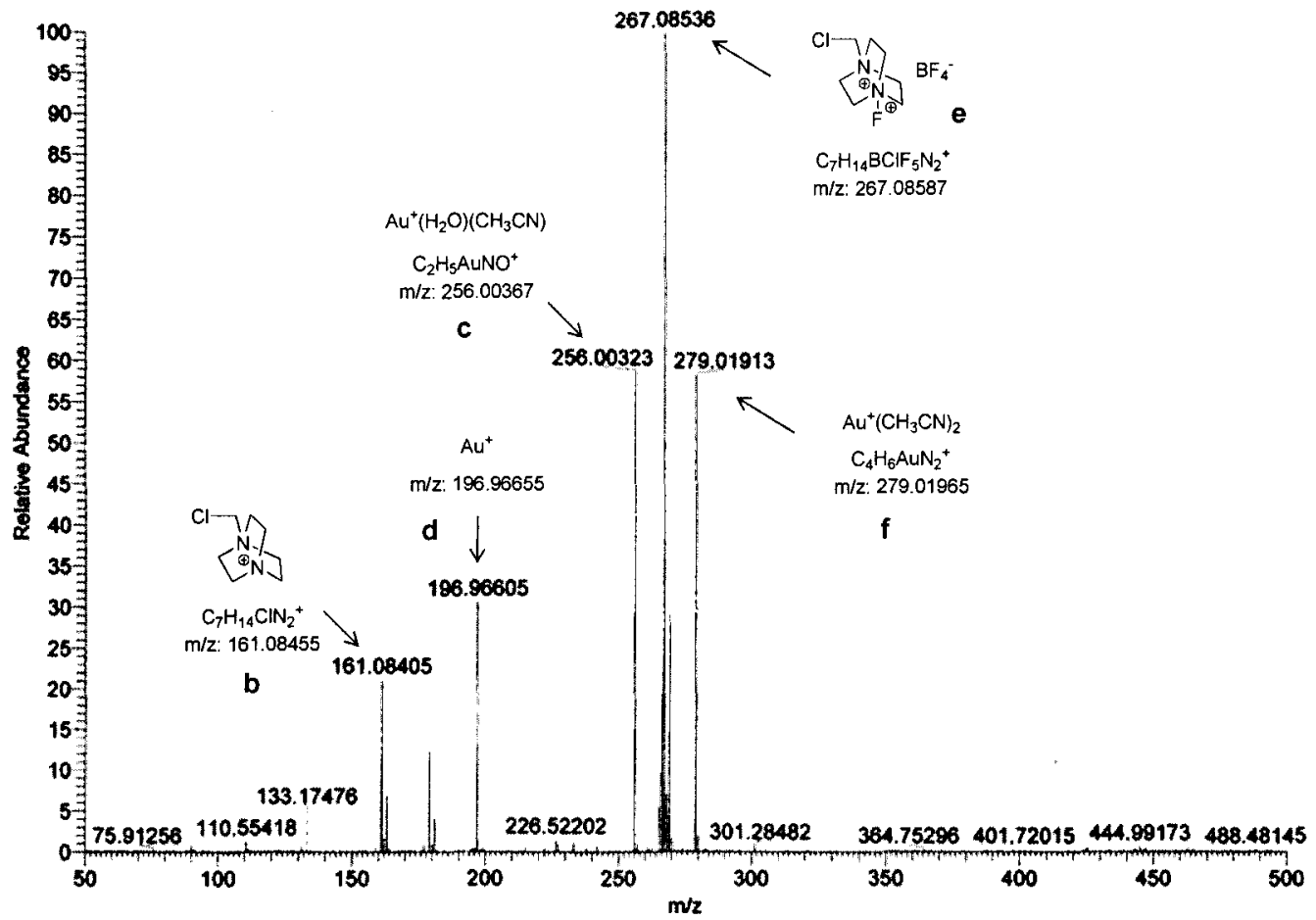

Figure 5. ESI-MS of sample A.

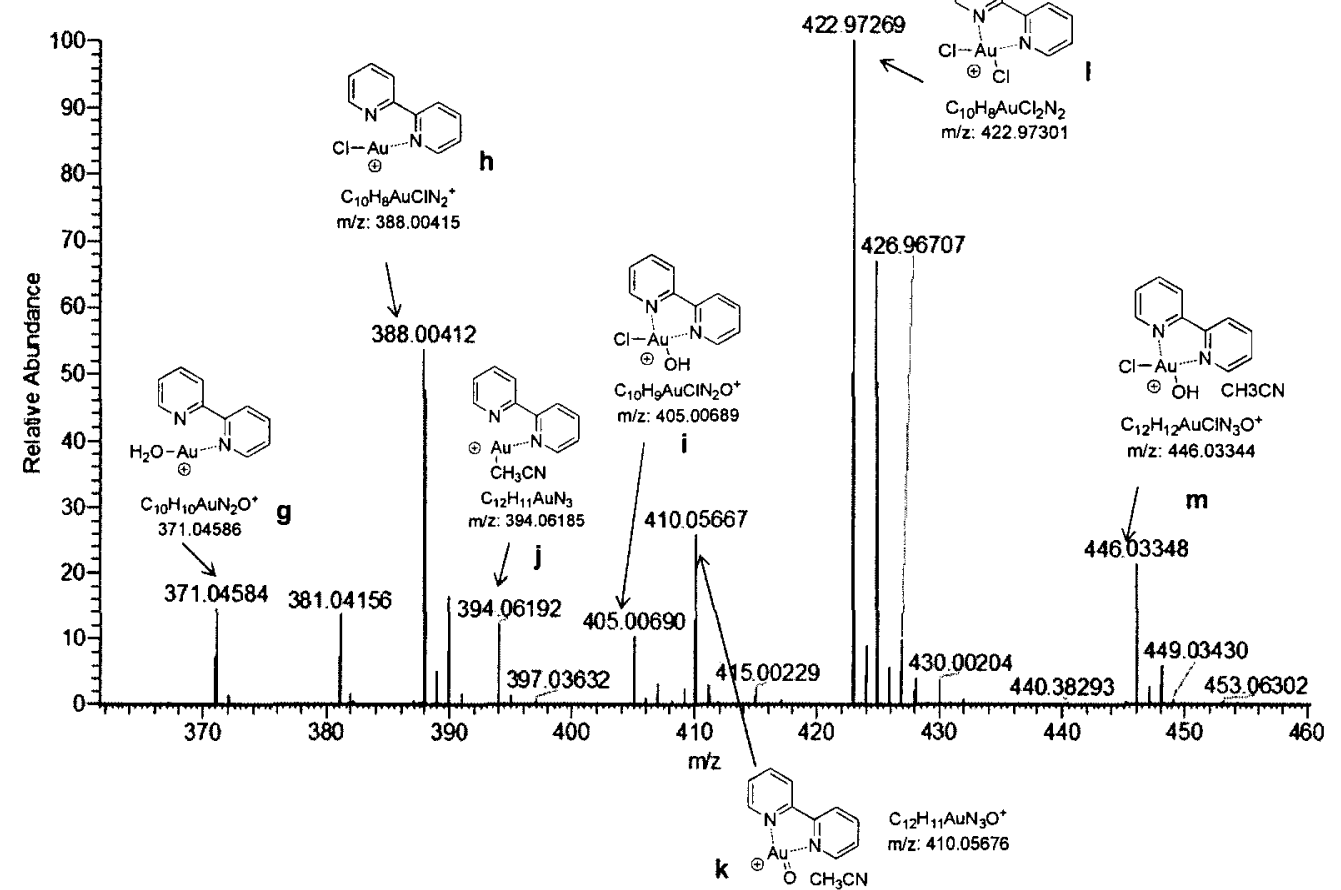

Figure 6. ESI-MS of sample C (part 1, m/z 360-460). 


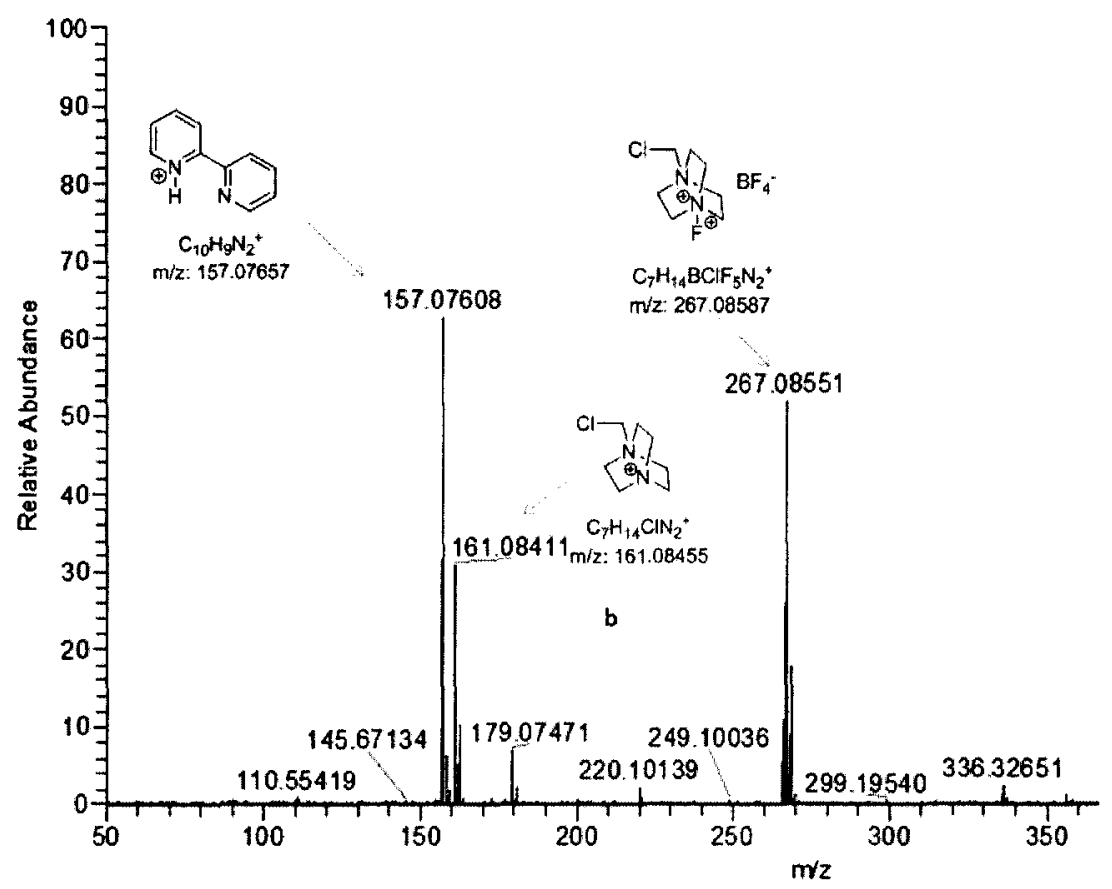

Figure 7. ESI-MS of sample $C$ (part 2, $\mathrm{m} / \mathrm{z}$ from 50 to 360 ).

In Figure 6, various cationic Au(III) species were detected (peaks i, $\mathbf{k}, \mathbf{I}, \mathbf{m}$ ), but $[\mathrm{Au}(\mathrm{III}) \mathrm{CIF}]^{+}$itself was not detected; this may be due to the fact that metal-fluorine bonds tend to be labile and reactive. Indeed, gold(I) fluoride, was once thought impossible to prepare. Compared to many other metal fluorine bonds, Au-F is a weaker bond. So, under the ESI-MS conditions (high temperature during the electrospray ionization), $[\mathrm{Au}(\mathrm{III}) \mathrm{CIF}]^{+}$(a) may lose fluorine and pick up chloride from other gold complexes or $\mathrm{OH}^{-}$from trace amounts of water in the system, because both chloride and hydroxyl have much stronger affinity to gold (Scheme 25). 


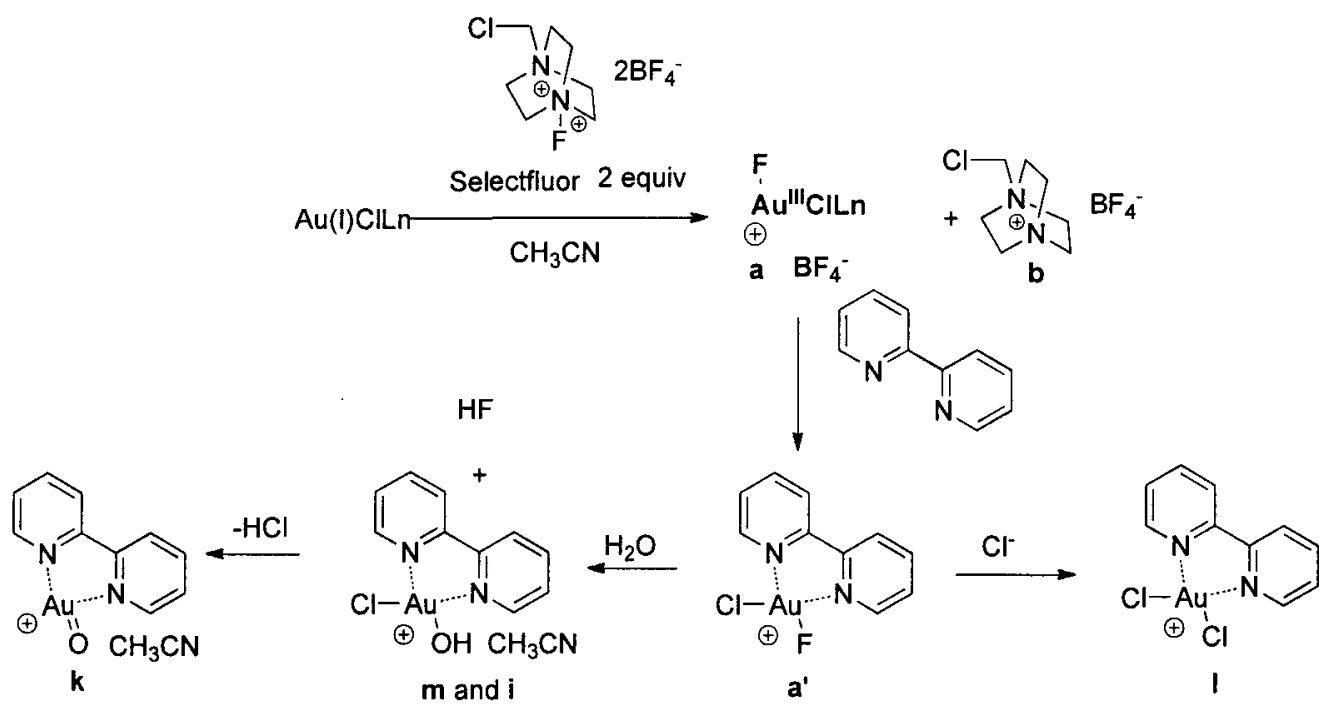

Scheme 25. Mechanism for the formation of gold(III) species in Figure 6.

\subsection{Summary and future directions}

In sum, a potentially new role for fluorine in cationic gold catalysis was proposed, an example of which is the functionalized hydration of alkynes to give $\alpha$ substituted- $\alpha$-fluoroketones, in one pot and under mild conditions. The ready availability of alkynes and organoboronic acids, and the current interest in $\alpha$ fluoroketones makes this reaction quite attractive. The broader implications of cationic metal species enabled by fluorine are currently under study in our laboratory.

\subsection{Experimental}

\section{General}

${ }^{1} \mathrm{H},{ }^{13} \mathrm{C}$ and ${ }^{19} \mathrm{~F}$ NMR spectra were recorded at 500,126 and $470 \mathrm{MHz}$ respectively, using $\mathrm{CDCl}_{3}$ as a solvent. The chemical shifts are reported in $\delta$ (ppm) values relative to $\mathrm{CHCl}_{3}\left(\delta 7.26 \mathrm{ppm}\right.$ for ${ }^{1} \mathrm{H}$ NMR and $\delta 77.0 \mathrm{ppm}$ for ${ }^{13} \mathrm{C}$ $\mathrm{NMR}$ ) and $\mathrm{CFCl}_{3}\left(\delta 0 \mathrm{ppm}\right.$ for $\left.{ }^{19} \mathrm{~F} \mathrm{NMR}\right)$, multiplicities are indicated by $\mathrm{s}$ (singlet), 
$\mathrm{d}$ (doublet), $\mathrm{t}$ (triplet), $\mathrm{q}$ (quartet), $\mathrm{p}$ (pentet), $\mathrm{h}$ (hextet), $\mathrm{m}$ (multiplet) and $\mathrm{br}$ (broad). Coupling constants, $J$, are reported in Hertz. Coupling constants are reported in hertz $(\mathrm{Hz})$. All air and/or moisture sensitive reactions were carried out under argon atmosphere. Solvents (tetrahydrofuran, ether, dichloromethane and DMF) were chemically dried using a commercial solvent purification system. All other reagents and solvents were employed without further purification. The products were purified using a Biotage flash+ system or Chromatotron apparatus or a regular glass column. TLC was developed on Merck silica gel 60 F254 aluminum sheets. Elemental analysis was performed at Atlantic Microlabs Inc., Norcross, Georgia 30091. High resolution ESI-MS were obtained using a MSFTICR-MS $^{n}$ system (LTQ FT, Thermo Electron Corp.) at the CREAM Mass Spectrometry Facility, University of Louisville, Kentucky. When needed, reactions were monitored using ${ }^{19} \mathrm{~F}$ NMR and the mixture percentage yield was obtained using $\alpha, \alpha, \alpha$-trifluoromethylbenzene as internal reference.

\section{General.procedure for preparation of 3-3.}

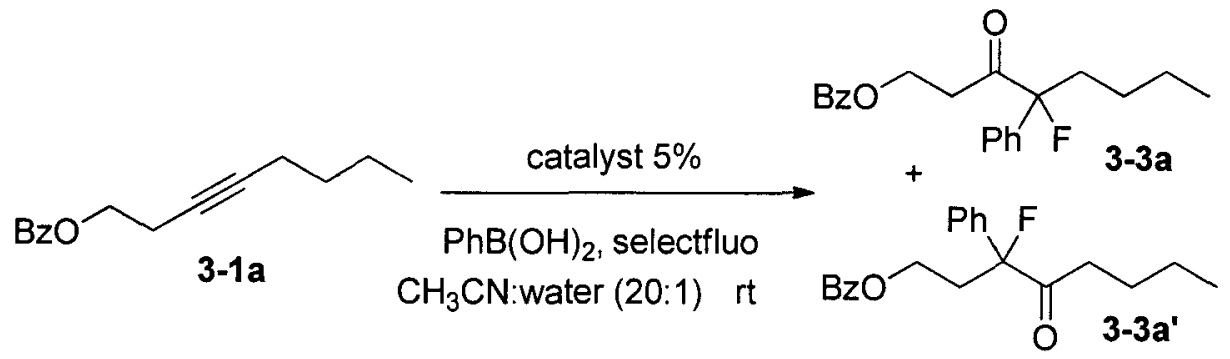

Selectfluor (354 mg, $1.0 \mathrm{mmol}, 2.5$ equiv) was added to a solution of the alkyne 3-1a (92 mg, $0.4 \mathrm{mmol}$ ), $\mathrm{Ph}_{3} \mathrm{PAuCl}(9.8 \mathrm{mg}, 0.02 \mathrm{mmol}, 5 \%$ equiv) and phenylboronic acid (98 mg, $0.8 \mathrm{mmol}, 2$ equiv) in $3 \mathrm{~mL} \mathrm{MeCN}: \mathrm{H}_{2} \mathrm{O}(20: 1)$. The reaction was stirred at the room temperature for $18 \mathrm{~h}$. The reaction mixture was 
quenched with saturated $\mathrm{NH}_{4} \mathrm{Cl}$ solution, the resulting aqueous mixture was extracted by diethyl ether ( $15 \mathrm{~mL} \times 3)$, and then the combined organic layer was dried over $\mathrm{Na}_{2} \mathrm{SO}_{4}$. The solvent was removed under reduced pressure to give crude product, the crude product was purified by flash silica gel chromatography ( $30 \%$ dicholormethane in hexane $-60 \%$ dicholormethane in hexane) to give the product 3-3a as a mixture of two regioisomer (3-3a: $\left.3-3 \mathbf{a}^{\prime}=6.7: 1\right) 118 \mathrm{mg}$ $(88 \%)$.

\section{Spectroscopic data of compounds 3-3}

3-3a:4-fluoro-3-oxo-4-phenyloctyl benzoate, 3-fluoro-4-oxo-3-phenyloctyl benzoate

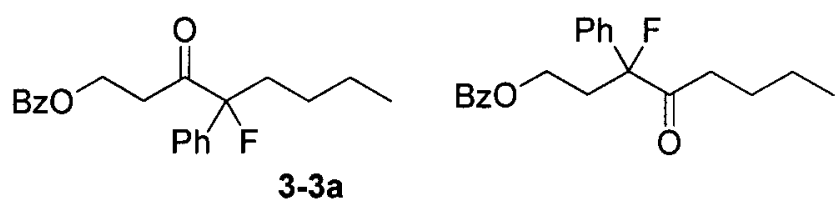

IR (neat): v 2958, 1724, 1450,1275, 1116, $711 \mathrm{~cm}^{-1} ;{ }^{1} \mathrm{H}$ NMR $\left(500 \mathrm{MHz}, \mathrm{CDCl}_{3}\right)$, Major isomer: $\delta 0.87(\mathrm{t}, J=6.5 \mathrm{~Hz}, 3 \mathrm{H}), 1.29-1.31(\mathrm{~m}, 4 \mathrm{H}), 2.03-2.18(\mathrm{~m}, 1 \mathrm{H})$, 2.22-2.38 (m, H), 3.08-3.1 (m, 2H), $4.55(\mathrm{t}, J=6 \mathrm{~Hz}, 2 \mathrm{H}), 7.31-7.53(\mathrm{~m}, 8 \mathrm{H}), 7.82$ (d, $J=7.5 \mathrm{~Hz}, 2 \mathrm{H}) ;{ }^{13} \mathrm{C} \mathrm{NMR}\left(125 \mathrm{MHz}, \mathrm{CDCl}_{3}\right.$ ), major isomer: $\delta 14.0,22.8,22.5$, 36.6, $37.8(d, J=22 \mathrm{~Hz}), 59.4,103.5(d, J=186 \mathrm{~Hz}), 124.5(d, J=10.5 \mathrm{~Hz})$, $128.4,128.8,129.7,133.1,137.6(\mathrm{~d}, J=22 \mathrm{~Hz}), 166.4,208.5(\mathrm{~d}, J=30 \mathrm{~Hz}) ;{ }^{19} \mathrm{~F}$ NMR (470 MHz, $\left.\mathrm{CDCl}_{3}\right)$ : Major isomer: $\delta-170.04(t, J=25.4 \mathrm{~Hz})$; GC/MS (EI) m/z: 221, 201, 177, 135, 77; Anal. Calcd. for $\mathrm{C}_{21} \mathrm{H}_{23} \mathrm{FO}_{3}: \mathrm{C}, 73.66 ; \mathrm{H}, 6.77$. Found: $\mathrm{C}, 73.42 ; \mathrm{H}, 6.75$. 


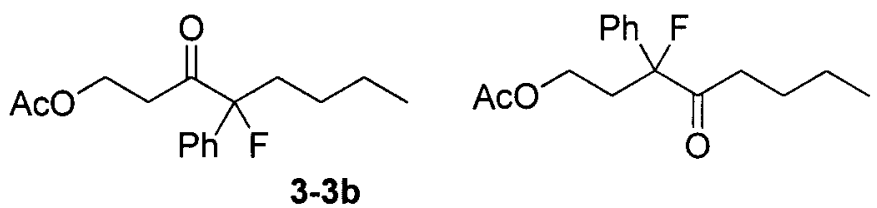

3-3b: 4-fluoro-3-oxo-4-phenyloctyl acetate, 3-fluoro-4-oxo-3-phenyloctyl acetate colorless oil, $88 \%$, obtained as a mixture of two regioisomers in ratio of $4.6: 1$. IR (neat): v 2959, 1744, 1366, 1237, 1038, $700 \mathrm{~cm}^{-1} ;{ }^{1} \mathrm{H}$ NMR $\left(500 \mathrm{MHz}, \mathrm{CDCl}_{3}\right)$, major isomer: $\delta$ 0.81-0.89 (m, 3H), 1.19-1.34 (m, 4H), $1.9(\mathrm{~s}, 3 \mathrm{H}), 2.05-2.15(\mathrm{~m}$, H), 2.18-2.29 (m, H), 2.85-2.91 (m, H), 2.96-3.03 (m, H), 4.23-4.33 (m, 2H), 7.33$7.44(\mathrm{~m}, 5 \mathrm{H}) ;{ }^{13} \mathrm{C}$ NMR $\left(125 \mathrm{MHz}, \mathrm{CDCl}_{3}\right)$, major isomer: $\delta$ 14.0, 20.9, 22.8, 25.1, 36.6, $37.7(\mathrm{~d}, J=21 \mathrm{~Hz}), 58.9(\mathrm{~d}, J=2 \mathrm{~Hz}), 102.8(\mathrm{~d}, J=186 \mathrm{~Hz}), 124.5(\mathrm{~d}, J=$ $10.0 \mathrm{~Hz}), 128.4,128.7,137.6(\mathrm{~d}, J=22 \mathrm{~Hz}), 170.9,206.8(\mathrm{~d}, J=30.0 \mathrm{~Hz}) ;{ }^{19} \mathrm{~F}$ NMR (470 MHz, $\left.\mathrm{CDCl}_{3}\right)$ : major isomer: $\delta-169.95(\mathrm{t}, J=24.9 \mathrm{~Hz})$; GC/MS (El) m/z: 221, 201, 165, 145, 135, 109, 85; Anal. Calcd. for $\mathrm{C}_{16} \mathrm{H}_{21} \mathrm{FO}_{3}: \mathrm{C}, 68.55 ; \mathrm{H}$, 7.55. Found: $\mathrm{C}, 69.31 ; \mathrm{H}, 7.67$.

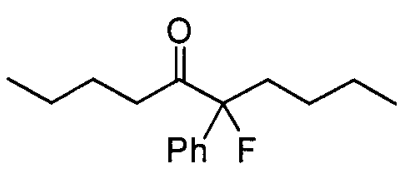

3-3c

3-3c: 6-fluoro-6-phenyldecan-5-one

colorless oil, $63 \%$, IR (neat): v 2958, 2872, $1723,1448,699 \mathrm{~cm}^{-1} ;{ }^{1} \mathrm{H}$ NMR (500 $\left.\mathrm{MHz}, \mathrm{CDCl}_{3}\right): \delta$ 0.83-0.96 $(\mathrm{m}, 6 \mathrm{H}), 1.21-1.34(\mathrm{~m}, 6 \mathrm{H}), 1.44-1.54(\mathrm{~m}, 2 \mathrm{H}), 2.05-$ $2.13(\mathrm{~m}, 1 \mathrm{H}), 2.19-2.51(\mathrm{~m}, 1 \mathrm{H}), 2.51-2.58(\mathrm{~m}, 1 \mathrm{H}), 2.65-2.71(\mathrm{~m}, 1 \mathrm{H}), 7.30-7.33$ 
$(\mathrm{m}, 1 \mathrm{H}), 7.36-7.39(\mathrm{~m}, 2 \mathrm{H}), 7.43-7.45(\mathrm{~m}, 2 \mathrm{H}) ;{ }^{13} \mathrm{C}$ NMR $\left(125 \mathrm{MHz}, \mathrm{CDCl}_{3}\right): \delta$ $13.9,14.0,22.3,22.9,25.2,25.3,37.2,37.9,(\mathrm{~d}, J=21 \mathrm{~Hz}), 103.6(\mathrm{~d}, J=186 \mathrm{~Hz})$, $124.5,128.2,128.6,138.3(\mathrm{~d}, J=22 \mathrm{~Hz}), 209.9(\mathrm{~d}, J=29 \mathrm{~Hz}) ;{ }^{19} \mathrm{~F}$ NMR $(470$ $\left.\mathrm{MHz}, \mathrm{CDCl}_{3}\right): \delta-169.52(\mathrm{t}, J=24.9 \mathrm{~Hz}$ ); GC/MS (EI) $m / z: 231,165,145,109,85$, 57; Anal. Calcd. for $\mathrm{C}_{16} \mathrm{H}_{23}$ FO: $\mathrm{C}, 76.76 ; \mathrm{H}, 9.26$. Found: $\mathrm{C}, 76.74 ; \mathrm{H}, 9.28$.

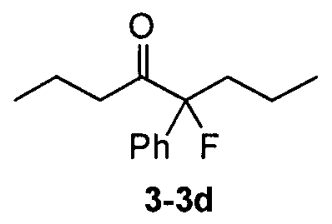

3-3d : 5-fluoro-5-phenyloctan-4-one

colorless oil, $79 \%$, IR (neat): v 2963, $2875,1724,1448,758,700 \mathrm{~cm}^{-1} ;{ }^{1} \mathrm{H}$ NMR $\left(500 \mathrm{MHz}, \mathrm{CDCl}_{3}\right): \delta 0.83(\mathrm{t}, J=7.5 \mathrm{~Hz}, 3 \mathrm{H}), 0.91(\mathrm{t}, J=7.5 \mathrm{~Hz}, 3 \mathrm{H}), 1.28-1.35$ $(\mathrm{m}, 2 \mathrm{H}), 1.48-1.60(\mathrm{~m}, 2 \mathrm{H}), 2.01-2.11(\mathrm{~m}, 1 \mathrm{H}), 2.16-2.26(\mathrm{~m}, 1 \mathrm{H}), 2.50-2.56(\mathrm{~m}$, $1 \mathrm{H}), 2.63-2.69(\mathrm{~m}, 1 \mathrm{H}), 7.30-7.33(\mathrm{~m}, 1 \mathrm{H}), 7.37(\mathrm{t}, J=7.5 \mathrm{~Hz}, 2 \mathrm{H}), 7.44-7.46(\mathrm{~m}$, $2 \mathrm{H}) ;{ }^{13} \mathrm{C}$ NMR $\left(125 \mathrm{MHz}, \mathrm{CDCl}_{3}\right): \delta 13.7,14.3,16.6,(\mathrm{~d}, J=1.9 \mathrm{~Hz}), 16.7(\mathrm{~d}, J=$ $2.9 \mathrm{~Hz}), 39.4,40.3(\mathrm{~d}, J=21.9 \mathrm{~Hz}), 103.4(\mathrm{~d}, J=186.9 \mathrm{~Hz}), 124.5(\mathrm{~d}, J=10.5$ $\mathrm{Hz}), 128.2,128.7(\mathrm{~d}, J=1.9 \mathrm{~Hz}), 138.3(\mathrm{~d}, J=22 \mathrm{~Hz}), 209.8(\mathrm{~d}, J=29.6 \mathrm{~Hz}) ;{ }^{19} \mathrm{~F}$ NMR (470 MHz, $\left.\mathrm{CDCl}_{3}\right): \delta-169.51(\mathrm{t}, J=24.4 \mathrm{~Hz}$ ); GC/MS (EI) $\mathrm{m} / \mathrm{z}: 203,151$, 109, 71; Anal. Calcd. for $\mathrm{C}_{14} \mathrm{H}_{19} \mathrm{FO}$ : C, 75.64; H, 8.61. Found: $\mathrm{C}, 75.93 ; \mathrm{H}, 8.59$. 


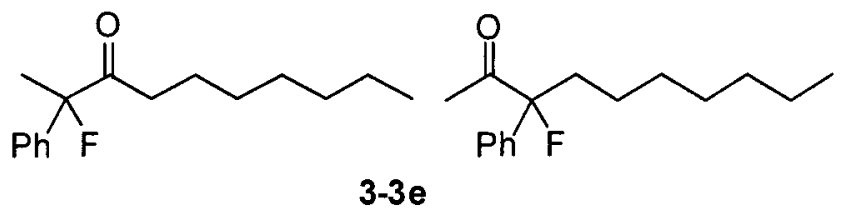

3-3e: 2-fluoro-2-phenyldecan-3-one, 3-fluoro-3-phenyldecan-2-one

colorless oil, $85 \%$, obtained as a mixture of two regioisomers in ratio of $2.2: 1$. IR (neat): v 2929, 2856, 1725, 1448, 1372, 1072, 759, 699 $\mathrm{cm}^{-1} ;{ }^{1} \mathrm{H}$ NMR $(500 \mathrm{MHz}$, $\left.\mathrm{CDCl}_{3}\right)$ : major isomer: $\delta$ 0.85-0.90 $(\mathrm{m}, 3 \mathrm{H}), 1.16-1.29(\mathrm{~m}, 8 \mathrm{H}), 1.46-1.56(\mathrm{~m}, 2 \mathrm{H})$, $1.79(\mathrm{~d}, J=23 \mathrm{~Hz}, 3 \mathrm{H}), 2.51-2.57(\mathrm{~m}, 1 \mathrm{H}), 2.68-2.75(\mathrm{~m}, 1 \mathrm{H}), 7.31-7.35(\mathrm{~m}, 1 \mathrm{H})$, $7.38(\mathrm{t}, J=7.5 \mathrm{~Hz}, 2 \mathrm{H}), 7.43-7.46(\mathrm{~m}, 2 \mathrm{H}) ;{ }^{13} \mathrm{C} \mathrm{NMR}\left(125 \mathrm{MHz}, \mathrm{CDCl}_{3}\right)$ : major isomer: $\delta 14.3,22.8(\mathrm{~d}, J=3.8 \mathrm{~Hz}), 23.2(\mathrm{~d}, J=15.4 \mathrm{~Hz}), 29.2(\mathrm{~d}, J=10.5 \mathrm{~Hz})$, $31.9(\mathrm{~d}, J=10.5 \mathrm{~Hz}), 36.7,100.9(\mathrm{~d}, J=183.1 \mathrm{~Hz}), 103.2(\mathrm{~d}, J=186 \mathrm{~Hz}), 124.3(\mathrm{~d}, J$ $=9.5 \mathrm{~Hz}), 124.5(\mathrm{~d}, J=10.5 \mathrm{~Hz}), 128.4(\mathrm{~d}, J=8.6 \mathrm{~Hz}), 128.8(\mathrm{~d}, J=8.1 \mathrm{~Hz}), 138.1$ $(\mathrm{d}, J=21.9 \mathrm{~Hz}), 139.4(\mathrm{~d}, J=22.9 \mathrm{~Hz}), 208.0(\mathrm{~d}, J=31.4 \mathrm{~Hz}), 209.5(\mathrm{~d}, J=$ $29.6 \mathrm{~Hz}) ;{ }^{19} \mathrm{~F} \mathrm{NMR}\left(470 \mathrm{MHz}, \mathrm{CDCl}_{3}\right)$ : major isomer: $\delta-157.44(\mathrm{q}, J=23.0 \mathrm{~Hz})$; GC/MS (EI) $m / z: 231,165,145,109,85,57$; Anal. Calcd. for $\mathrm{C}_{16} \mathrm{H}_{23} \mathrm{FO}: \mathrm{C}, 76.76$; $H, 9.26$. Found: C, 76.78; $H, 9.23$.

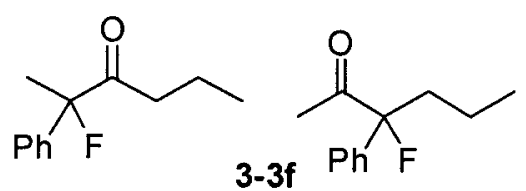

3-3f: 2-fluoro-2-phenylhexan-3-one, 3-fluoro-3-phenylhexan-2-one colorless oil, $47 \%$, obtained as a mixture of two regioisomers in ratio of $2.1: 1$. IR (neat): v 2959, 2873, 1725, 1448, 1138, 1038, 760, 699 $\mathrm{cm}^{-1} ;{ }^{1} \mathrm{H}$ NMR $(500 \mathrm{MHz}$, 
$\left.\mathrm{CDCl}_{3}\right)$ : major isomer: $\delta$ 0.84-0.90 $(\mathrm{m}, 3 \mathrm{H}), 1.20-1.34(\mathrm{~m}, 4 \mathrm{H}), 1.79(\mathrm{~d}, \mathrm{~J}=23 \mathrm{~Hz}$, $3 \mathrm{H}), 2.51-2.58(\mathrm{~m}, 1 \mathrm{H}), 2.69-2.76(\mathrm{~m}, 1 \mathrm{H}), 7.32-7.35(\mathrm{~m}, 1 \mathrm{H}), 7.39(\mathrm{t}, \mathrm{J}=7.5 \mathrm{~Hz}$, 2H), 7.44-7.46 (m, 2H); ${ }^{19} \mathrm{~F} \mathrm{NMR}\left(470 \mathrm{MHz}, \mathrm{CDCl}_{3}\right)$ : major isomer: $\delta-157.38$ (q, $J=23.0 \mathrm{~Hz}$ ); GC/MS (EI) m/z: 189, 165, 123, 63 .<smiles>CCCCOC(=O)OCCCCC(F)(C(=O)CCCC)C(=O)CCCC(=O)C(F)(c1ccccc1)c1ccccc1</smiles>

3-3g: 6-fluoro-5-oxo-6-phenyldecyl benzoate, 5-fluoro-6-oxo-5-phenyldecyl

colorless oil, $83 \%$, obtained as a mixture of two regioisomers in ratio of $5: 1$. IR (neat): v 2929, 1724, 1274, 1115, 711 $\mathrm{cm}^{-1} ;{ }^{1} \mathrm{H}$ NMR (500 MHz, $\mathrm{CDCl}_{3}$ ), Major isomer: $\delta$ 0.81-0.90 $(\mathrm{m}, 3 \mathrm{H}), 1.24-1.32(\mathrm{~m}, 8 \mathrm{H}), 2.05-2.16(\mathrm{~m}, 1 \mathrm{H}), 2.22-2.33(\mathrm{~m}$, $1 \mathrm{H}), 3.03-3.12(\mathrm{~m}, 2 \mathrm{H}), 4.55(\mathrm{t}, J=6.0 \mathrm{~Hz}, 2 \mathrm{H}), 7.27-7.49(\mathrm{~m}, 8 \mathrm{H}), 7.82(\mathrm{~d}, J=$ $8.5 \mathrm{~Hz}, 2 \mathrm{H}) ;{ }^{19} \mathrm{~F} \mathrm{NMR}\left(470 \mathrm{MHz}, \mathrm{CDCl}_{3}\right)$ : Major isomer: $\delta-170.03(\mathrm{t}, J=24.4 \mathrm{~Hz})$; GC/MS (EI) m/z: 257, 249, 230, 135, 113, 105, 95; Anal. Calcd. for $\mathrm{C}_{23} \mathrm{H}_{27} \mathrm{FO}_{3}: \mathrm{C}$, 74.57; $H, 7.35$. Found: $C, 74.67 ; H, 7.43$. 
<smiles>CCCCC(=O)C(F)(CCOC(=O)COC(=O)OCc1ccccc1)c1ccccc1</smiles>

3-3h: 4-fluoro-4-phenyl-1-((1-phenylvinyl)peroxy)octan-3-one, 3-fluoro-3-phenyl1-((1-phenylvinyl)peroxy)octan-4-one

colorless oil, $70 \%$, obtained as a mixture of two regioisomers in ratio of $5.0: 1 .{ }^{1} \mathrm{H}$ NMR (500 MHz, $\left.\mathrm{CDCl}_{3}\right)$ : major isomer: $\delta$ 0.89-0.92 $(\mathrm{m}, 3 \mathrm{H}), 1.20-1.37(\mathrm{~m}, 4 \mathrm{H})$, 2.08-2.17 (m, 1H), 2.20-2.30 (m, 1H), 2.87-2.94 (m, 1H), 3.00-3.06 (m, 1H), 3.50 $(\mathrm{S}, 2 \mathrm{H}), 4.29-4.38(\mathrm{~m}, 2 \mathrm{H}), 7.21-7.46(\mathrm{~m}, 10 \mathrm{H}) ;{ }^{19} \mathrm{~F} \mathrm{NMR}\left(470 \mathrm{MHz}, \mathrm{CDCl}_{3}\right)$ : Major isomer: $\delta-169.89(t, J=23.9 H z)$; GC/MS (El) $m / z: 221,201,191,165$, $145,135,109$

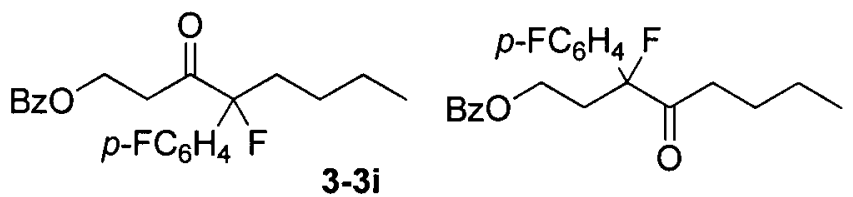

3-3i: 4-fluoro-4-(4-fluorophenyl)-3-oxooctyl benzoate, 3-fluoro-3-(4-fluorophenyl)4-oxooctyl benzoate

colorless oil, $88 \%$, obtained as a mixture of two regioisomers in ratio of $5.3: 1$. IR (neat): $\mathrm{u} 2959,1724,1275,1116,835,712 \mathrm{~cm}^{-1} ;{ }^{1} \mathrm{H}$ NMR $\left(500 \mathrm{MHz} \mathrm{CDCl}_{3}\right)$ : major isomer: $\delta 0.75-1.00(\mathrm{~m}, 3 \mathrm{H}), 1.16-1.23(\mathrm{~m}, 4 \mathrm{H}), 1.92-2.09(\mathrm{~m}, 1 \mathrm{H}), 2.09-$ $2.20(\mathrm{~m}, 1 \mathrm{H}), 2.93-3.01(\mathrm{~m}, 2 \mathrm{H}), 4.42-4.47(\mathrm{~m}, 2 \mathrm{H}), 6.91-6.98(\mathrm{~m}, 2 \mathrm{H}), 7.26-7.36$ $(\mathrm{m}, \quad 4 \mathrm{H}), 7.41-7.44(\mathrm{~m}, 1 \mathrm{H}), 7.69-7.71(\mathrm{~m}, 2 \mathrm{H}) ;{ }^{19} \mathrm{~F}$ NMR $\left(470 \mathrm{MHz}, \mathrm{CDCl}_{3}\right)$ : Major isomer: $\delta-169.27(t, J=24.9 H z)$; GC/MS (EI) $m / z: 239,219,177,153$, 
127, 105, 77; Anal. Calcd. for $\mathrm{C}_{21} \mathrm{H}_{22} \mathrm{~F}_{2} \mathrm{O}_{3}: \mathrm{C}, 69.99 ; \mathrm{H}, 6.15$. Found: $\mathrm{C}, 70.26 ; \mathrm{H}$, 6.07 .

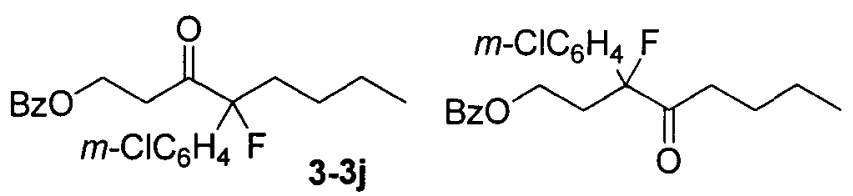

3-3j: 4-(3-chlorophenyl)-4-fluoro-3-oxooctyl benzoate, 3-(3-chlorophenyl)-3fluoro-4-oxooctyl benzoate

colorless oil, $71 \%$, obtained as a mixture of two regioisomers in ratio of $3.4: 1$. IR (neat): v 2959, 1724, 1274, 1115, 712 $\mathrm{cm}^{-1}$; ${ }^{1} \mathrm{H}$ NMR (500 MHz, $\mathrm{CDCl}_{3}$ ): major isomer: $\delta$ 0.80-0.91 (m, 3H), 1.14-1.34 (m, 4H), 2.02-2.19 (m, 1H), 2.19-2.30 (m, $1 \mathrm{H}), 2.85-3.11(\mathrm{~m}, 2 \mathrm{H}), 4.55(\mathrm{t}, J=6.5 \mathrm{~Hz}, 2 \mathrm{H}), 7.27-7.46(\mathrm{~m}, 7 \mathrm{H}), 7.51-7.55(\mathrm{~m}$, 1H), 7.82-7.84 (m, 1H); $\left.{ }^{19} \mathrm{~F} \mathrm{NMR} \mathrm{(470} \mathrm{MHz,} \mathrm{CDCl}_{3}\right)$ : Major isomer: $\delta-169.27(\mathrm{t}, J$ $=24.9 \mathrm{~Hz}$ ); GC/MS (EI) m/z: 291, 257, 236, 189, 169, 105; Anal. Calcd. for $\mathrm{C}_{21} \mathrm{H}_{22} \mathrm{ClFO}_{3}: \mathrm{C}, 66.93 ; \mathrm{H}, 5.88$. Found: $\mathrm{C}, 66.97 ; \mathrm{H}, 5.85$.

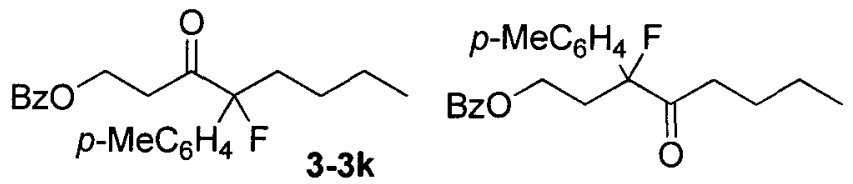

3-3k: 4-fluoro-3-oxo-4-(p-tolyl)octyl benzoate, 3-fluoro-4-oxo-3-(p-tolyl)octyl benzoate

colorless oil, $88 \%$, obtained as a mixture of two regioisomers in ratio of $6.7: 1$. IR (neat): $v 2958,2871,1724,1452,1275,1115,712 \mathrm{~cm}^{-1} ;{ }^{1} \mathrm{H}$ NMR $(500 \mathrm{MHz}$, $\left.\mathrm{CDCl}_{3}\right)$ : major isomer: $\delta 0.85-0.88(\mathrm{~m}, 3 \mathrm{H}), 1.26-1.33(\mathrm{~m}, 4 \mathrm{H}), 2.02-2.18(\mathrm{~m}, 1 \mathrm{H})$, 
2.19-2.30 (m, 1H), 2.33(d, $J=4 \mathrm{~Hz}, 3 \mathrm{H}), 3.06-3.09(\mathrm{~m}, 2 \mathrm{H}), 4.54(\mathrm{t}, J=5.5 \mathrm{~Hz}$, $2 \mathrm{H}), 7.15-7.18(\mathrm{~m}, 2 \mathrm{H}), 7.31-7.42(\mathrm{~m}, 4 \mathrm{H}), 7.52-7.55(\mathrm{~m}, 1 \mathrm{H}), 7.82-7.84(\mathrm{~m}, 2 \mathrm{H})$; ${ }^{19} \mathrm{~F} \mathrm{NMR}\left(470 \mathrm{MHz}, \mathrm{CDCl}_{3}\right)$ : major isomer: $\delta-169.71(\mathrm{t}, J=24.9 \mathrm{~Hz})$; GC/MS (EI) $m / z: 296,277,261,221,196,185,165,123,105,77$; Anal. Calcd. for $\mathrm{C}_{22} \mathrm{H}_{25} \mathrm{FO}_{3}: \mathrm{C}, 74.13 ; \mathrm{H}, 7.07$. Found: $\mathrm{C}, 74.40 ; \mathrm{H}, 7.08$.

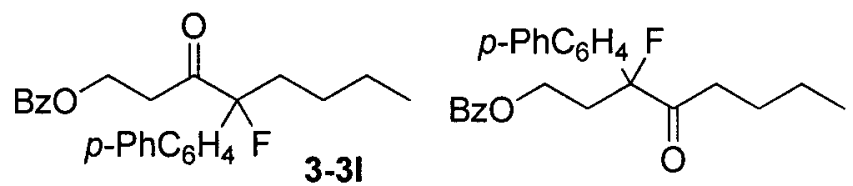

3-3I: 4-([1,1'-biphenyl]-4-yl)-4-fluoro-3-oxooctyl benzoate, 3-([1,1'-biphenyl]-4-yl)3-fluoro-4-oxooctyl benzoate colorless oil, $90 \%$, obtained as a mixture of two regioisomers in ratio of 5.3: 1. IR (neat): v 2958, 1723, 1487, 1275, 1115, 765, 712 $\mathrm{cm}^{-1} ;{ }^{1} \mathrm{H}$ NMR $(500 \mathrm{MHz}$, $\left.\mathrm{CDCl}_{3}\right)$ : major isomer: $\delta 0.89-1.18(\mathrm{~m}, 3 \mathrm{H}), 1.27-1.44(\mathrm{~m}, 4 \mathrm{H}), 2.11-2.22(\mathrm{~m}, 1 \mathrm{H})$, 2.27-2.38 (m, 1H), 3.10-3.16 (m, 2H), $4.59(\mathrm{t}, J=6.0 \mathrm{~Hz}, 2 \mathrm{H}), 7.31-7.63(\mathrm{~m}, 12 \mathrm{H})$, 7.84-7.85(m, 2H); ${ }^{19} \mathrm{~F} \mathrm{NMR}\left(470 \mathrm{MHz}, \mathrm{CDCl}_{3}\right)$ : major isomer: $\delta-169.75(\mathrm{t}, \mathrm{J}=$ 24.9Hz); GC/MS (EI) m/z: 296, 277, 261, 242, 222, 199, 185, 165, 116, 90; Anal. Calcd. for $\mathrm{C}_{27} \mathrm{H}_{27} \mathrm{FO}_{3}: \mathrm{C}, 77.49 ; \mathrm{H}, 6.50$. Found: $\mathrm{C}, 77.62 ; \mathrm{H}, 6.57$. 
${ }^{1} \mathrm{H},{ }^{13} \mathrm{C},{ }^{19} \mathrm{~F}$ Spectras of compound 3-3a
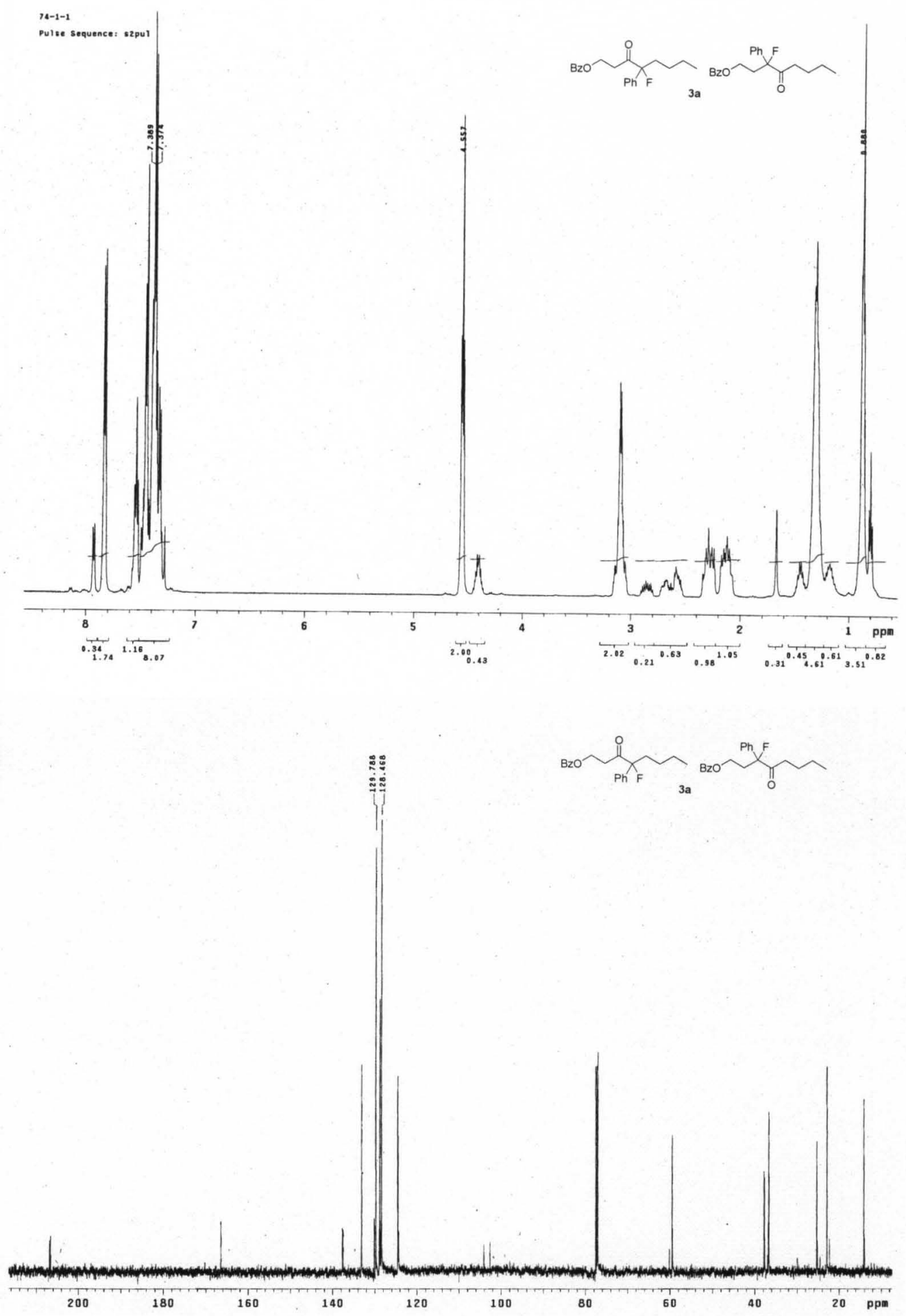


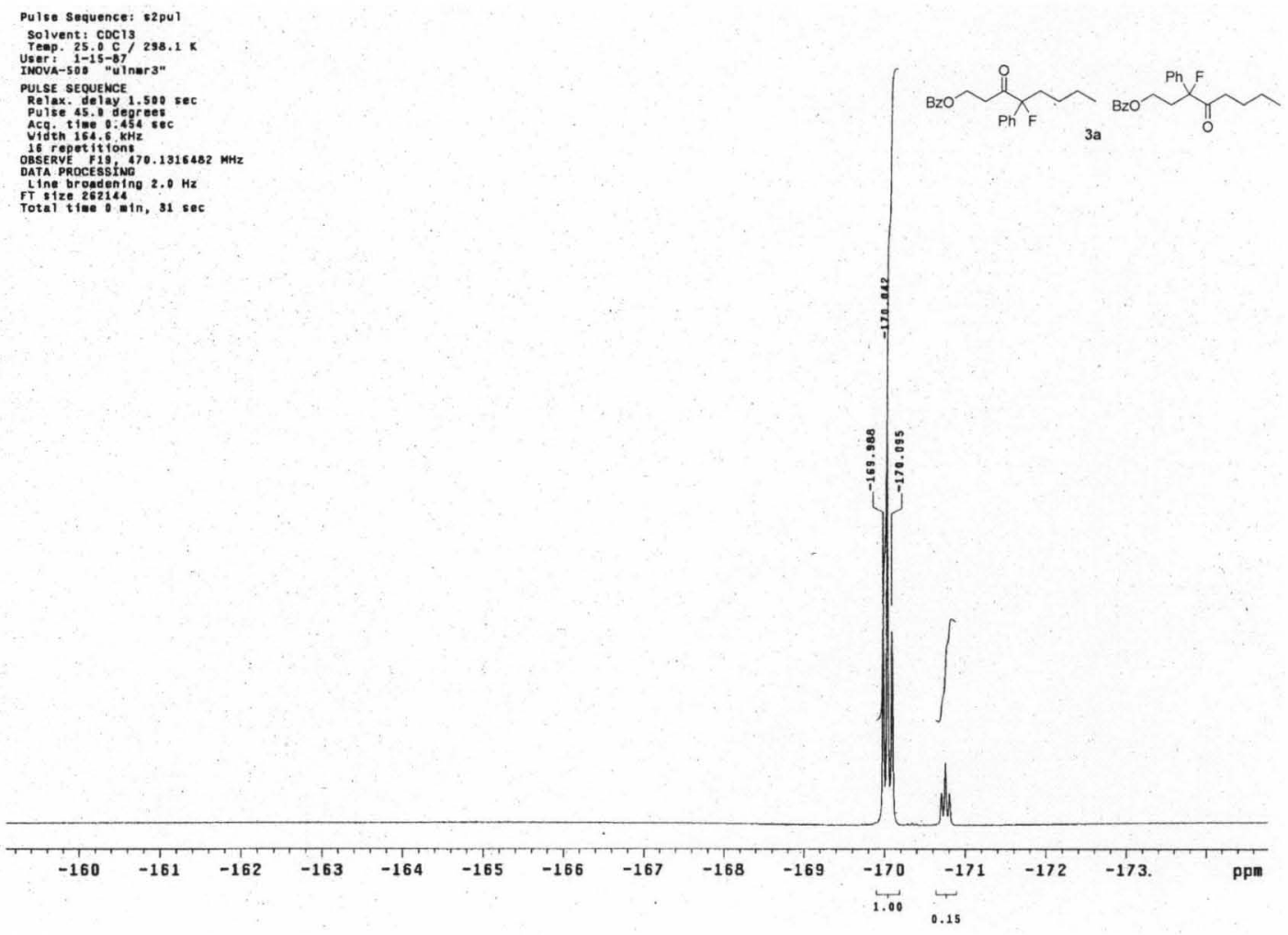




\section{CHAPTER 4. SYNTHESIS OF FLUOROHYDRINS FROM ALLYL SILANES}

\subsection{Background}

Extensive research has established that the chemical reactivity of fluorinated organic compounds is distinctly different from other halide-containing analogues. ${ }^{18-24}$ Consequently, fluorine substitution can effectively modify the physico-chemical properties of a molecule. In this regard, fluorohydrins have been sought after as intermediates and biological targets. ${ }^{137-145}$ Typically, fluorohydrins are synthesized by an epoxide ring opening using a fluorinating agent, ${ }^{146-152}$ but in many cases the regioselectivity and yields are less than satisfactory. There are other methods that rely on fluorinated molecular building blocks, but these building blocks are often derived from potential ozone depleting agents like $\mathrm{CFHCl}_{2}{ }^{153}$

\subsection{Results and discussion}

Selectfluor is an exceptionally stable, virtually non-hygroscopic crystalline electrophilic fluorinating agent ${ }^{36,37}$ used in several applications such as fluorohydroxylation of aryl substituted allenes. ${ }^{154}$ Recently, we reported a versatile synthesis of fluoroketones via a gold-catalyzed fluorination of alkynes using Selectfluor. ${ }^{155}$ During our attempts to extend the scope of this reaction to 
alkenes, we conducted the fluorination of allyltriisopropylsilane 4-1a in the presence of $5 \% \mathrm{AuClPPh}_{3}$; this reaction afforded the fluorohydrin product 4-2a in around $50 \%$ yield (eq 3). Further investigations revealed that no other regioisomer formed. This reaction represented a highly regioselective intermolecular fluorohydroxylation of an alkene. Gouverneur and co-workers have reported an electrophilic fluorocyclization of allyl silanes, ${ }^{156}$ but to the best of our knowledge, the synthetically more useful intermolecular fluorohydroxylation of allyl silanes has not been reported before.

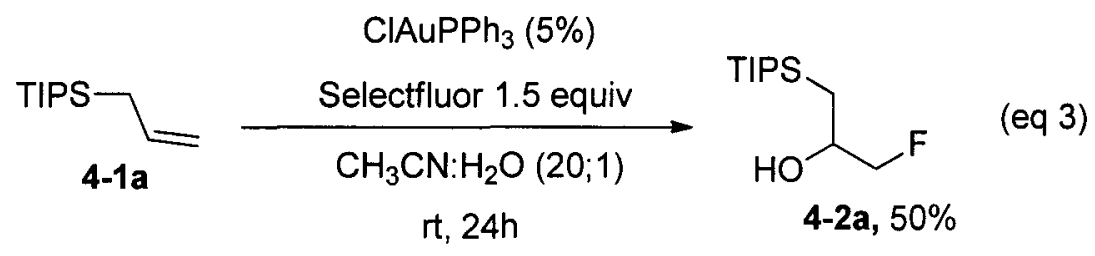

Further optimization of this transformation is shown in Table 7. Without any gold catalyst, the fluorination of 4-1a in $\mathrm{CH}_{3} \mathrm{CN}: \mathrm{H}_{2} \mathrm{O}$ (20:1) gave 1-fluoro-3(triisopropylsilyl)propan-2-ol 4-2a (entry 1) in 56\%, which indicated that the reaction occurred independently of the gold catalyst. Increasing the amount of water led to a slightly increased yield (entry 2) but further increases in water content actually decreased the yield (entry 3). We also investigated other nucleophiles. No reaction was observed when ethanol only was used as nucleophile and solvent (entry 4), but the fluorination of 4-1a in $\mathrm{CH}_{3} \mathrm{CN}: \mathrm{C}_{2} \mathrm{H}_{5} \mathrm{OH}$ (10:1) afforded (2-ethoxy-3-fluoropropyl) triisopropylsilane $4-2 a$ in $61 \%$ yield (entry 5). This result indicated that the solvent $\left(\mathrm{CH}_{3} \mathrm{CN}\right)$ played an important role in this transformation. The reaction of 4-1a with other nucleophiles like acetic acid, formamide and diethylamine afforded complicated mixtures (entries 6-8). 
Thus, the reaction condition presented in entry 2 was regarded as optimum for further studies.

Table 7. Screening conditions for the reaction of fluorohydroxylation of allyl silanes.

\begin{tabular}{cll} 
& Nucleophile $\left(\mathrm{CH}_{3} \mathrm{CN}: \mathrm{Nu}\right)$ & $\begin{array}{l}\text { Selectfluor 1.5 equiv } \\
\mathrm{CH}_{3} \mathrm{CN} \text { rt, } 24 \mathrm{~h}\end{array}$ \\
\hline nucleophile $(\mathrm{Nu})$ & product yield \\
\hline 1 & $\mathrm{H}_{2} \mathrm{O}(20: 1)$ & $56 \%$ \\
2 & $\mathrm{H}_{2} \mathrm{O}(10: 1)$ & $60 \%$ \\
3 & $\mathrm{H}_{2} \mathrm{O}(5: 1)$ & $55 \%$ \\
4 & $\mathrm{C}_{2} \mathrm{H}_{5} \mathrm{OH}$ only & no rxn \\
5 & $\mathrm{C}_{2} \mathrm{H}_{5} \mathrm{OH}(10: 1)$ & $61 \%$ \\
6 & $\mathrm{CH}_{3} \mathrm{COOH}(10: 1)$ & complex mixture \\
7 & $\mathrm{HCONH}_{2}(10: 1)$ & complex mixture \\
8 & $\mathrm{Et}_{2} \mathrm{NH}(10: 1)$ & no rxn \\
\hline
\end{tabular}

With optimized reaction conditions on hand, we explored the scope of this transformation (Table 8). The reactions of allyltriisopropylsilane 4-1a with different nucleophiles like water, ethanol, isopropanol, allyl alcohol, butan-1-ol and 2-cyclohexylethanol gave good yields (entries 1-6,). The relative more sterically hindered isopropanol reduced the yield slightly (entry 3, Table 8). Higher temperature $\left(60^{\circ} \mathrm{C}\right)$ was needed for the completion of the reaction of $4-1 \mathrm{a}$ with allyl alcohol, furnishing product $\mathbf{4 - 2 d}$ in $61 \%$ yield (entry 4 , (Table 8). Reaction of allyltriphenylsilane $4-1 b$ with $\mathrm{CH}_{3} \mathrm{CN}: \mathrm{H}_{2} \mathrm{O}$ (10:1) afforded $4-2 \mathrm{~g}$ in $55 \%$ yield (entry 7, Table 8). Diallyl silanes, like diallyldiphenylsilane 4-1c, seemed highly reactive under the standard conditions and failed to give the 
desired fluorinated product (entry 8 , Table 8 ). The reaction of allyl silane with a non-terminal double bond like 4-1d worked well (entry 9, Table 8). The good, but not excellent, yields observed in Table 8 may be due to a competing electrophilic fluorodesilylation reaction of allyl silane 4-1. Gouverneur and co-workers have developed efficient syntheses of allyl or propargyl fluorides through fluorodesilylation of allyl and allenyl silanes. ${ }^{157-162}$ In those transformations, ${ }^{157-162}$ allyl silanes with a smaller silyl group (e.g. TMS) were used. The bulkier silyl group (e.g., TIPS) used in our examples are more resisting to fluorodesilylation, but may not completely prevent the fluorodesilylation process. If desired, the silyl group in 4-2 can be removed using literature methods. ${ }^{156}$

The proposed mechanism is shown in Scheme 26. It has been well established that the silyl group has a strong stabilization effect on $\beta$-carbocations or radical cations. $^{163}$ This fact is probably the key factor for the regioselectivity observed. We propose that allyl silane reacts with Selectfluor to give $\beta$-carbocation 4-A, and quenching of 4-A by a nucleophile to give the final product 4-2 (Scheme 26-b). Single electron transfer (SET) has been proposed in many Selectfluor-mediated reactions; ${ }^{36}$ it is also possible that our reaction goes through a SET mechanism (Scheme 26-a), that is, the reaction of 4-1 with Selectfluor would give radical cation 4-B which will undergo F-atom transfer and then react with a nucleophile to give the final product $\mathbf{4 - 2}$. 
Table 8. Scope for the reaction of fluorohydroxylation of allyl silanes.

$\underbrace{}_{3}$

${ }^{a}$ isolated yields; ${ }^{b}$ reaction was conducted at $60^{\circ} \mathrm{C}$. 


$$
\mathrm{R}_{3}^{\prime} \stackrel{\oplus}{\mathrm{N}-\mathrm{F}}=\underset{2 \mathrm{BF}_{4}^{-}}{\text {Selectfluor }}
$$
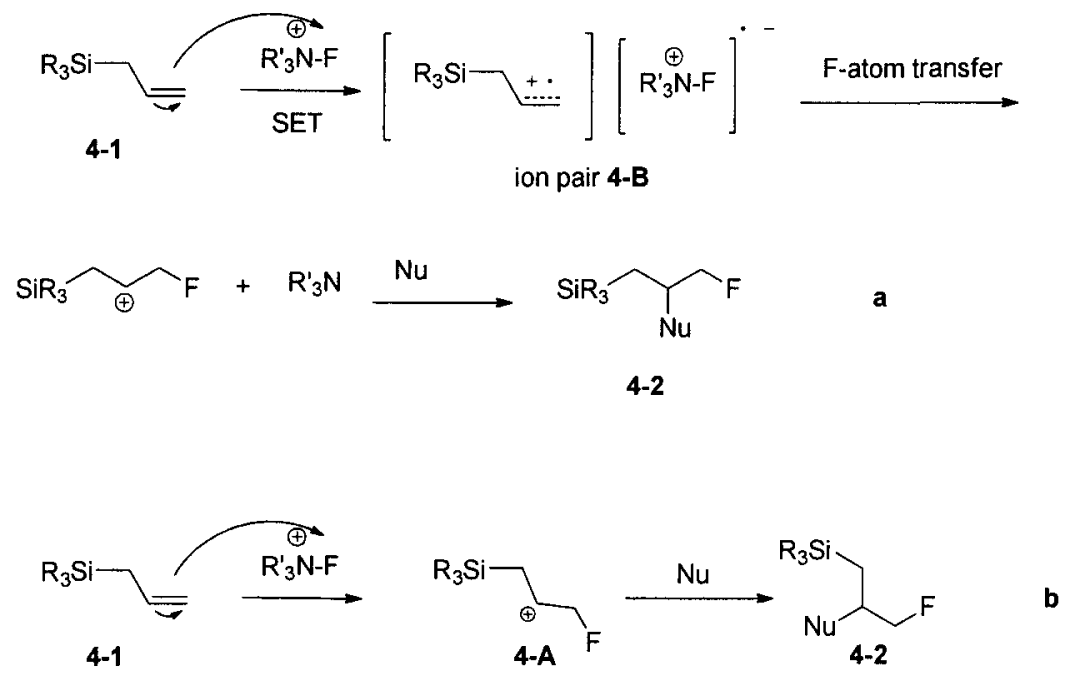

Scheme 26. Proposed mechanism for formation of compound 4-2.

\subsection{Conclusion}

In conclusion, we have developed a convenient method for the efficient monofluorination of allyl silanes using Selectfluor as the electrophilic fluorination reagent. The stabilization effect of the silyl group on the $\beta$-carbocation is critical for the success of this fluorohydroxylation reaction. The use of easy-to-handle NF reagents is a particularly attractive feature of our reaction. Further research on the implications of this transformation, including an asymmetrical version, is currently being conducted in our laboratory. 


\subsection{Experimental}

\section{General}

${ }^{1} \mathrm{H},{ }^{13} \mathrm{C}$ and ${ }^{19} \mathrm{~F}$ NMR spectra were recorded at 500,126 and $470 \mathrm{MHz}$ respectively, using $\mathrm{CDCl}_{3}$ as a solvent. The chemical shifts are reported in $\delta$ (ppm) values relative to $\mathrm{CHCl}_{3}$ (7.26 ppm for ${ }^{1} \mathrm{H}$ NMR and $77.0 \mathrm{ppm}$ for ${ }^{13} \mathrm{C}$ $\mathrm{NMR})$ and $\mathrm{CFCl}_{3}\left(0 \mathrm{ppm}\right.$ for ${ }^{19} \mathrm{~F}$ NMR), multiplicities are indicated by $\mathrm{s}$ (singlet), $\mathrm{d}$ (doublet), $\mathrm{t}$ (triplet), q (quartet), $\mathrm{p}$ (pentet), h (hextet), $\mathrm{m}$ (multiplet) and br (broad). Coupling constants, $J$, are reported in Hertz. Coupling constants are reported in hertz $(\mathrm{Hz})$. All air and/or moisture sensitive reactions were carried out under argon atmosphere. Solvents (tetrahydrofuran, ether, dichloromethane and DMF) were chemically dried using a commercial solvent purification system. All other reagents and solvents were employed without further purification. The products were purified using a CombiFlash system (Teledyne ISCO) or a regular glass column. TLC was developed on Merck silica gel 60 F254 aluminum sheets. IR spectra were recorded on a Bruker IFS 25 spectrometer. High resolution ESI-MS were obtained using a MS-FTICR-MS system (LTQ FT, Thermo Electron Corp.) at the CREAM Mass Spectrometry Facility, University of Louisville, Kentucky, 40292. When needed, reactions were monitored using ${ }^{19} \mathrm{~F}$ NMR and the mixture percentage yield was obtained using $\alpha, \alpha, \alpha$-trifluoromethylbenzene as internal reference. 
General procedure for synthesis of compound 4-2.

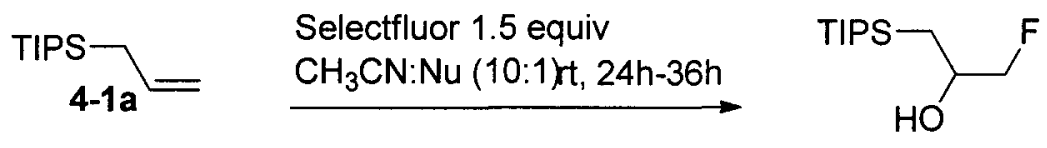

$4-2 a, 60 \%$

To a solution of $4-1 \mathrm{a}(99 \mathrm{mg}, 0.5 \mathrm{mmol})$ in $3 \mathrm{~mL}$ of $\mathrm{MeCN}: \mathrm{H}_{2} \mathrm{O}(10: 1)$ was added subsequently Selectfluor $(266 \mathrm{mg}, 0.75 \mathrm{mmol})$. Then the reaction mixture was stirred at room temperature for $24-36 \mathrm{~h}$; the progress of reaction was monitored by TLC. After completion of the reaction, the mixture was quenched with saturated $\mathrm{NH}_{4} \mathrm{Cl}$ solution, extracted with hexane or ether $(15 \mathrm{~mL} \times 2)$ and the combined organic layers were dried over $\mathrm{Mg}_{2} \mathrm{SO}_{4}$. After evaporation of organic solvents, the residue was subjected to flash silica gel column chromatography (from hexane to hexane $/ \mathrm{CH}_{2} \mathrm{Cl}_{2}=1: 1$ ), affording $4-2 \mathrm{a}$ as colorless oil (70 mg, $60 \%)$.

\section{Spectroscopic data of compounds 4-2}

1-fluoro-3-(triisopropylsilyl)propan-2-ol (4-2a)

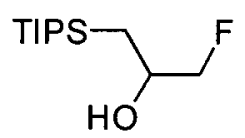

Colorless oil, yield 60\%. ${ }^{1} \mathrm{H}$ NMR $\left(500 \mathrm{MHz}, \mathrm{CDCl}_{3}\right): \delta$ 0.68-0.74 $(\mathrm{m}, 1 \mathrm{H}), 0.78$ $0.86(\mathrm{~m}, 1 \mathrm{H}), 1.02-1.17(\mathrm{~m}, 21 \mathrm{H}), 2.17(\mathrm{~s}, 1 \mathrm{H}), 4.10-4.27(\mathrm{~m}, 2 \mathrm{H}), 4.31-4.44(\mathrm{~m}$, 1H). ${ }^{13} \mathrm{C}$ NMR (125 MHz, $\left.\mathrm{CDCl}_{3}\right): \delta 11.6,12.2(\mathrm{~d}, J=4 \mathrm{~Hz}), 19.0(\mathrm{~d}, J=2 \mathrm{~Hz})$, 68.2 (d, $J=18 \mathrm{~Hz}), 89.2(\mathrm{~d}, J=170 \mathrm{~Hz}) .{ }^{19} \mathrm{~F} \mathrm{NMR}\left(470 \mathrm{MHz}, \mathrm{CDCl}_{3}\right): \delta-220.8--$ 
220.5 (m).GC/MS (EI) m/z: 172, 103, 41.HRMS (ESI) calcd. for $\mathrm{C}_{12} \mathrm{H}_{27} \mathrm{FNaOSi}^{+}$ $\left([\mathrm{M}+\mathrm{Na}]^{+}\right) 257.1713$, found 257.1712 .

(2-ethoxy-3-fluoropropyl)triisopropylsilane (4-2b)

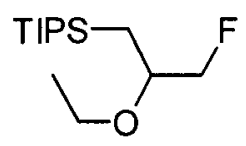

Colorless oil (yield 61\%). ${ }^{1} \mathrm{H}$ NMR $\left(500 \mathrm{MHz}, \mathrm{CDCl}_{3}\right): \delta$ 0.73-0.77 $(\mathrm{m}, 1 \mathrm{H}), 0.89-$ $0.94(\mathrm{~m}, 1 \mathrm{H}), 1.04-1.09(\mathrm{~m}, 21 \mathrm{H}), 1.20(\mathrm{t}, J=7 \mathrm{~Hz}, 3 \mathrm{H}), 3.47-3.53(\mathrm{~m}, 1 \mathrm{H}), 3.71-$ $3.78(\mathrm{~m}, 2 \mathrm{H}), 4.29-4.36(\mathrm{~m}, 1 \mathrm{H}), 4.39-4.46(\mathrm{~m}, 1 \mathrm{H}) .{ }^{13} \mathrm{C} \mathrm{NMR}\left(125 \mathrm{MHz}, \mathrm{CDCl}_{3}\right): \delta$ 11.7, $11.8(\mathrm{~d}, J=5 \mathrm{~Hz}), 15.9,19.0,65.5,75.9(\mathrm{~d}, J=18 \mathrm{~Hz}), 87.9(\mathrm{~d}, J=174$ $\mathrm{Hz}) .{ }^{19} \mathrm{~F} \mathrm{NMR}\left(470 \mathrm{MHz}, \mathrm{CDCl}_{3}\right): \delta-220.3--220.1$ (m).GC/MS (EI) m/z: 243, 202, 147, 121,41; Anal. Calcd. for $\mathrm{C}_{14} \mathrm{H}_{31}$ FOSi: C, 64.06; H, 11.90.HRMS (ESI) calcd. for $\left(\mathrm{C}_{14} \mathrm{H}_{31} \mathrm{FNaOSi}\right)^{+}\left([\mathrm{M}+\mathrm{Na}]^{+}\right)$285.2026, found 285.2026.

(3-fluoro-2-isopropoxypropyl)triisopropylsilane (4-2c)<smiles>CCSCC(CF)OC(C)C</smiles>

Colorless oil, yield 43\%. ${ }^{1} \mathrm{H}$ NMR $\left(500 \mathrm{MHz}, \mathrm{CDCl}_{3}\right): \delta 0.76-0.83(\mathrm{~m}, 2 \mathrm{H}), \quad 0.96-$ $1.03(\mathrm{~m}, 21 \mathrm{H}), 1.09(\mathrm{~d}, J=7.5 \mathrm{~Hz}, 6 \mathrm{H}), 3.71-3.81(\mathrm{~m}, 2 \mathrm{H}), 4.16-4.38(\mathrm{~m}, 2 \mathrm{H}) .{ }^{13} \mathrm{C}$ NMR $\left(125 \mathrm{MHz}, \mathrm{CDCl}_{3}\right): \delta 11.5,12.5(\mathrm{~d}, J=7.5 \mathrm{~Hz}), 18.8(\mathrm{~d}, J=5 \mathrm{~Hz}), 22.3$, 23.2, $69.8(\mathrm{~d}, J=2 \mathrm{~Hz}), 72.8(\mathrm{~d}, J=22 \mathrm{~Hz}), 87.4(\mathrm{~d}, J=216 \mathrm{~Hz}) \cdot{ }^{19} \mathrm{~F}$ NMR $(470$ $\mathrm{MHz}, \mathrm{CDCl}_{3}$ ): $\delta-220.4--220.1$; GC/MS (EI) $\mathrm{m} / z: 216,192,172,103 . \mathrm{HRMS}$ (ESI+) calcd. for $\mathrm{C}_{15} \mathrm{H}_{33} \mathrm{FNaOSi}{ }^{+}\left([\mathrm{M}+\mathrm{Na}]^{+}\right)$299.2182, found 299.2184 . 
(2-(allyloxy)-3-fluoropropyl)triisopropylsilane (4-2d)

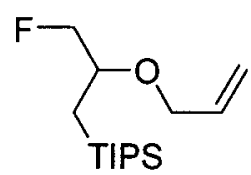

Colorless oil, yield $61 \% .{ }^{1} \mathrm{H}$ NMR $\left(500 \mathrm{MHz}, \mathrm{CDCl}_{3}\right): \delta 0.67-0.71(\mathrm{~m}, 2 \mathrm{H}), \quad 0.77-$ $1.03(\mathrm{~m}, 21 \mathrm{H}), 3.70-3.78(\mathrm{~m}, 1 \mathrm{H}), 3.94-3.98(\mathrm{~m}, 1 \mathrm{H}), 4.10-4.15(\mathrm{~m}, 1 \mathrm{H}), 4.22-4.29$ $(\mathrm{m}, 1 \mathrm{H}), 4.34-4.30(\mathrm{~m}, 1 \mathrm{H}), 5.05-5.09(\mathrm{~m}, 1 \mathrm{H}), 5.17-5.21(\mathrm{~m}, 1 \mathrm{H}), 5.80-5.89(\mathrm{~m}$, $1 \mathrm{H}) .{ }^{13} \mathrm{C}$ NMR $\left(125 \mathrm{MHz}, \mathrm{CDCl}_{3}\right): \delta 11.4,18.8,71.0(\mathrm{~d}, J=3 \mathrm{~Hz}), 75.6(\mathrm{~d}, J=22$ $\mathrm{Hz}), 88.7(\mathrm{~d}, J=217 \mathrm{~Hz}), 116.5,135.1 .{ }^{19} \mathrm{~F} \mathrm{NMR}\left(470 \mathrm{MHz}, \mathrm{CDCl}_{3}\right): \delta-219.5--$ 219.2 (m).GC/MS (EI) m/z: 213, 189, 171, 81.HRMS (ESI) calcd. for $\mathrm{C}_{15} \mathrm{H}_{31} \mathrm{FNaOSi}^{+}\left([\mathrm{M}+\mathrm{Na}]^{+}\right)$297.2026, found 297.2026.

(2-butoxy-3-fluoropropyl)triisopropylsilane (4-2e):

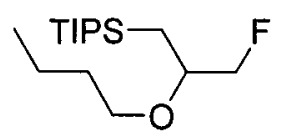

Colorless oil, yield $60 \% .{ }^{1} \mathrm{H}$ NMR $\left(500 \mathrm{MHz}, \mathrm{CDCl}_{3}\right): \delta 0.74-0.78(\mathrm{~m}, 2 \mathrm{H}), 0.90-$ $0.95(\mathrm{~m}, 3 \mathrm{H}), 1.05-1.10(\mathrm{~m}, 21 \mathrm{H}), 1.36-1.40(\mathrm{~m}, 2 \mathrm{H}), 1.53-1.60(\mathrm{~m}, 2 \mathrm{H}), 3.43-$ $3.47(m, 1 H), 3.62-3.67(m, 1 H), 3.69-3.77(m, 1 H), 4.29-4.36(m, 1 H), 4.39-4.46$ $(\mathrm{m}, 1 \mathrm{H}) .{ }^{13} \mathrm{C}$ NMR $\left(125 \mathrm{MHz}, \mathrm{CDCl}_{3}\right): \delta 11.7,11.8,14.1,19.1,19.6,32.6,70.0$, $76.0(\mathrm{~d}, J=17 \mathrm{~Hz}), 87.8(\mathrm{~d}, J=174 \mathrm{~Hz}) .{ }^{19} \mathrm{~F} \mathrm{NMR}\left(470 \mathrm{MHz}, \mathrm{CDCl}_{3}\right): \delta-220.5--$ $220.2(\mathrm{~m})$. GC/MS (EI) $\mathrm{m} / \mathrm{z}: 275,231,174,100$. HRMS $\left(\mathrm{ESI}^{+}\right)$calcd. for $\mathrm{C}_{16} \mathrm{H}_{35} \mathrm{FNaOSi}{ }^{+}\left([\mathrm{M}+\mathrm{Na}]^{+}\right)$313.2339, found 313.2339. 
(2-(2-cyclohexylethoxy)-3-fluoropropyl) triisopropylsilane (4-2f):

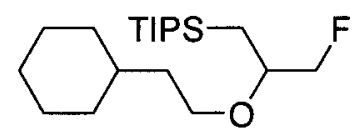

Colorless oil, $60 \% .{ }^{1} \mathrm{H}$ NMR $\left(500 \mathrm{MHz}, \mathrm{CDCl}_{3}\right): \delta 0.64-0.90(\mathrm{~m}, 2 \mathrm{H}), 0.81-0.87(\mathrm{~m}$, $3 \mathrm{H}), 0.92-1.04(\mathrm{~m}, 21 \mathrm{H}), 1.05-1.19(\mathrm{~m}, 4 \mathrm{H}), 1.30-1.41(\mathrm{~m}, 2 \mathrm{H}), 1.51-1.63(\mathrm{~m}$, $4 \mathrm{H}), 3.34-3.40(\mathrm{~m}, 1 \mathrm{H}), 3.58-3.68(\mathrm{~m}, 2 \mathrm{H}), 4.19-4.26(\mathrm{~m}, 1 \mathrm{H}), 4.33-4.38(\mathrm{~m}$, 1H).${ }^{13} \mathrm{C}$ NMR $\left(125 \mathrm{MHz}, \mathrm{CDCl}_{3}\right): \delta 11.7,11.8,18.3,19.1(\mathrm{~d}, J=3 \mathrm{~Hz}), 26.7(\mathrm{~d}, J=$ $37 \mathrm{~Hz}), 33.6(\mathrm{~d}, J=23 \mathrm{~Hz}), 34.7,38.0,68.1,76.0(\mathrm{~d}, J=18 \mathrm{~Hz}), 87.9(\mathrm{~d}, J=174$ $\mathrm{Hz}) ;{ }^{19} \mathrm{~F}$ NMR (470 MHz, $\mathrm{CDCl}_{3}$ ): $\delta$-220.0- -219.7 (m); GC/MS (EI) m/z: 283,214, 172, 158, 69.HRMS $\left(\mathrm{ESI}^{+}\right)$calcd. for $\mathrm{C}_{20} \mathrm{H}_{41} \mathrm{FNaOSi}^{+}\left([\mathrm{M}+\mathrm{Na}]^{+}\right) 367.2808$, found 367.2808 .

1-fluoro-3-(triphenylsilyl)propan-2-ol (4-2g)<smiles>OC(CF)C[SiH2]P</smiles>

Colorless oil, yield 55\%. ${ }^{1} \mathrm{H}$ NMR $\left(500 \mathrm{MHz}, \mathrm{CDCl}_{3}\right): \delta$ 0.64-0.90 $(\mathrm{m}, 2 \mathrm{H}), 0.81-$ $0.87(\mathrm{~m}, 3 \mathrm{H}), 0.92-1.04(\mathrm{~m}, 21 \mathrm{H}), 1.05-1.19(\mathrm{~m}, 4 \mathrm{H}), 1.30-1.41(\mathrm{~m}, 2 \mathrm{H}), 1.51-$ $1.63(\mathrm{~m}, 4 \mathrm{H}), 3.34-3.40(\mathrm{~m}, 1 \mathrm{H}), 3.58-3.68(\mathrm{~m}, 2 \mathrm{H}), 4.19-4.26(\mathrm{~m}, 1 \mathrm{H}), 4.33-4.38$ $(\mathrm{m}, 1 \mathrm{H}) .{ }^{13} \mathrm{C}$ NMR $\left(125 \mathrm{MHz}, \mathrm{CDCl}_{3}\right): \delta 11.7,11.8,18.3,19.1(\mathrm{~d}, \mathrm{~J}=3 \mathrm{~Hz}), 26.7$ $(d, J=37 \mathrm{~Hz}), 33.6$ (d, $J=23 \mathrm{~Hz}), 34.7,38.0,68.1,76.0(\mathrm{~d}, J=18 \mathrm{~Hz}), 87.9(\mathrm{~d}, J$ $=174 \mathrm{~Hz}) \cdot{ }^{19} \mathrm{~F}$ NMR $\left(470 \mathrm{MHz}, \mathrm{CDCl}_{3}\right): \delta-220.0--219.7(\mathrm{~m}) . \mathrm{GC} / \mathrm{MS}$ (EI) $\mathrm{m} / \mathrm{z}$ : $283,214,172,158,69$ 
2-fluoro-3-hydroxy-4-(triisopropylsilyl)butyl acetate (4-2h)

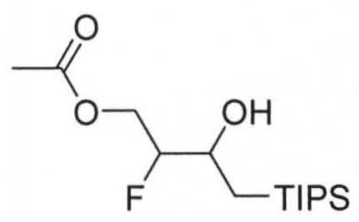

Colorless oil, yield 59\%. ${ }^{1} \mathrm{H}$ NMR $\left(500 \mathrm{MHz}, \mathrm{CDCl}_{3}\right): \delta$ 0.79-0.82 $(\mathrm{m}, 1 \mathrm{H}), 0.91-$ $0.96(\mathrm{~m}, 1 \mathrm{H}), 1.06-1.14(\mathrm{~m}, 21 \mathrm{H}), 1.99(\mathrm{~d}, J=5 \mathrm{~Hz}, 1 \mathrm{H}), 2.11-2.13(\mathrm{~m}, 3 \mathrm{H}), 3.98-$ $4.04(\mathrm{~m}, 1 \mathrm{H}), 4.25-4.35(\mathrm{~m}, 1 \mathrm{H}), 4.37-4.43(\mathrm{~m}, 1 \mathrm{H}), 4.48-4.51(\mathrm{~m}, 1 \mathrm{H}) .{ }^{13} \mathrm{C} N M R$ (125 MHz, $\left.\mathrm{CDCl}_{3}\right): \delta 11.6(\mathrm{~d}, J=9 \mathrm{~Hz}), 13.5,19.0,21.0,63.7(\mathrm{~d}, J=23 \mathrm{~Hz}), 68.5$ $(\mathrm{d}, J=20 \mathrm{~Hz}), 95.8(\mathrm{~d}, J=175 \mathrm{~Hz}) \cdot{ }^{19} \mathrm{~F} \mathrm{NMR}\left(470 \mathrm{MHz}, \mathrm{CDCl}_{3}\right): \delta-198.2--197.9$ (m). GC/MS (EI) $m / z: 285,225,181,112,43$. HRMS (ESI) calcd. for $\mathrm{C}_{15} \mathrm{H}_{31} \mathrm{FNaO}_{3} \mathrm{Si}^{+}\left([\mathrm{M}+\mathrm{Na}]^{+}\right) 329.1924$, found329.1924.

${ }^{1} \mathrm{H},{ }^{13} \mathrm{C},{ }^{19} \mathrm{~F}$ spectras of compound $4-2 \mathrm{~b}$

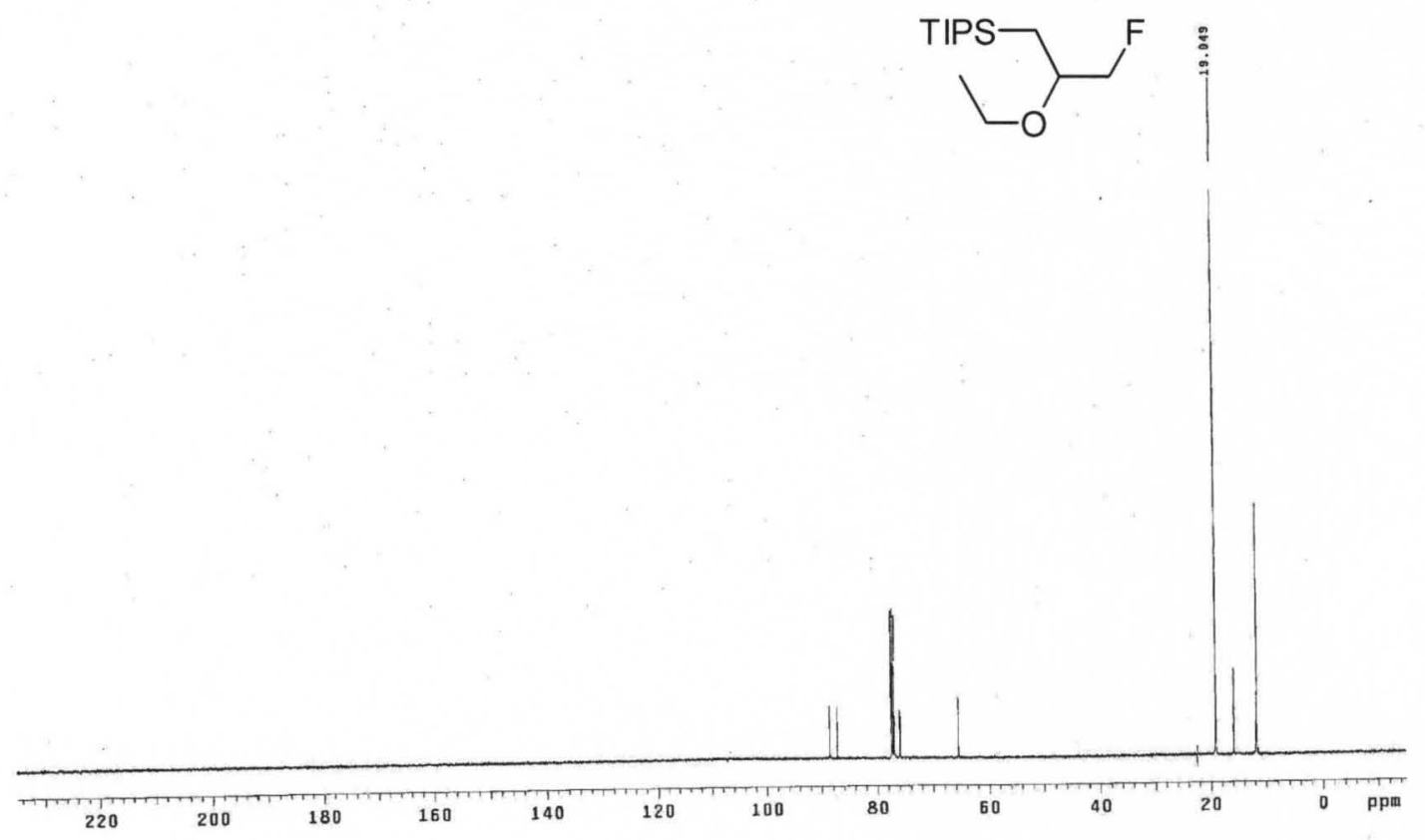



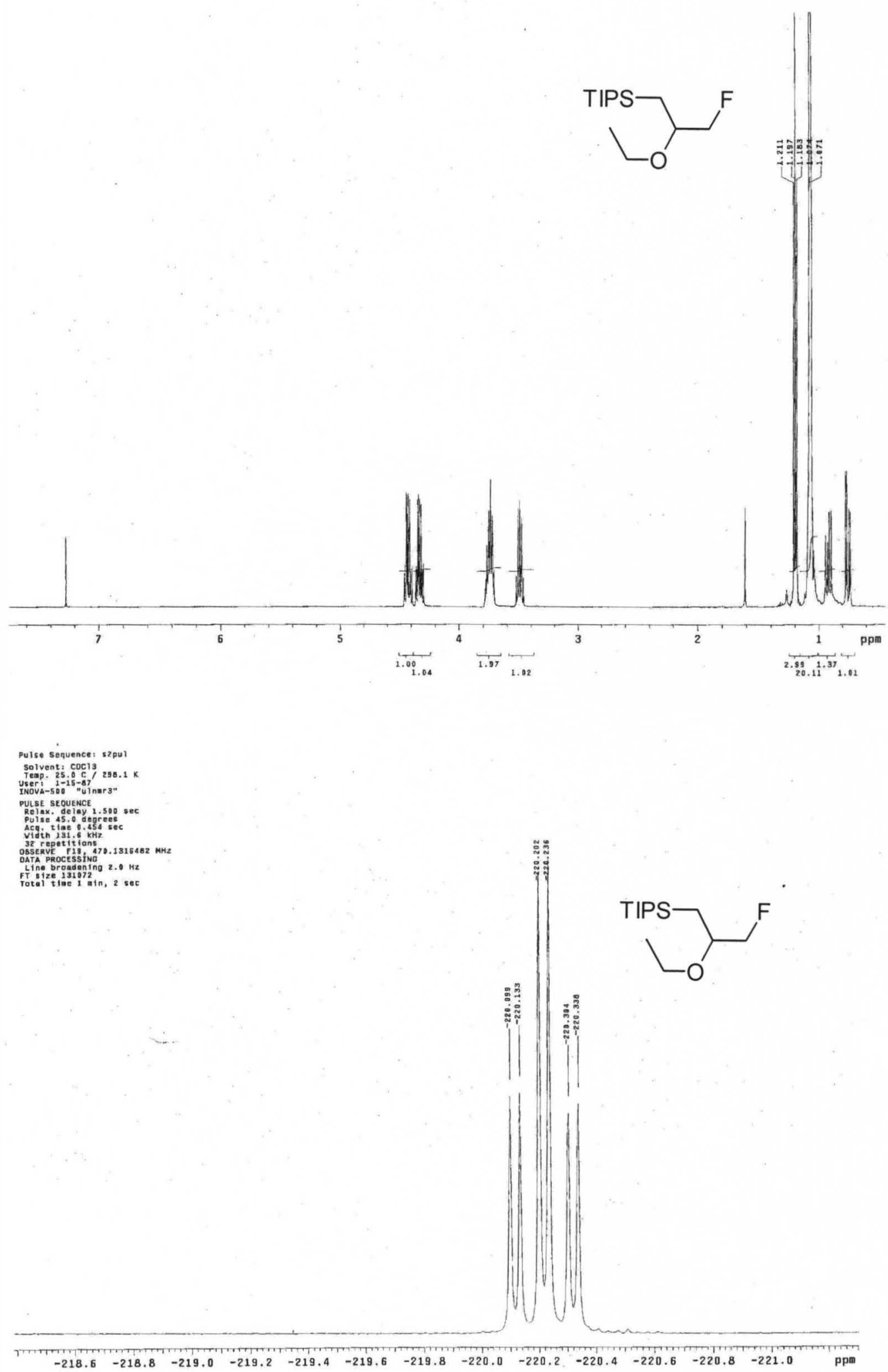


\section{REFERENCES}

(1) Hashmi, A. S. K. Gold-Catalyzed Organic Reactions. Chem. Rev. 2007, 107, 3180-3211.

(2) Garcia, P.; Malacria, M.; Aubert, C.; Gandon, V.; Fensterbank, L. GoldCatalyzed Cross-Couplings: New Opportunities for C-bond-C Bond Formation. Chem CatChem 2010, 2, 493-497.

(3) Arcadi, A. Alternative Synthetic Methods through New Developments in Catalysis by Gold. Chem. Rev. 2008, 108, 3266-3325.

(4) Gorin, D. J.; Sherry, B. D.; Toste, F. D. Ligand Effects in Homogeneous Au Catalysis. Chem. Rev. 2008, 108, 3351-3378.

(5) Jimenez-Nunez, E.; Echavarren, A. M. Gold-Catalyzed Cycloisomerizations of Enynes: A Mechanistic Perspective. Chem. Rev. 2008, 108, 3326-3350.

(6) Li, Z.; Brouwer, C.; He, C. Gold-Catalyzed Organic Transformations. Chem. Rev. 2008, 108, 3239-3265.

(7) Hashmi, A. S. K.; Rudolph, M. Gold catalysis in total synthesis. Chem. Soc. Rev. 2008, 37, 1766-1775.

(8) Widenhoefer, R. A. Recent developments in enantioselective gold(I) catalysis. Chem.-Eur. J. 2008, 14, 5382-5391.

(9) Demann, E. T. K., Stein, P. S., Haubenrich, J. E. Gold as an Implant in Medicine and Dentistry. J. Long-Term Effects Med. Implants 2005, 15, 687.

(10) Nolan, S. P. Catalytic gold rush. Nature 2007, 445, 496.

(11) A. Stephen K. Hashmi, L. S., Ji-Hyun Choi, Tanja M. Frost, A New GoldCatalyzed C-C Bond Formation. Angew. Chem., Int. Ed. 2000, 39, 22852288.

(12) Teles, J. H. B., S.; Chabanas, M. Cationic Gold(I) Complexes: Highly Efficient Catalysts for the Addition of Alcohols to Alkynes. Angew. Chem. Int. Ed. 1998, 37, 1415.

(13) A. Stephen K. Hashmi, J. P. W., Wolfgang Frey, and Jan W. Bats Gold Catalysis: Mild Conditions for the Synthesis of Oxazoles from $\mathrm{N}$ Propargylcarboxamides and Mechanistic Aspects. Org. Lett. 2004, 6, 4391. 
(14) Hashmi, A. S. K. e. a. Gold Catalysis: Isolation of Vinylgold Complexes Derived from Alkynes. Angew. Chem. Int. Ed. 2009, 48, 8247.

(15) Morita, N. K., N. The First Gold-Catalyzed CS Bond Formation: Cycloisomerization of -Thioallenes to 2,5-Dihydrothiophenes. Angew. Chem. Int. Ed. 2006, 45, 1897.

(16) Markham, J. P. S., S. T.; Toste, F. D. Gold(I)-Catalyzed Ring Expansion of Cyclopropanols and Cyclobutanols. j. Am. Chem. Soc. 2005, 127, 9708.

(17) Nieto-Oberhuber, C.; Lopez, S.; Jimenez-Nunez, E.; Echavarren, A. M. The mechanistic puzzle of transition-metal-catalyzed skeletal rearrangements of enynes. Chemistry--A European Journal 2006, 12, 5916-5923.

(18) Chambers, R. D. Fluorine in organic chemistry; Blackwell Publishing Ltd./CRC Press, Boca Raton, Fl, 2004.

(19) Hiyama, T. Organofluorine compounds, chemistry and applications; Springer-Verlag, Berlin, 2000.

(20) Kirsch, P. Modern fluoroorganic chemistry; Wiley-VCH, Weinheim, 2004.

(21) Muller, K.; Faeh, C.; Diederich, F. Fluorine in pharmaceuticals: Looking beyond intuition. Science 2007, 317, 1881-1886.

(22) Schlosser, M. Parametrization of substituents: Effects of fluorine and other heteroatoms on $\mathrm{OH}, \mathrm{NH}$, and $\mathrm{CH}$ acidities. Angew. Chem. Int. Ed. 1998, 37, 1496.

(23) Soloshonok, V. A. Fluorine-containing synthons, ACS symposium series 911; Oxford University Press,Washington, D.C, 2005.

(24) Uneyama, K. Organofluorine Chemistry; Blackwell publishing: Oxford, 2006.

(25) Balz, G.; Schiemann, G. Ber. Dtsch. Chem. Ges. 1927, 60.

(26) Finger, G. C.; Kruse, C. W. Aromatic fluorine compounds. VII. Replacement of aromatic chloro and nitro groups by fluorine. J. Am. Chem. Soc. 1956, 78, 6034-7.

(27) Ball, N. D.; Sanford, M. S. Synthesis and Reactivity of a Mono-s-Aryl Palladium(IV) Fluoride Complex. J. Am. Chem. Soc. 2009, 131, 37963797.

(28) Hull, K. L.; Anani, W. Q.; Sanford, M. S. Palladium-Catalyzed Fluorination of Carbon-Hydrogen Bonds. J. Am. Chem. Soc. 2006, 128, 7134-7135.

(29) Hull, K. L.; Sanford, M. S. Mechanism of Benzoquinone-Promoted Palladium-Catalyzed Oxidative Cross-Coupling Reactions. J. Am. Chem. Soc. 2009, 131, 9651-9653.

(30) Diederich, F.; Stang, P.; Tykwinski, R. R. Acetylene chemistry: chemistry, biology, and material science Wiley-VCH: Weinheim, 2005. 
(31) Krause, N.; Hashmi, A. S. Modern allene chemistry; Wiley-VCH: Weinheim, 2004.

(32) Chiusoli, G. P.; Maitlis, P. M.; Royal Society of Chemistry (Great Britain) Metal-catalysis in industrial organic processes; [Softback ed.; RSC Publishing: Cambridge, 2008.

(33) Benitez, D.; Shapiro, N. D.; Tkatchouk, E.; Wang, Y.; Goddard, W. A.; Toste, F. D. A bonding model for gold(I) carbene complexes. Nat Chem 2009, 1, 482-486.

(34) Zhang, G.; Peng, Y.; Cui, L.; Zhang, L. Gold-Catalyzed Homogeneous Oxidative Cross-Coupling Reactions. Angew. Chem., Int. Ed. 2009, 48, 3112-3115.

(35) Okabayashi, T.; Nakaoka, Y.; Yamazaki, E.; Tanimoto, M. Millimeter- and submillimeter-wave spectroscopy of AuF in the ground X1[Sigma]+ state. Chem. Phys. Lett. 2002, 366, 406-411.

(36) Nyffeler, P. T.; Duron, S. G.; Burkart, M. D.; Vincent, S. P.; Wong, C.-H. Selectfluor: Mechanistic insight and applications. Angew. Chem., Int. Ed. 2005, 44, 192-212.

(37) Schueler, M. Selectfluor \& Deoxofluor in industrial applications. Speciality Chemicals Magazine 2006, 26, 20.

(38) Furuya, T.; Kaiser, H. M.; Ritter., T. Palladium-Mediated Fluorination of Arylboronic Acids. Angew. Chem. Int. Ed. 2008, 47, 5993.

(39) Furuya, T.; Ritter, T. Carbon-Fluorine Reductive Elimination from a HighValent Palladium Fluoride. J. Am. Chem. Soc. 2008, 130, 10060.

(40) Furuya, T.; Ritter, T. Fluorination of Boronic Acids Mediated by Silver(I) Triflate. Org. Lett. 2009, 11, 2860.

(41) Hull, K. L.; Anani, W. Q.; Sanford, M. S. Palladium-Catalyzed Fluorination of Carbon 鈭扝 ydrogen Bonds. J. Am. Chem. Soc. 2006, 128, 7134-7135.

(42) Schuler, M.; Silva, F.; Bobbio, C.; Tessier, A.; Gouverneur, V. Gold(I)Catalyzed Alkoxyhalogenation of $\beta$-Hydroxy- $\alpha, \alpha$-Difluoroynones. Angew. Chem., Int. Ed. 2008, 47, 7927-7930.

(43) Peng, Y.; Cui, L.; Zhang, G.; Zhang, L. Gold-Catalyzed Homogeneous Oxidative C-O Bond Formation: Efficient Synthesis of 1-Benzoxyvinyl Ketones. J. Am. Chem. Soc. 2009, 131, 5062-5063.

(44) Rosewall, C. F.; Sibbald, P. A.; Liskin, D. V.; Michael, F. E. PalladiumCatalyzed Carboamination of Alkenes Promoted by $\mathrm{N}$ Fluorobenzenesulfonimide via $C$ 鈭扝 Activation of Arenes. J. Am. Chem. Soc. 2009, 131, 9488-9489.

(45) Watson, D. A.; Su, M.; Teverovskiy, G.; Zhang, Y.; Garcia-Fortanet, J.; Kinzel, T.; Buchwald, S. L. Formation of ArF from LPdAr(F): Catalytic 
Conversion of Aryl Triflates to Aryl Fluorides. Science 2009, 325, 16611664.

(46) Csaky, A. G.; Plumet, J. Stereoselective coupling of ketone and carboxylate enolates. Chem. Soc. Rev. 2001, 30, 313-320.

(47) Aoki, S.; Nakamura, E. Synthesis of 1,4-dicarbonyl compounds and 4-keto pimelates by palladium-catalyzed carbonylation of siloxycyclopropanes. Tetrahedron 1991, 47, 3935-46.

(48) Aoki, S.; Nakamura, E. Synthesis of 1,4-dicarbonyl compounds by palladium-catalyzed carbonylative arylation of siloxycyclopropanes. Synlett 1990, 741-2.

(49) Muthusamy, S.; Srinivasan, P. New rhodium(II) catalyzed synthesis of 1,4dicarbonyl compounds from a-diazo ketones using vinyl ethers as twocarbon synthons. Tetrahedron Lett. 2006, 47, 6297-6300.

(50) Cai, Y.; Roberts, B. P.; Tocher, D. A.; Barnett, S. A. Carbon-carbon bond formation by radical addition-fragmentation reactions of O-alkylated enols. Org. Biomol. Chem. 2004, 2, 2517-2529.

(51) Meyers, A. I.; Wallace, R. H.; Harre, M.; Garland, R. The asymmetric synthesis of 2,2-dialkyl carboxylic esters and 2,2-disubstituted dihydronaphthalenes. J. Org. Chem. 1990, 55, 3137-43.

(52) Isaka, M.; Nakamura, E. Carbocupration of cyclopropene. Asymmetric synthesis of quaternary carbon centers. J. Am. Chem. Soc. 1990, 112, 7428-30.

(53) Momiyama, N.; Kanan, M. W.; Liu, D. R. Synthesis of Acyclic $\alpha, \beta-$ Unsaturated Ketones via Pd(II)-Catalyzed Intermolecular Reaction of Alkynamides and Alkenes. J. Am. Chem. Soc. 2007, 129, 2230-2231.

(54) Hintermann, L.; Labonne, A. Catalytic hydration of alkynes and its application in synthesis. Synthesis 2007, 1121-1150.

(55) Kamiguchi, S.; Takahashi, I.; Kondo, K.; Nagashima, S.; Kurokawa, H.; Miura, H.; Chihara, T. Catalytic Hydration of Alkynes over Bronsted Acid Sites Developed on Halide Clusters. J. Cluster Sci. 2007, 18, 845-853.

(56) Tsuchimoto, T.; Joya, T.; Shirakawa, E.; Kawakami, Y. Bronsted acidcatalyzed hydration of alkynes: a convenient route to diverse carbonyl compounds. Synlett 2000, 1777-1778.

(57) Menashe, N.; Shvo, Y. Hydration of alkynes in anhydrous medium with formic acid as water donor. J. Org. Chem. 1993, 58, 7434-9.

(58) Tokunaga, M.; Wakatsuki, Y. The first anti-Markovnikov hydration of terminal alkynes: formation of aldehydes catalyzed by a ruthenium(II)/phosphine mixture. Angew. Chem., Int. Ed. 1998, 37, $2867-$ 2869. 
(59) Ackermann, L.; Kaspar, L. T. TiCl4-Catalyzed Indirect Anti-Markovnikov Hydration of Alkynes: Application to the Synthesis of Benzo[b]furans. J. Org. Chem. 2007, 72, 6149-6153.

(60) Grotjahn, D. B.; Lev, D. A. A general bifunctional catalyst for the antiMarkovnikov hydration of terminal alkynes to aldehydes gives enzyme-like rate and selectivity enhancements. J. Am. Chem. Soc. 2004, 126, 1223212233.

(61) Halpern, J.; James, B. R.; Kemp, A. L. W. Catalysis of the hydration of acetylenic compounds by ruthenium(III) chloride. J. Am. Chem. Soc. 1961, 83, 4097-8.

(62) Johnson, D. S.; Li, J. J. The art of drug synthesis; Wiley-Interscience: Hoboken, N.J., 2007.

(63) Kim, S. y.; Chin, C. S.; Eum, M.-S. Cyclic acetals from catalytic addition of diols to terminal alkynes with a cationic iridium complex containing two labile ligands. J. Mol. Catal. A: Chem. 2006, 253, 245-248.

(64) Lucey, D. W.; Atwood, J. D. Insight into the Selective Room-Temperature Platinum(II) Catalytic Hydration of Alkynes in Water. Organometallics 2002, 21, 2481-2490.

(65) Baidossi, W.; Lahav, M.; Blum, J. Hydration of Alkynes by a PtC/4-CO Catalyst. J. Org. Chem. 1997, 62, 669-672.

(66) Hartman, J. W.; Hiscox, W. C.; Jennings, P. W. Catalytic hydration of alkynes with platinum(II) complexes. J. Org. Chem. 1993, 58, 7613-14.

(67) Hiscox, W.; Jennings, P. W. Catalytic hydration of alkynes with Zeise's dimer. Organometallics 1990, 9, 1997-9.

(68) Mizushima, E.; Cui, D.-M.; Nath, D. C. D.; Hayashi, T.; Tanaka, M. Au(I)catalyzed hydration of alkynes: 2,8-nonanedione. Org. Synth. 2006, 83, 55-60.

(69) Mizushima, E.; Sato, K.; Hayashi, T.; Tanaka, M. Highly efficient Aulcatalyzed hydration of alkynes. Angew. Chem., Int. Ed. 2002, 41, 45634565.

(70) Fukuda, Y.; Utimoto, K. Effective transformation of unactivated alkynes into ketones or acetals with a gold(III) catalyst. J. Org. Chem. 1991, 56, 3729-31.

(71) Casado, R.; Contel, M.; Laguna, M.; Romero, P.; Sanz, S. Organometallic Gold(III) Compounds as Catalysts for the Addition of Water and Methanol to Terminal Alkynes. J. Am. Chem. Soc. 2003, 125, 11925-11935.

(72) Grotjahn, D. B.; Lev, D. A. A General Bifunctional Catalyst for the AntiMarkovnikov Hydration of Terminal Alkynes to Aldehydes Gives EnzymeLike Rate and Selectivity Enhancements. J. Am. Chem. Soc. 2004, 126, 12232-12233. 
(73) Liu, W.-J.; Li, J.-H. Cerium(IV) sulfate-catalyzed hydration of alkynes. Youji Huaxue 2006, 26, 1073-1078.

(74) Vasudevan, A.; Verzal, M. K. Neutral, metal-free hydration of alkynes using microwave irradiation in superheated water. Synlett 2004, 631-634.

(75) Meier, I. K.; Marsella, J. A. Hydration of acetylenic compounds without using mercury. J. Mol. Catal. 1993, 78, 31-42.

(76) Finiels, A.; Geneste, P.; Lasperas, M.; Marichez, F.; Moreau, P. Triple bond hydration using zeolites as catalysts. Stud. Surf. Sci. Catal. 1991, 59, 565-71.

(77) Finiels, A.; Geneste, P.; Marichez, F.; Moreau, P. Hydration reaction of alkynes catalyzed by zeolites. Catal. Lett. 1989, 2, 181-4.

(78) Olah, G. A.; Meidar, D. Heterogenous catalysis by solid superacids; 10. Mercury impregnated Nafion-H perfluorinated resinsulfonic acid catalyzed hydration of alkynes. Synthesis 1978, 671-2.

(79) Imi, K.; Imai, K.; Utimoto, K. Regioselective hydration of alkynones by palladium catalysis. Tetrahedron Lett. 1987, 28, 3127-30.

(80) Detert, H.; Meier, H. Chemical and spectroscopical properties of mediumsized trans- and cis-bicyclo[n.1.0]alk-2-ynes. Liebigs Ann./Recl. 1997, 1565-1570.

(81) Utimoto, K. Palladium-catalyzed synthesis of heterocycles. Pure Appl. Chem. 1983, 55, 1845-52.

(82) Stork, G.; Borch, R. New synthesis of 1,4- and 1,5-diketones. J. Am. Chem. Soc. 1964, 86, 935-6.

(83) Francisco, L. W.; Moreno, D. A.; Atwood, J. D. Synthesis, Characterization, and Reaction Chemistry of PtCl2[P( $m-C 6 H 4 S O 3 N a) 3] 2$, an Alkyne Hydration Catalyst. Organometallics 2001, 20, 4237-4245.

(84) Arcadi, A.; Cerichelli, G.; Chiarini, M.; Di Giuseppe, S.; Marinelli, F. Sequential alkylation/transition metal catalysed annulation reactions of 1,3-dicarbonyl compounds with propargyl bromide. Tetrahedron Lett. 2000, 41, 9195-9198.

(85) Jennings, P. W.; Hartman, J. W.; Hiscox, W. C. Alkyne hydration using Pt(II) catalysts. Inorg. Chim. Acta 1994, 222, 317-322.

(86) Baldwin, J. E. Rules for ring closure. J. Chem. Soc., Chem. Commun. 1976, 734-736.

(87) Sun, J.; Conley, M. P.; Zhang, L.; Kozmin, S. A. Au- and Pt-Catalyzed Cycloisomerizations of 1,5-Enynes to Cyclohexadienes with a Broad Alkyne Scope. J. Am. Chem. Soc. 2006, 128, 9705-9710.

(88) Fustero, S.; Fernandez, B.; Bello, P.; Del, P. C.; Arimitsu, S.; Hammond, G. B. Intramolecular Hydroamination of Difluoropropargyl Amides: 
Regioselective Synthesis of Fluorinated $\beta$ - and $\gamma$-Lactams. Org. Lett. 2007, 9, 4251-4253.

(89) Nakamura, I.; Sato, T.; Terada, M.; Yamamoto, Y. Gold-Catalyzed Cyclization of (ortho-Alkynylphenylthio) silanes: Intramolecular Capture of the Vinyl-Au Intermediate by the Silicon Electrophile. Org. Lett. 2007, 9, 4081-4083.

(90) Akana, J. A.; Bhattacharyya, K. X.; Mueller, P.; Sadighi, J. P. Reversible $C-F$ Bond Formation and the Au-Catalyzed Hydrofluorination of Alkynes. J. Am. Chem. Soc. 2007, 129, 7736-7737.

(91) Hashmi, A. S. K.; Schwarz, L.; Choi, J.-H.; Frost, T. M. A new goldcatalyzed C-C bond formation. Angew. Chem., Int. Ed. 2000, 39, 22852288.

(92) Liu, Y.; Liu, M.; Guo, S.; Tu, H.; Zhou, Y.; Gao, H. Gold-Catalyzed Highly Efficient Access to 3(2H)-Furanones from 2-Oxo-3-butynoates and Related Compounds. Org. Lett. 2006, 8, 3445-3448.

(93) weibo wang, B. X., and Gerald B. Hammond Synthesis of functionalized $\alpha$, $\alpha$-Disubstituted $\beta$-Alkynyl Esters from allenoates throught and Alkynylenolate Intermediate. Org. Lett. 2008, 10, 3713-3716.

(94) Le-Ping Liu, B. X., and Gerald B. Hammond Michael Addition of allenoates to Electron-deficient Olefins: Facile Synthesis of 2-alkynyl-substituted Glutaric Acid Derivatives. Org. Lett. 2008, 10, 3887-3890.

(95) Marion, N.; Ramon, R. S.; Nolan, S. P. [(NHC)Aul]-Catalyzed Acid-Free Alkyne Hydration at Part-per-Million Catalyst Loadings. J. Am. Chem. Soc. 2009, 131, 448-449.

(96) Wang, W.; Xu, B.; Hammond, G. B. Efficient Synthesis of $\gamma$-Keto Esters through Neighboring Carbonyl Group-Assisted Regioselective Hydration of 3-Alkynoates. J. Org. Chem. 2009, 74, 1640-1643.

(97) Heasley, G. E.; Codding, C.; Sheehy, J.; Gering, K.; Heasley, V. L.; Shellhamer, D. F.; Rempel, T. Chlorination of 1-hexyne and 3-hexyne in acetic acid and methanol. The Journal of Organic Chemistry 2002, 50, 1773-1776.

(98) Neale, R. S. The Chemistry of Ion Radicals. The Free-Radical Addition of $\mathrm{N}$-Chloramines to Olefinic and Acetylenic Hydrocarbons. J. Am. Chem. Soc. 2002, 86, 5340-5342.

(99) Benati, L.; Montevecchi, P. C.; Spagnolo, P. A convenient synthesis of [beta]-keto phenyl sulphides from alkynes. Tetrahedron Lett. 1988, 29, 2381-2384.

(100) Tamao, K.; Maeda, K. Silafunctional compounds in organic synthesis. 29.1 Oxidation of (alkenyl)alkoxysilanes to [alpha]-hydroxy ketones. Tetrahedron Lett. 1986, 27, 65-68. 
(101) Guo, Y.; Twamley, B.; Shreeve, J. n. M. Pd-catalyzed arylation of silyl enol ethers of substituted alpha -fluoroketones. Org. Biomol. Chem. 2009, 7, 1716-1722.

(102) Kim, K.-Y.; Kim, B. C.; Lee, H. B.; Shin, H. Nucleophilic Fluorination of Triflates by Tetrabutylammonium Bifluoride. J. Org. Chem. 2008, 73, 8106-8108.

(103) Prakash, G. K. S.; Beier, P. Construction of Asymmetric Fluorinated Carbon Centers. Angew. Chem., Int. Ed. 2006, 45, 2172-2174.

(104) Burger, E. C.; Barron, B. R.; Tunge, J. A. Catalytic asymmetric synthesis of cyclic alpha -allylated alpha -fluoroketones. Synlett 2006, 2824-2826.

(105) Nakamura, M.; Hajra, A.; Endo, K.; Nakamura, E. Synthesis of Chiral alpha-Fluoroketones through Catalytic Enantioselective Decarboxylation. Angew. Chem., Int. Ed. 2005, 44, 7248-7251.

(106) Davis, F. A.; Han, W.; Murphy, C. K. Selective, Electrophilic Fluorinations Using N-Fluoro-o-benzenedisulfonimide. J. Org. Chem. 1995, 60, 4730-7.

(107) Reutrakul, V.; Kruahong, T.; Pohmakotr, M. A novel method for the synthesis of alpha -fluoroketones via Claisen rearrangement. Tetrahedron Lett. 1994, 35, 4853-6.

(108) Dolbier, W. R., Jr.; Lee, S. K.; Phanstiel, O. I. V. The in situ generation and trapping of some fluorine-substituted ketenes. Tetrahedron 1991, 47, 2065-72.

(109) Differding, E.; Ruegg, G. M.; Lang, R. W. Selective mono- and difluorination of enolates. Tetrahedron Lett. 1991, 32, 1779-82.

(110) Tarnus, C.; Jung, M. J.; Remy, J. M.; Baltzer, S.; Schirlin, D. G. New fluoroketones as human renin inhibitors. FEBS Lett. 1989, 249, 47-50.

(111) Bravo, P.; Piovosi, E.; Resnati, G. Homochiral fluoro-organic compounds. Part 10. A new protocol for the synthesis of variously functionalized alpha -fluoro-ketones and alpha -fluoro-alcohols. J. Chem. Res., Synop. 1989, 134-5.

(112) Bravo, P.; Resnati, G. Homochiral alpha -fluoroketones from racemic alpha -fluorocarboxylic esters and enantiomerically pure sulfoxides. J. Chem. Soc., Chem. Commun. 1988, 218-19.

(113) Bhilare, S. V.; Darvatkar, N. B.; Deorukhkar, A. R.; Raut, D. G.; Trivedi, G. K.; Salunkhe, M. M. Synthesis of 1,1-diaryl ethylenes by Cu-catalyzed arene $\mathrm{C}-\mathrm{H}$ addition to aryl acetylenes. Tetrahedron Lett. 2009, 50, 893896.

(114) Yamamoto, Y.; Kirai, N.; Harada, Y. Cu-catalyzed stereoselective conjugate addition of arylboronic acids to alkynoates. Chem. Commun. 2008, 2010-2012. 
(115) Miyamoto, M.; Harada, Y.; Tobisu, M.; Chatani, N. Rh(l)-Catalyzed Reaction of 2-(Chloromethyl)phenylboronic Acids and Alkynes Leading to Indenes. Org. Lett. 2008, 10, 2975-2978.

(116) Lin, P.-S.; Jeganmohan, M.; Cheng, C.-H. Cobalt (II)-catalyzed regio- and stereoselective hydroarylation of alkynes with organoboronic acids. Chemistry--A European Journal 2008, 14, 11296-11299.

(117) Yang, M.; Zhang, X.; Lu, X. Cationic Palladium(II)-Catalyzed Highly Enantioselective [3+2] Annulation of 2-Acylarylboronic Acids with Substituted Alkynes. Org. Lett. 2007, 9, 5131-5133.

(118) Miura, T.; Takahashi, Y.; Murakami, M. Stereoselective Synthesis of 3Alkylideneoxindoles by Rhodium-Catalyzed Cyclization Reaction of 2Alkynylaryl Isocyanates with Aryl- and Alkenylboronic Acids. Org. Lett. 2007, 9, 5075-5077.

(119) Harada, Y.; Nakanishi, J.; Fujihara, H.; Tobisu, M.; Fukumoto, Y.; Chatani, N. Rh(I)-Catalyzed Carbonylative Cyclization Reactions of Alkynes with 2Bromophenylboronic Acids Leading to Indenones. J. Am. Chem. Soc. 2007, 129, 5766-5771.

(120) Zhou, C.; Larock, R. C. Tetrasubstituted Olefin Synthesis via PdCatalyzed Addition of Arylboronic Acids to Internal Alkynes Using $\mathrm{O} 2$ as an Oxidant. J. Org. Chem. 2006, 71, 3184-3191.

(121) Tsukamoto, H.; Ueno, T.; Kondo, Y. Palladium(0)-Catalyzed Alkylative Cyclization of Alkynals and Alkynones: Remarkable trans-Addition of Organoboronic Reagents. J. Am. Chem. Soc. 2006, 128, 1406-1407.

(122) Chen, Y.; Lee, C. Rhodium-Catalyzed Arylative and Alkenylative Cyclization of 1,5-Enynes Induced by Geminal Carbometalation of Alkynes. J. Am. Chem. Soc. 2006, 128, 15598-15599.

(123) Shintani, R.; Tsurusaki, A.; Okamoto, K.; Hayashi, T. Highly chemo- and enantioselective arylative cyclization of alkyne-tethered electron-deficient olefins catalyzed by rhodium complexes with chiral dienes. Angew. Chem., Int. Ed. 2005, 44, 3909-3912.

(124) Shintani, R.; Okamoto, K.; Otomaru, Y.; Ueyama, K.; Hayashi, T. Catalytic Asymmetric Arylative Cyclization of Alkynals: Phosphine-Free Rhodium/Diene Complexes as Efficient Catalysts. J. Am. Chem. Soc. 2005, 127, 54-55.

(125) Miura, T.; Shimada, M.; Murakami, M. Rhodium-catalyzed cyclization of 1,6-enynes triggered by addition of arylboronic acids. J. Am. Chem. Soc. 2005, 127, 1094-1095.

(126) Satoh, T.; Ogino, S.; Miura, M.; Nomura, M. Synthesis of highly substituted 1,3-butadienes by palladium-catalyzed arylation of internal alkynes. Angew. Chem., Int. Ed. 2004, 43, 5063-5065. 
(127) Zhang, X.; Larock, R. C. Synthesis of Highly Substituted 1,3-Dienes and 1,3,5-Trienes by the Palladium-Catalyzed Coupling of Vinylic Halides, Internal Alkynes, and Organoboranes. Org. Lett. 2003, 5, 2993-2996.

(128) Oh, C. H.; Jung, H. H.; Kim, K. S.; Kim, N. The palladium-catalyzed addition of organoboronic acids to alkynes. Angew. Chem., Int. Ed. 2003, $42,805-808$.

(129) Liu, L.-P.; Xu, B.; Mashuta, M. S.; Hammond, G. B. Synthesis and Structural Characterization of Stable Organogold(I) Compounds. Evidence for the Mechanism of Gold-Catalyzed Cyclizations. J. Am. Chem. Soc. 2008, 130, 17642-17643.

(130) The fluorination of a ketone bearing aromatic ring has been reported: Enders, D., Huttle, M.R.M. Synlett, 2005, 991.

(131) Hashmi, A. S. K.; Ramamurthi, T. D.; Rominger, F. Synthesis, structure and reactivity of organogold compounds of relevance to homogeneous gold catalysis. J. Organomet. Chem. 2009, 694, 592-597.

(132) Yang, F.; Wu, Y. Facile Synthesis of Substituted Alkynes by Cyclopalladated Ferrocenylimine Catalyzed Cross-Coupling of Arylboronic Acids/Esters with Terminal Alkynes. Eur. J. Org. Chem. 2007, 2007, 34763479.

(133) Hooper, T. N.; Green, M.; Russell, C. A. Cationic Au(i) alkyne complexes: synthesis, structure and reactivity. Chem. Commun. 2010, 46, 2313-2315.

(134) Choy, J.-H.; Kim, Y.-I. Gold Valence in (Au/3)0.25Bi2Sr2CaCu2Oy by XPS and XANES Spectroscopy. J. Phys. Chem. B 2003, 107, 3348-3350.

(135) Casaletto, M. P.; Longo, A.; Martorana, A.; Prestianni, A.; Venezia, A. M. XPS study of supported gold catalysts: the role of $A u(0)$ and $A u(l)$ species as active sites. Surf. Interface Anal. 2006, 38, 215-218.

(136) Tkatchouk, E.; Mankad, N. P.; Benitez, D.; Goddard, W. A.; Toste, F. D. Two Metals Are Better Than One in the Gold Catalyzed Oxidative Heteroarylation of Alkenes. J. Am. Chem. Soc. 2011, 133, 14293-14300.

(137) Camps, F.; Fabrias, G.; Guerrero, A. Synthesis of a fluorinated analog of the sex pheromone of the processionary moth Thaumetopoea pityocampa (Denis and Schiff.). Tetrahedron 1986, 42, 3623-9.

(138) Fox, D. T.; Poulter, C. D. Synthesis and evaluation of 1-deoxy-D-xylulose 5-phosphoric acid analogues as alternate substrates for methylerythritol phosphate synthase. J.Org. Chem. 2005, 70, 1978-1985.

(139) Jie, M. S. F. L. K.; Lau, M. M. L.; Lam, C. N. W.; Alam, M. S.; Metzger, J. O.; Biermann, U. Novel halo-oxo-allenic fatty ester derivatives from epoxidized methyl santalbate (methyl trans-11-octadecen-9-ynoate). Chem. Phys. Lipids 2003, 125, 93-101.

(140) Kim, H. O.; Lim, M. H.; Park, J. G.; Moon, H. R.; Jacobson, K. A.; Kim, H.D.; Chun, M. W.; Jeong, L. S. Design and synthesis of $A 3$ adenosine 
receptor ligands, 3'-fluoro analogues of Cl-IB-MECA. Nucleosides, Nucleotides Nucleic Acids 2003, 22, 923-925.

(141) Lan, Y.; Hammond, G. B. An Efficient Preparation of TIPSHalofluoropropyne and Its Application to the Diastereoselective Synthesis of Propargylic Fluorohydrins. J. Org. Chem. 2000, 65, 4217-4221.

(142) Lan, Y.; Hammond, G. B. Functionalization of monofluoroallene and the synthesis of aryl-substituted conjugated fluorodienes. Org. Lett. 2002, 4, 2437-2439.

(143) Lim, M. H.; Kim, H. O.; Moon, H. R.; Lee, S. J.; Chun, M. W.; Gao, Z.-G.; Melman, N.; Jacobson, K. A.; Kim, J. H.; Jeong, L. S. Design, synthesis and binding affinity of 3'-fluoro analogues of Cl-IB-MECA as adenosine A3 receptor ligands. Bioorg. Med. Chem. Lett. 2003, 13, 817-820.

(144) Mastihubova, M.; Biely, P. A common access to 2- and 3-substituted methyl b-D-xylopyranosides. Tetrahedron Lett. 2001, 42, 9065-9067.

(145) Runge, M.; Haufe, G. Enantioselective Synthesis of a Fluorinated Analogue of the Orsellinic Acid-Type Twelve-Membered Lactone Lasiodiplodin. J. Org. Chem. 2000, 65, 8737-8742.

(146) Akiyama, Y.; Fukuhara, T.; Hara, S. Regioselective synthesis of fluorohydrines via $S_{N} 2$-type ring-opening of epoxides with TBABF-KHF2. Synlett 2003, 1530-1532.

(147) Bruns, S.; Haufe, G. Enantioselective introduction of fluoride into organic compounds. First asymmetric ring-opening of epoxides by hydrofluorinating reagents. J. Fluorine Chem. 2000, 104, 247-254.

(148) Islas-Gonzalez, G.; Puigjaner, C.; Vidal-Ferran, A.; Moyano, A.; Riera, A.; Pericas, M. A. Boron trifluoride-induced reactions of phenylglycidyl ethers: a convenient synthesis of enantiopure, stereodefined fluorohydrins. Tetrahedron Lett. 2004, 45, 6337-6341.

(149) Mikami, K.; Ohba, S.; Ohmura, H. Regioselective, stereospecific, and chemoselective fluorination of epoxy alcohols: development of fluorinating hybrid reagents, associated with Lewis acid metal fluoride/ammonium hydrogen fluoride. J. Organometallic Chem. 2002, 662, 77-82.

(150) Nicoletti, M.; O'Hagan, D.; Slawin, A. M. Z. $\alpha, \beta, \gamma$-Trifluoroalkanes: A stereoselective synthesis placing three vicinal fluorines along a hydrocarbon chain. J. Am. Chem. Soc. 2005, 127, 482-483.

(151) Schaus, S. E.; Brandes, B. D.; Larrow, J. F.; Tokunaga, M.; Hansen, K. B.; Gould, A. E.; Furrow, M. E.; Jacobsen, E. N. Highly selective hydrolytic kinetic resolution of terminal epoxides catalyzed by chiral (salen)CollI complexes. Practical synthesis of enantioenriched terminal epoxides and 1,2-diols. J. Am. Chem. Soc. 2002, 124, 1307-1315.

(152) Yoshino, H.; Nomura, K.; Matsubara, S.; Oshima, K.; Matsumoto, K.; Hagiwara, R.; Ito, Y. A mild ring opening fluorination of epoxide with ionic 
liquid 1-ethyl-3-methylimidazorium oligo hydrogenfluoride (EMIMF(HF)2.3). J. Fluorine Chem. 2004, 125, 1127-1129.

(153) Xu, B.; Hammond, G. B. A new convenient synthesis of propargylic fluorohydrins and 2,5-disubstituted furans from fluoropropargyl chloride. J. Org. Chem. 2006, 71, 3518-3521.

(154) Zhou, C.; Li, J.; Lu, B.; Fu, C.; Ma, S. An Efficient Approach for Monofluorination via Highly Regioselective Fluorohydroxylation Reaction of 3-Aryl-1,2-allenes with Selectfluor. Org. Lett. 2008, 10, 581-583.

(155) Wang, W.; Jasinski, J.; Hammond, G. B.; Xu, B. Fluorine-enabled cationic gold catalysis: Functionalized hydration of alkynes. Angew. Chem. Int. Ed. 2010, 49, 7247-7252.

(156) Wilkinson, S. C.; Lozano, O.; Schuler, M.; Pacheco, M. C.; Salmon, R.; Gouverneur, V. Electrophilic Fluorocyclization of Allyl Silanes. Angew. Chem., Int. Ed. 2009, 48, 7083-7086.

(157) Tredwell, M.; Gouverneur, V. Electrophilic fluorination of organosilanes. Org. Biomol. Chem. 2006, 4, 26-32.

(158) Pacheco, M. C.; Gouverneur, V. Electrophilic fluorodesilylation of allenylmethylsilanes: A novel entry to 2-fluoro-1,3-dienes. Org. Lett. 2005, 7, 1267-1270.

(159) Greedy, B.; Paris, J.-M.; Vidal, T.; Gouverneur, V. Regio- and enantioselective synthesis of allylic fluorides by electrophilic fluorodesilylation of allyl silanes. Angew. Chem., Int. Ed. 2003, 42, 32913294.

(160) Sawicki, M.; Kwok, A.; Tredwell, M.; Gouverneur, V. Single and double stereoselective fluorination of (E)-allylsilanes. Beilstein J. Org. Chem. 2007, 3, No. 34, No pp. given.

(161) Carroll, L.; McCullough, S.; Rees, T.; Claridge, T. D. W.; Gouverneur, V. Stereospecific anti SE2' fluorination of allenylsilanes: synthesis of enantioenriched propargylic fluorides. Org. Biomol. Chem. 2008, 6, 17311733.

(162) Carroll, L.; Pacheco, M. C.; Garcia, L.; Gouverneur, V. Synthesis of propargylic fluorides from allenylsilanes. Chem. Commun. (Cambridge, $U$. K.) 2006, 4113-4115.

(163) Olah, G. A.; Prakash, G. K. S. Carbocation chemistry; Wiley-Interscience: Hoboken, N.J., 2004. 


\section{APPENDIX}

\section{LIST OF ABBREVIATIONS}

Cl: Chemical Ionization

BE: Binding energy

DAST: Diethylaminosulfur trifluoride

DCM: Dichloromethane

DMSO: Dimethylsulfonyl Oxide

ESI-MS: Electrospray Ionization mass spectrometry

EtOAc: Ethyl Acetate

GC: Gas Liquid Chromatography

h: Hour

HOAc: Acetic acid

HOMO: Highest occupied molecular orbital

HPLC: High performance liquid chromatography

HRMS: High resolution mass spectroscopy

Hz: Hertz

IR: Infrared

LDA: Lithium diisopropylamide

LUMO: Lowest unoccupied molecular orbital

M: Molar

$\boldsymbol{m}$ : meta

mg: milligram

min: minute 
mL: milliliter

mmol: millimole

MsOH: Methanesulfonic acid

mT: millitorr

$\mathrm{m} / \mathbf{z}$ : mass to charge ratio

NFSI: $N$-fluorobenzenesulfonimide

NMR: Nuclear magnetic resonance spectroscopy

o: ortho

p: para

ppm: Parts per million

PTSA: $p$-Toluene sulfonic acid

RT: Room temperature

SELECTFLUOR: 1-Chloromethyl-4-fluoro-1,4-diazoniabicyclo[2.2.2]octane bis(tetrafluoroborate)

SET: Single electron transfer

TBAF: Tetra- $n$-butylammonium fluoride

TBS: tert-Butyldimethylsilyl

tert: tertiary

TIPS: Triisopropylsilyl

TMS: Trimethylsilyl

TfOH: Trifluoromethanesulfonic acid

THF: Tetrahydrofuran

TLC: Thin layer chromatography

TON: Turnover number

TOF: Turnover frequency

XPS: X-ray photoelectron spectroscopy 


\section{CURRICULUM VITAE}

Weibo Wang

Lab address:

Department of Chemistry (Rm:312)

University of Louisville

2320 South Brook St.

Louisville, KY 40292
Home address:

2203 James Guthrie ct \#3

Louisville, KY 40217

E-mail: w0wang03@louisville.edu

Phone: $502-807-8435$ (c)

$502-852-5978(0)$

\section{Academic Profile:}

Doctoral Candidate in chemistry, 2009-Present GPA: 3.7

Department of Chemistry, University of Louisville, KY, USA

Master of Science in Chemistry, 2006-2009

Master of Engineering in Biochemical Engineering, 2001 - 2004

East China University of Science and Technology, Shanghai, China

Bachelor of Engineering in Biochemical Engineering, 1997 - 2001

Zhejiang University of Technology, Hangzhou, China

\section{RESEARCH EXPERIENCE:}

On-going Project: Organic Synthesis (2008-Present) 
1. Exploration of the chemistry of extended enolates, especially alkynyl enolates.

2. Exploration of the reaction of alkynyl enolate silyl acetal with various electrophiles such as halogen, epoxide, aldehyde, imine etc.

3. Synthesis of functionalized $\alpha, \alpha$-disubstituted $\beta$-alkynyl esters from allenoates through an alkynyl enolate intermediates.

4. Gold(III) catalyzed highly regioselective hydration of internal alkynes.

5. Gold catalyzed fluorination of alkynes and alkenes.

Natural Products Purification and Identification (2006-2007)

1. Isolation and purification of several natural products from Peruvian plants such as Himatanthus sucuuba and Anredera Diffusa through various chromatographic techniques.

2. A number of new compounds have been identified by UV, IR, MS, ${ }^{1} H$ NMR, ${ }^{13} \mathrm{C}$ NMR and 2D NMR data. Testing of their biological activities will commence in the near future.

\section{Separation and Purification of Salidroside from Rhodiola Sachalinesis} (2001-2004)

1. Purification of traditional Chinese medicine salidroside $(\$ 200,000 / \mathrm{Kg})$ from Rhodiola sachalinesis extract $(\$ 20 / \mathrm{Kg})$ by adsorption chromatography with satisfactory yield. (The product is marketed by HuaChang polymer Co., Ltd.)

2. Thermodynamics study of adsorption chromatography for industry scale-up.

\section{Generate Yeast Strain for Fast Fermentation (2000-2001)}

Successfully generated and selected fast fermentation yeast strain which can shorten fermentation time while other quality indices (such as growth rate, sugar consumption, nitrogen consumption, diacetyl content, medium flocculation, and taste) still meet or exceed national standards.

\section{OTHER EXPERIENCE:}

Teaching Assistant 2006 - Present ( $>500$ hours)

Department of Chemistry, University of Louisville, KY, USA

Teaching Organic Chemistry Labs (CHEM 343); Organic Chemistry recitation (CHEM 341), Analytical Chemistry Labs (CHEM 208 and CHEM 209).

1. Instructed organic related classes,

2. Demonstrated experimental and equipment setups,

3. Supervised experiments run by undergraduate students

4. Review of assignments and exams. 
Research Assistant 2001 -2003

Hua Chang polymer Co., Ltd, Shanghai, China

1. Calibrated and maintained lab instruments

2. Preparing files, documents and posters.

\section{HIGHLIGHT:}

10 years experience in synthetic organic chemistry, biochemical engineering, and natural products research.

Hands-on experience with HPLC, GC-MS, IR, UV-Vis, 1D and 2D-NMR.

Proficient with MS Office, Chemoffice, Windows, and Scifinder etc.

Excellent communication skills, multilingual (English and Chinese).

\section{AWARDS \& SCHOLARSHIPS:}

Excellent league member of Department (East China University of Science and Technology, ECUST) $1999-2000$

University Scholarship for Academic Excellence (ECUST) $1999-2000$

Excellent Student of Department (ECUST) $1999-2000$

\section{PUBLICATIONS:}

(1) Xu, B.; Wang, W.; Hammond, G. B. Library-friendly synthesis of fluorinated ketones through functionalized hydration of alkynes and investigation of the reaction mechanism. J. Fluorine Chem. 2011, 132, 804-810.

(2) Wang, W.; Xu, B.; Hammond, G. B. Synthesis of Fluorohydrins through Electrophilic Fluorination of Allyl Silanes. Synthesis 2011, 2011, 2383,2386 .

(3) Xu, B.; Wang, W.; Liu, L.-P.; Han, J.; Jin, Z.; Hammond, G. B. Synthetic evolutions in the nucleophilic addition to alkynes. J. Organomet. Chem. 2010, 696, 269-276.

(4) Wang, W.; Jasinski, J.; Hammond, G. B.; Xu, B. Fluorine-enabled cationic gold catalysis: Functionalized hydration of alkynes. Angew. Chem. Int. Ed. 2010, 49, 7247-7252.

(5) Wang, W.; Xu, B.; Hammond, G. B. Efficient Synthesis of $\gamma$-Keto Esters through Neighboring Carbonyl Group-Assisted Regioselective Hydration of 3-Alkynoates. J. Org. Chem. 2009, 74, 1640-1643.

(6) Wang, W.; Xu, B.; Hammond, G. B. Synthesis of functionalized $\alpha, \alpha$ disubstituted $\beta$-alkynyl esters from allenoates through an alkynylenolate Intermediate. Org. Lett. 2008, 10, 3713-3716. 
Highlighted by Organic Chemistry Portal twice: http://www.organicchemistry.org/abstracts/lit2/444.shtm and http://www.organicchemistry.org/Highlights/2009/26October.shtm

Also featured by Synfacts 2009, 5, 552

(7) Wang, W.; Xu, H.; Liu, Z.; Wu, X. Study on isolation and purification of salidroside from Chinese medicinal plant Rhodiola sachalinensis using 816 macroporous resin. Chinese Traditional and Herbal Drugs, suppl. 2003, 129-132.

\section{PRESENTATIONS:}

1. Xu, B.; Liu, L.; Wang, W.; Hammond, G. B.; "Transformative alkynylogation: Extension of the electronic effects of propargyl or allenyl substrates", The Gordon Research Conferences on Stereochemistry, July 27 - August 1, 2008; Salve Regina University, Newport, RI

2. Xu, B.; Wang, W.; Liu, L.-P.; Yang, H.; Aponte, J. C.; Hammond, G. B., Extreme Makeover: Re-visiting vinylogy and its applications in synthesis. 41st National Organic Chemistry Symposium, Boulder, Colorado, United States, Jun 7-11, 2009, Poster No. C5.

3. "What Lies Beyond Fluorine Substitution? New Vistas from a Synthetic Standpoint" G.B. Hammond, B. Xu, W. Wang, H. Yang. Keynote Speaker presentation, 9th International Symposium on Fluorine Chemistry and ISoFT'09, Jackson Hole, Wyoming, August 23-28, 2009. Abstract: 43. 